Universidade de São Paulo - USP

Escola de Engenharia de São Carlos - EESC

Departamento de Engenharia Elétrica

\title{
ESTUDO DE TOPOLOGIAS PARA REDES WDM-PON
}

Guilherme Enéas Vaz Silva

Dissertação de mestrado apresentada à Escola de Engenharia de São Carlos, Departamento de Engenharia Elétrica da Universidade de São Paulo, como parte dos requisitos para obtenção do título de Mestre em Engenharia Elétrica.

Orientador: Prof. Dr. Murilo Araujo Romero

São Carlos 



\section{FOLHA DE JULGAMENTO}

Candidato: Bacharel em Ciências da Computação GUILHERME ENÉAS VAZ SILVA.

Dissertação defendida e julgada em 19/03/2010 perante a Comissão Julgadora:

\|\|

Prof. Titular MURILO ARAUJO ROMERO - (Orientador)

(Escola de Engenharia de São Carlos/USP)

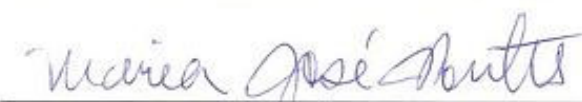

Prof?. Dr.4. MARIA JOSÉ PONTES

(Universidade Federal do Espírito Santo/UFES)

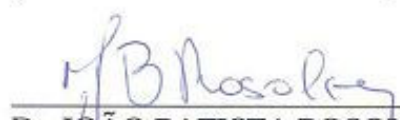

Dr. JOÃO BATISTA ROSOLEM

(CPqD-Campinas)

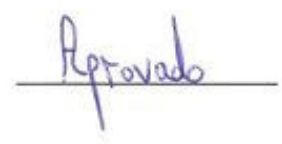

APROVADO

\section{,}

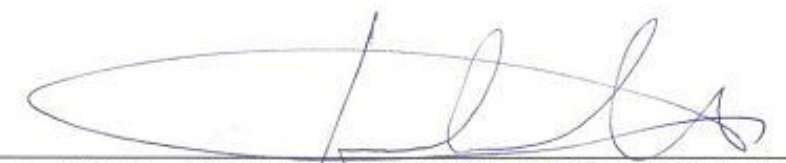

Prof. Titular GERALDO ROBERTO MARTINS DA COSTA Coordenador do Programa de Pós-Graduação em Engenharia Elétrica e Presidente da Comissão de Pós-Graduação 



\section{EPÍGRAFE}

NÃO CONSEGUIMOS ENCONTRAR RESPOSTA PARA TODOS OS NOSSOS PROBLEMAS. AS QUE ENCONTRAMOS NOS LEVARAM A FORMULAR NOVAS QUESTÕES

SENTIMO-NOS HOJE TÃO CONFUSOS COMO ANTES. ACREDITAMOS, ENTRETANTO, QUE ESTAMOS CONFUSOS EM UM NÍVEL MAIS ALTO E SOBRE COISAS MAIS IMPORTANTES.

Cartaz de alerta aos visitantes, encontrado na entrada do departamento de matemática de uma universidade escandinava. 



\section{AGRADECIMENTOS}

A Deus, por iluminar meu caminho.

Aos meus pais, Oliveira e Regina, pelo exemplo, incentivo, carinho, paciência e por serem os principais responsáveis por minha formação humana e profissional.

À minha filha Nicolli, que abençoou esse trabalho com seu nascimento.

À minha esposa Naiana, por seu amor, carinho e companhia.

Aos meus irmãos, sobrinhos, avós, tios, primos e cunhados, pela torcida e incentivo durante a realização desse trabalho.

Ao meu orientador, professor Dr. Murilo Araujo Romero, pela oportunidade, orientação, profissionalismo e imenso conhecimento repassado. Dez minutos de conversa equivaliam a um mês de estudo!

Ao meu grupo de estudo na Telecom, representado principalmente pela Regiane, pelo incentivo, apoio, inúmeros seminários, debates e companhia nessa jornada.

Aos amigos piauienses e às diversas amizades feitas em São Carlos (baianos, mineiros, paulistas, paraenses, maranhenses, cearenses ...), pelos bons momentos de alegria, companheirismo e apoio. Aos professores do grupo de Telecom, pelo conhecimento repassado.

A todos os profissionais e colegas que de alguma forma contribuíram nesse trabalho. 



\section{Resumo}

A demanda de largura de banda exigida pelos usuários de redes de acesso vem aumentando rapidamente e a rede óptica passiva baseada em multiplexação por divisão de comprimento de onda (WDM-PON) tem se destacado como a tecnologia capaz de suprir essa demanda. Dessa forma, este trabalho conduz, inicialmente, uma comparação entre uma rede WDM-PON ideal e uma rede TDM-PON, discutindo também aspectos de segurança desta última, bem como estratégias de migração entre estes dois esquemas. Devido ao custo elevado da WDM-PON em seu esquema original, investigou-se em seguida as principais arquiteturas alternativas relatadas na literatura, em busca de maior viabilidade de implementação. Com base nesse estudo, fez-se então uma análise mais profunda sobre topologias recentes derivadas da RITENET, referenciadas na literatura como arquiteturas baseadas em fontes ópticas centralizadas (CLS). Tais configurações são baseadas no travamento de diodos lasers Fabry-Pérot através da injeção do sinal de ASE de um EDFA e foram estudadas por meio de simulações computacionais empregando o software OptiSystem 8.0.

Palavras-chave: WDM-PON, TDM-PON, fontes ópticas centralizadas 


\begin{abstract}
The demand for bandwidth by access networks users has increased rapidly and the Wavelength Division Multiplexing - Passive Optical Network (WDM-PON) has been pointed out as the technology capable of meeting this demand. In this framework, this work initially carries out a comparison between an ideal WDM-PON network and a TDM-PON network, also discussing TDM-PON security issues as well as migration strategies from TDM-PON to WDM-PON configurations. Next, taking into account the high implementation cost of the WDM-PON original scheme, we investigated alternative topologies available in the literature. Based on this study, we performed a more in-depth analysis regarding recently proposed topologies, derived from the RITENET, which are refered at the literature as centralized light sources (CLS) based architectures. Such networks are based on the locking of Fabry-Pérot lasers diodes through the injection of the ASE signal from an EDFA and were studied by using the software OptiSystem 8.0.
\end{abstract}

Keywords: WDM-PON, TDM-PON, centralized light source 


\section{Lista de Figuras}

1.1 Representação das redes de acesso como gargalo da Internet [3] . . . . . . . 2

1.2 Topologia em árvore de uma Rede Óptica Passiva . . . . . . . . . . . . . 7

1.3 Esquemas FTTx (FTTH, FTTB, FTTC e FTTCab) sendo empregados como uma rede convergente de vídeo, voz e dados $[20] \ldots \ldots \ldots$

2.1 Esquema de downstream da TDM-PON . . . . . . . . . . . . . . 10

2.2 Esquema de upstream da TDM-PON . . . . . . . . . . . . . . . . . . . 10

2.3 Esquema simulado para disposição da ONU vítima e ONU maliciosa. . . . . 16

2.4 BER para potências recebidas pela ONU maliciosa e medições back-to-back 17

2.5 Taxa de erro para diversos valores de ORL de conectores mal instalados. . . 18

2.6 Representação de um splitter 1x4 formado por três acopladores . . . . . . . 19

2.7 Representação de um splitter 1x32 formado por diversos acopladores . . . . 20

2.8 Esquema idealizado de uma WDM-PON $[45] \ldots \ldots \ldots \ldots . \ldots . \ldots . \ldots 23$

2.9 Espectro de saída (a) de um laser, (b) do multiplexador do OLT . . . . . . 28

2.10 Diagrama de olho para ONU $1 \ldots \ldots$. . . . . . . . . . . . . . . . . . . . .

2.11 Varredura de potências para 1,25 Gbps, 2,5 Gbps e 10 Gbps . . . . . . . . . 31

2.12 BER dos 32 canais a 2,5Gbps em $20 \mathrm{Km} \ldots \ldots \ldots$. . . . . . . . . 32

2.13 Varredura de distâncias com potência de $-4,0 \mathrm{dBm} \ldots \ldots . \ldots . . . \ldots 33$

2.14 Varredura de potências para GPON em 20Km . . . . . . . . . . . . 34

2.15 OTDV na saída (a) da ONU 1, (b) da ONU 12 e (c) do splitter. . . . . . . 35

2.16 Espectro de saída do splitter no sentido upstream . . . . . . . . . . . . 36

2.17 Rede TDM-PON já instalada com OLT conectado a 8 ONUs . . . . . . . . 37

2.18 Esquema de migração de TDM-PON para WDM-PON . . . . . . . . . . . . 37

2.19 Esquema de migração de TDM-PON para WDM-PON com duas propostas de upgrade para ONUs antigas . . . . . . . . . . . . . 38

2.20 Alternativa de upgrade com esquema duplicando largura de banda das ONUs legadas . . . . . . . . . . . . . . . . . . . . . 39

3.1 Característica bidirecional do AWG [60] . . . . . . . . . . . . . . . 41

3.2 O comportamento periódico do AWG . . . . . . . . . . . . . 42

3.3 Estrutura interna do AWG . . . . . . . . . . . . . . . 43

3.4 Fonte óptica baseada no esquema de travamento por injeção de F-P LD [76] 44 
3.5 Espectro de saída e o diagrama de olho: (a) antes do travamento de comprimento de onda, (b) e depois do travamento de comprimento de onda [77]. . 46

3.6 Diagrama esquemático de uma rede CPON $[78] \ldots \ldots \ldots \ldots$. . . . . . . 47

3.7 LARNET $[45] \ldots \ldots \ldots \ldots \ldots \ldots \ldots \ldots$

3.8 RITENET $[45] \ldots \ldots \ldots \ldots \ldots \ldots \ldots$

3.9 Travamento por injeção de FP-LD no upstream $[93] \ldots \ldots$. . . . . . . 50

3.10 Múltiplos estágios $[100] \ldots \ldots \ldots \ldots \ldots$. . . . . . . . . . . . . . . . . . . 52

3.11 Exemplo de escalabilidade na arquitetura Multi-Estágios [21] . . . . . . 56

3.12 DWDM-TDM PON de longo alcance $[107] \ldots \ldots \ldots \ldots$. . . . . . 57

4.1 Representação esquemática da arquitetura RITENET proposta originalmente

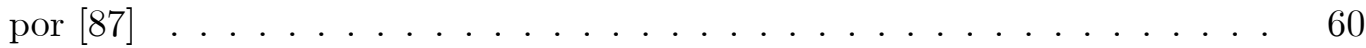

4.2 Taxa de erro versus a potência do laser CW no OLT em $20 \mathrm{~km}$ de fibra . . 60

4.3 Espectro de saída de um Fabry-Pérot com 9 modos sem a injeção de sinal óptico externo. O modo central é referenciado como $\mathrm{m}=0$, os modos à sua esquerda são numerados negativamente e os modos à direita são numerados

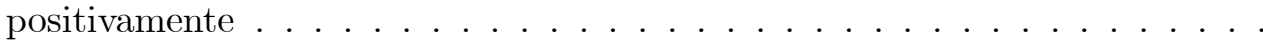

4.4 Espectro de saída de um Fabry-Pérot com 9 modos com a injeção de sinal óptico externo (a) travamento do modo central $(\mathrm{m}=0)$, (b) travamento do primeiro modo lateral à esquerda $(\mathrm{m}=-1) \ldots \ldots \ldots$. . . . . . .

4.5 Espectro banda larga de um sinal de ASE gerado a partir de componente do software OptiSystem . . . . . . . . . . . . . . . .

4.6 (a) sinal da ASE fatiado que sai na porta 1 do AWG, (b) sinal da ASE fatiado que sai na porta 5 do AWG, (c) modo lateral do F-P LD $(\mathrm{m}=4)$ travado com o sinal de "a", (d) modo central do F-P LD $(\mathrm{m}=0)$ travado com o sinal de "b"

4.7 Representação esquemática da rede contendo 8 ONUs equipadas com lasers Fabry-Pérot idênticos . . . . . . . . . . . . . . . . .

4.8 BER como função da distância considerando-se uma taxa de transmissão de 1,25 Gbps no esquema com F-P LDs situados nas ONUs. São mostrados os modos central $\mathrm{m}=0$ e lateral $\mathrm{m}=4 \ldots \ldots \ldots \ldots$

4.9 BER como função da distância considerando-se uma taxa de transmissão de 622 Mbps no esquema com F-P LDs situados nas ONUs. São mostrados os modos central $\mathrm{m}=0$ e lateral $\mathrm{m}=4 \ldots \ldots \ldots$. . . . . . . . 68

4.10 Representação esquemática da rede CLS simulada . . . . . . . . . . . . . . . 69

4.11 Representação esquemática da fonte WDM . . . . . . . . . . . . . . 70

4.12 Taxa de erro como função da distância considerando-se uma taxa de transmissão de 622 Mbps na rede CLS . . . . . . . . . . . . . . . .

4.13 Taxa de erro como função da distância considerando-se uma taxa de transmissão de 1,25 Gbps na rede CLS . . . . . . . . . . . . . . . . . .

4.14 Taxa de erro como função da distância considerando-se uma taxa de transmissão de 2,5 Gbps na rede CLS . . . . . . . . . . . . . . .

4.15 Espectro de saída de um Fabry-Pérot com 21 modos sem a injeção de sinal óptico externo . . . . . . . . . . . . . . . . . . . . 
4.16 Taxa de erro dos modos $\mathrm{m}=-10, \mathrm{~m}=-7, \mathrm{~m}=-3$ e $\mathrm{m}=0$ considerando as taxas de transmissão de $622 \mathrm{Mbps}, 1,25$ Gbps e 2,5 Gbps . . . . . . . . . 
viii

\section{Lista de Tabelas}

1.1 Tecnologias DSL: alcance $\mathrm{x}$ taxa $[16] \ldots \ldots \ldots \ldots \ldots$

1.2 Versões do padrão DOCSIS $[17] \ldots \ldots \ldots \ldots \ldots \ldots$

2.1 Potência necessária para atingir uma BER de 10-9 . . . . . . . . . . 17

2.2 Potência máxima no upstream - norma GPON [25] . . . . . . . . . . . . . 18

2.3 Orçamento de potência para splitter de 4 portas . . . . . . . . . . . . . . 19

2.4 Orçamento de potência para splitter de 32 portas . . . . . . . . . . . . . . 21

2.5 Orçamento de potência para splitter de 16 portas . . . . . . . . . . . . . 21

2.6 Orçamento de potência para splitter de 8 portas . . . . . . . . . . . 22

2.7 Largura de banda necessária para alguns serviços $[48] \ldots \ldots$. . . . . . 26

2.8 Principais características das tecnologias PON $[57,58] \ldots \ldots \ldots$

2.9 Orçamento de potência . . . . . . . . . . . . . . . . 31

3.1 Comparativa das arquiteturas WDM-PON. Fonte: [46] . . . . . . . . . . 53

3.2 Opções para implementação de WDM-PONs utilizando ONUs colorless. Fonte:

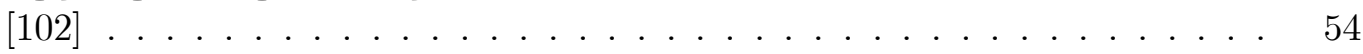

4.1 Valores utilizados nas simulações e disponibilizados pela literatura [75] . . 63 


\section{Sumário}

Lista de Figuras $\quad$ v

Lista de Tabelas $\quad$ vi

1 Introdução 1

1.1 Tecnologias para as redes de acesso . . . . . . . . . . . . . . . 2

1.1 .1 As redes sem fio . . . . . . . . . . . . . . . . . . 3

1.1.2 xDSL e modem a cabo . . . . . . . . . . . . . . . . . 4

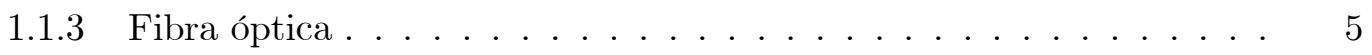

1.2 Descrição do trabalho . . . . . . . . . . . . . . . . . 7

2 Redes Ópticas Passivas 9

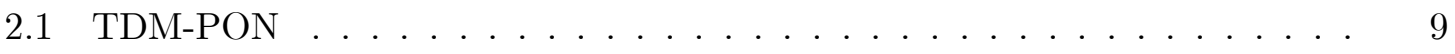

2.1 .1 Broadband PON . . . . . . . . . . . . . . . . 11

2.1 .2 Ethernet $\mathrm{PON} \ldots \ldots \ldots \ldots \ldots$

2.1 .3 Gigabit PON . . . . . . . . . . . . . . . . . . . . . . . . . 12

2.2 Problemas de segurança em TDM-PONs . . . . . . . . . . . . . . . . . . 13

2.2.1 Ataque de falta de serviço . . . . . . . . . . . . . . . . 13

2.2 .2 Escuta não autorizada . . . . . . . . . . . . . . . . . . 13

2.2 .3 ONU mascarada . . . . . . . . . . . . . . . . . . . . 14

2.2 .4 Esquema simulado e resultados . . . . . . . . . . . . . . . . . . . 14

2.2.5 Estudo de novos cenários . . . . . . . . . . . . . . . 17

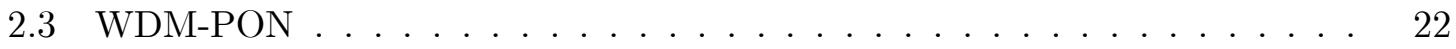

2.3.1 Por que utilizar WDM-PON ? ................ 24

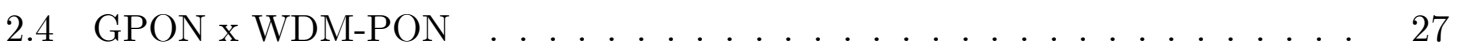

2.4 .1 Rede WDM-PON . . . . . . . . . . . . . . . . 27

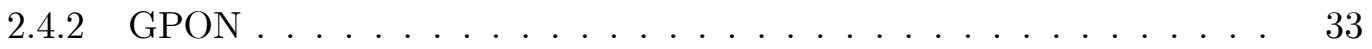

2.5 MigraçãoTDM-PON para WDM-PON . . . . . . . . . . . . 36

3 WDM-PON: componentes e topologias 40

3.1 Principais componentes da rede WDM . . . . . . . . . . . . . . . . 40

3.1.1 Array Waveguide Grating (AWG) . . . . . . . . . . . . . . . . 40

3.1.2 Fonte óptica multi-comprimento de onda . . . . . . . . . . . 43 


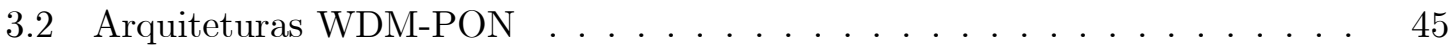

3.2.1 Composite PON . . . . . . . . . . . . . . . . 45

3.2.2 Local Access Router Network (LARNET) . . . . . . . . . . . . . . . 47

3.2.3 Remote Interrogation of Terminal Network (RITENET) . . . . . . . 48

3.2.4 WDM-PON multi-estágios . . . . . . . . . . . . . . . . 51

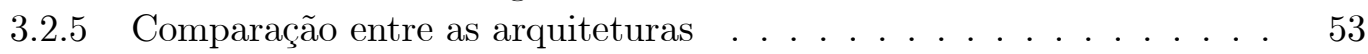

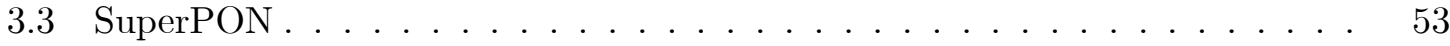

4 Estudo de Arquiteturas Baseadas no Travamento Óptico de Lasers FabryPérot $\quad \mathbf{5 8}$

4.1 Proposta original da RITENET . . . . . . . . . . . . . . . . . . 59

4.2 Rede com F-P LD na ONU . . . . . . . . . . . . . . . . . . 61

4.3 Rede de Fonte Óptica Centralizada . . . . . . . . . . . . . . . . . . . 67

4.4 Rede CLS com 21 modos . . . . . . . . . . . . . . . . . 73

$\begin{array}{llr}5 & \text { Conclusão } & 76\end{array}$

$\begin{array}{ll}\text { Referências Bibliográficas } & 78\end{array}$ 


\section{Lista de Acrônomos}

\begin{tabular}{|c|c|c|}
\hline Acrônimo & Português & Inglês \\
\hline $\begin{array}{l}\text { ACTS- } \\
\text { PLANET }\end{array}$ & $\begin{array}{l}\text { Tecnologias e Serviços } \\
\text { de Comunicação } \\
\text { Avançada - Rede } \\
\text { Fotônica de Acesso } \\
\text { Local }\end{array}$ & $\begin{array}{l}\text { Advanced } \\
\text { Communication } \\
\text { Technologies and } \\
\text { Services - Photonic } \\
\text { Local Access Network }\end{array}$ \\
\hline ADSL & $\begin{array}{l}\text { Linha Digital de } \\
\text { Assinante Assimétrica }\end{array}$ & $\begin{array}{l}\text { Asymmetric Digital } \\
\text { Subscriber Line }\end{array}$ \\
\hline AES & $\begin{array}{l}\text { Padrão de Encriptação } \\
\text { Avançado }\end{array}$ & $\begin{array}{l}\text { Advanced Encryption } \\
\text { Standard }\end{array}$ \\
\hline $\mathrm{AON}$ & Rede Óptica Ativa & Active Optical Network \\
\hline $\mathrm{APC}$ & Contato Físico Angulado & Angled Physical Contact \\
\hline ASE & Emissão Espontânea Amplificada & $\begin{array}{l}\text { Amplified Spontaneous } \\
\text { Emission }\end{array}$ \\
\hline ATM & $\begin{array}{l}\text { Modo de Transferência } \\
\text { Assíncrono }\end{array}$ & $\begin{array}{l}\text { Asynchronous Transfer } \\
\text { Mode }\end{array}$ \\
\hline $\begin{array}{l}\text { ATM PON } \\
(\mathrm{APON})\end{array}$ & $\begin{array}{l}\text { Rede Óptica Passiva } \\
\text { baseada no protocolo } \\
\text { Modo de Transferência } \\
\text { Assíncrono }\end{array}$ & $\begin{array}{l}\text { Asynchronous Transfer } \\
\text { Mode Passive Optical } \\
\text { Network }\end{array}$ \\
\hline AW & Vetor de Guias de Onda & Arrayed Waveguide \\
\hline AWG & $\begin{array}{l}\text { Grades Ordenadas em } \\
\text { Guias de Onda }\end{array}$ & $\begin{array}{l}\text { Arrayed Waveguide } \\
\text { Grating }\end{array}$ \\
\hline BER & Taxa de Erro de Bit & Bit Error Rate \\
\hline BLS & $\begin{array}{l}\text { Fonte de Luz de } \\
\text { Banda Larga }\end{array}$ & Broadband Light Source \\
\hline BPON & $\begin{array}{l}\text { Rede Óptica Passiva } \\
\text { Banda Larga }\end{array}$ & $\begin{array}{l}\text { Broadband Passive } \\
\text { Optical Network }\end{array}$ \\
\hline CATV & Televisão a Cabo & $\begin{array}{l}\text { Community Antenna } \\
\text { Television }\end{array}$ \\
\hline CLS & Fontes Ópticas Centralizadas & Centralized Light Sources \\
\hline $\mathrm{CO}$ & Central do Provedor de Serviço & Central Office \\
\hline $\mathrm{CPON}$ & $\begin{array}{l}\text { Rede Óptica } \\
\text { Passiva Composta }\end{array}$ & $\begin{array}{l}\text { Composite Passive } \\
\text { Optical Network }\end{array}$ \\
\hline CDWM & $\begin{array}{l}\text { Multiplexação por Divisão } \\
\text { Esparsa de Comprimento } \\
\text { de Onda }\end{array}$ & $\begin{array}{l}\text { Coarse Wavelength } \\
\text { Division Multiplexing }\end{array}$ \\
\hline DBA & $\begin{array}{l}\text { Alocação Dinâmica de } \\
\text { Largura de Banda }\end{array}$ & $\begin{array}{l}\text { Dynamic Bandwidth } \\
\text { Allocation }\end{array}$ \\
\hline DFB & Realimentação Distribuída & Distributed Feedback \\
\hline
\end{tabular}




\begin{tabular}{|c|c|c|}
\hline DGD & Atraso Diferencial de Grupo & Differential Group Delay \\
\hline DOCSIS & $\begin{array}{l}\text { Especificação de Interface } \\
\text { para o serviço "Dados } \\
\text { sobre Cabo" }\end{array}$ & $\begin{array}{l}\text { Data Over Cable } \\
\text { Service Interface } \\
\text { Specifications }\end{array}$ \\
\hline DSL & Linha Digital de Assinante & Digital Subscriber Line \\
\hline DWDM & $\begin{array}{l}\text { Multiplexação por Divisão } \\
\text { de Comprimento de Onda } \\
\text { Denso }\end{array}$ & $\begin{array}{l}\text { Dense Wavelength } \\
\text { Division Multiplexing }\end{array}$ \\
\hline EDFA & $\begin{array}{l}\text { Amplificador de Fibra } \\
\text { Dopada com Érbio }\end{array}$ & $\begin{array}{l}\text { Erbium Doped } \\
\text { Fiber Amplifier }\end{array}$ \\
\hline$\overline{E F M}$ & Ethernet na primeira milha & Ethernet in the First Mile \\
\hline EoD & Educação sob Demanda & Education on Demand \\
\hline EPON & $\begin{array}{l}\text { Rede Óptica Passiva } \\
\text { baseada no protocolo } \\
\text { Ethernet }\end{array}$ & Ethernet PON \\
\hline F-P LD & Diodo Laser Fabry-Perot & Fabry-Perot laser diode \\
\hline FPR & Região de Propagação Livre & Free Propagation Region \\
\hline FSAN & $\begin{array}{l}\text { Rede de Acesso de } \\
\text { Serviço Completo }\end{array}$ & $\begin{array}{l}\text { Full Service } \\
\text { Access Network }\end{array}$ \\
\hline FSR & Região Espectral Livre & Free Spectral Range \\
\hline FTTB & Fibra até o Prédio & Fiber to the Building \\
\hline FTTC & Fibra até o Meio Fio & Fiber to the Curb \\
\hline FTTCab & Fibra até o Armário & Fiber to the Cabinet \\
\hline FTTH & Fibra até a Residência & Fiber to the Home \\
\hline FWM & Mistura de Quatro Ondas & Four Wave Mixing \\
\hline GEM & $\begin{array}{l}\text { Método de Encapsulamento } \\
\text { Genérico }\end{array}$ & Generic Framing Method \\
\hline GPON & $\begin{array}{l}\text { Rede Óptica Passiva } \\
\text { capaz de atender Gigabit }\end{array}$ & $\begin{array}{l}\text { Gigabit-capable Passive } \\
\text { Optical Network }\end{array}$ \\
\hline G.SHDSL & $\begin{array}{l}\text { Linha Digital Simétrica } \\
\text { de Assinante de Alta } \\
\text { Velocidade }\end{array}$ & $\begin{array}{l}\text { Symmetric High-Speed } \\
\text { Digital Subscriber Line }\end{array}$ \\
\hline GUI & Interface Gráfica do Usuário & Graphical User Interface \\
\hline HDTV & Televisão de Alta Definição & High Definition Television \\
\hline $\mathrm{HFC}$ & $\begin{array}{l}\text { Rede Híbrida } \\
\text { Fibra-Coaxial }\end{array}$ & Hybrid Fibre-Coaxial \\
\hline IDSL & DSL baseada em ISDN & $\begin{array}{l}\text { ISDN Digital } \\
\text { Subscriber Line }\end{array}$ \\
\hline
\end{tabular}




\begin{tabular}{|c|c|c|}
\hline IEEE & $\begin{array}{l}\text { Instituto de Engenheiros } \\
\text { Eletricistas e Eletrônicos }\end{array}$ & $\begin{array}{l}\text { Institute of Electrical and } \\
\text { Electronics Engineers }\end{array}$ \\
\hline IP & Protocolo de Internet & Internet Protocol \\
\hline ISDN & $\begin{array}{l}\text { Rede Digital de } \\
\text { Serviços Integrados }\end{array}$ & $\begin{array}{l}\text { Integrated Service } \\
\text { Digital Network }\end{array}$ \\
\hline ITU-T & $\begin{array}{l}\text { Setor de Padronização } \\
\text { da Telecomunicação da } \\
\text { União Internacional de } \\
\text { Telecomunicações }\end{array}$ & $\begin{array}{l}\text { Telecommunication } \\
\text { Standardization } \\
\text { sector of International } \\
\text { Telecommunication } \\
\text { Union }\end{array}$ \\
\hline KAIST & $\begin{array}{l}\text { Instituto Coreano de } \\
\text { Ciência e Tecnologia } \\
\text { Avançada }\end{array}$ & $\begin{array}{l}\text { Korea Advanced } \\
\text { Institute of Science and } \\
\text { Technology }\end{array}$ \\
\hline $\mathrm{LAN}$ & Redes Locais & Local Area Networks \\
\hline LARNET & $\begin{array}{l}\text { Rede Roteada de } \\
\text { Acesso Local }\end{array}$ & $\begin{array}{l}\text { Local Access } \\
\text { Router Network }\end{array}$ \\
\hline LED & Diodo Emissor de Luz & Light Emitting Diode \\
\hline MAC & Controle de Acesso ao Meio & Media Access Control \\
\hline MAN & Redes Metropolitanas & Metro Area Networks \\
\hline NRZ & Não Retorno a Zero & Non-return-to-zero \\
\hline OADM & $\begin{array}{l}\text { Multiplexador Óptico de } \\
\text { Inserção e Retirada de } \\
\text { Comprimentos de Onda }\end{array}$ & $\begin{array}{l}\text { Optical Add- } \\
\text { Drop Multiplexer }\end{array}$ \\
\hline ODN & Rede de Distribuição Óptica & Optical Distribution Network \\
\hline OLT & Terminal de Linha Óptica & Optical Line Terminal \\
\hline $\mathrm{ONU}$ & Unidade de Rede Óptica & Optical Network Unit \\
\hline ORL & Perda de Retorno Óptica & Optical Return Loss \\
\hline OTDV & $\begin{array}{l}\text { Visualizador Óptico no } \\
\text { Domínio do Tempo }\end{array}$ & $\begin{array}{l}\text { Optical Time- } \\
\text { Domain Visualizer }\end{array}$ \\
\hline $\mathrm{OXC}$ & Comutador Óptico & Optical Cross-Connect \\
\hline $\mathrm{PC}$ & Contato Físico & Physical Contact \\
\hline PLC & Circuito Óptico Planar & Planar Lightwave Circuit \\
\hline $\mathrm{PON}$ & Rede Óptica Passiva & Passive Optical Network \\
\hline PRBS & $\begin{array}{l}\text { Sequência Pseudo- } \\
\text { Aleatória de Bits }\end{array}$ & $\begin{array}{l}\text { Pseudo Random } \\
\text { Binary Sequence }\end{array}$ \\
\hline PSTN & $\begin{array}{l}\text { Rede Pública de } \\
\text { Telefonia Comutada }\end{array}$ & $\begin{array}{l}\text { Public Switched } \\
\text { Telephone Network }\end{array}$ \\
\hline QoS & Qualidade de Serviço & Quality of Service \\
\hline REAM & $\begin{array}{l}\text { Modulador Reflexivo } \\
\text { de Eletro-Absorção }\end{array}$ & $\begin{array}{l}\text { Reflective Electro- } \\
\text { Absorption Modulator }\end{array}$ \\
\hline $\mathrm{RF}$ & Rádio Frequência & Radio frequency \\
\hline
\end{tabular}




\begin{tabular}{|c|c|c|}
\hline RITENET & $\begin{array}{l}\text { Interrogação Remota } \\
\text { do Terminal de Rede }\end{array}$ & $\begin{array}{l}\text { Remote Interrogation } \\
\text { of Terminal Network }\end{array}$ \\
\hline $\mathrm{RN}$ & Nó Remoto & Remote Node \\
\hline RSOA & $\begin{array}{l}\text { Amplificador Óptico } \\
\text { Semicondutor Reflexivo }\end{array}$ & $\begin{array}{l}\text { Reflective semiconductor } \\
\text { optical amplifier }\end{array}$ \\
\hline SBS & $\begin{array}{l}\text { Espalhamento Brillouin } \\
\text { Estimulado }\end{array}$ & $\begin{array}{l}\text { Stimulated Brillouin } \\
\text { Scattering }\end{array}$ \\
\hline SDSL & $\begin{array}{l}\text { Linha Digital } \\
\text { Simétrica de Assinante }\end{array}$ & $\begin{array}{l}\text { Symmetric Digital } \\
\text { Subscriber Line }\end{array}$ \\
\hline SLA & $\begin{array}{l}\text { Contrato de Nível } \\
\text { de Serviço }\end{array}$ & Service Level Agreement \\
\hline SLED & $\begin{array}{l}\text { Diodo } \\
\text { Superluminescente } \\
\text { Emissor de Luz }\end{array}$ & $\begin{array}{l}\text { Superluminescent Light } \\
\text { Emitting Diode }\end{array}$ \\
\hline$\overline{\mathrm{SPM}}$ & Automodulação de Fase & Self-Phase Modulation \\
\hline SRS & $\begin{array}{l}\text { Espalhamento Raman } \\
\text { Estimulado }\end{array}$ & $\begin{array}{l}\text { Stimulated Raman } \\
\text { Scattering }\end{array}$ \\
\hline SUCCESS & & Stanford University Access \\
\hline TDM & $\begin{array}{l}\text { Multiplexação por divisão } \\
\text { no tempo }\end{array}$ & Time-division multiplexing \\
\hline TDMA & $\begin{array}{l}\text { Acesso Múltiplo por } \\
\text { Divisão de Tempo }\end{array}$ & $\begin{array}{l}\text { Time Division } \\
\text { Multiple Access }\end{array}$ \\
\hline TDM-PON & $\begin{array}{l}\text { Rede Óptica Passiva } \\
\text { baseada em Multiplexação } \\
\text { por Divisão no Tempo }\end{array}$ & $\begin{array}{l}\text { Time Division } \\
\text { Multiplexing - Passive } \\
\text { Optical Network }\end{array}$ \\
\hline UPC & Ultra Contato Físico & Ultra Physical Contact \\
\hline VDSL & $\begin{array}{l}\text { Linha Digital de } \\
\text { Assinante de alta } \\
\text { velocidade }\end{array}$ & $\begin{array}{l}\text { Very-high-bit-rate } \\
\text { Digital Subscriber } \\
\text { Line }\end{array}$ \\
\hline $\mathrm{VoD}$ & Vídeo sob Demanda & Video on Demand \\
\hline WAN & $\begin{array}{l}\text { Redes Geograficamente } \\
\text { Distribuídas }\end{array}$ & Wide Area Networks \\
\hline WDM & $\begin{array}{l}\text { Multiplexação por Divisão } \\
\text { de Comprimento de Onda }\end{array}$ & $\begin{array}{l}\text { Wavelength Division } \\
\text { Multiplexing }\end{array}$ \\
\hline WDM-PON & $\begin{array}{l}\text { Rede Óptica Passiva } \\
\text { baseada em Multiplexação } \\
\text { por Divisão de } \\
\text { Comprimento de Onda }\end{array}$ & $\begin{array}{l}\text { Wavelenght Division } \\
\text { Multiplexed - Passive } \\
\text { Optical Network }\end{array}$ \\
\hline WiMax & $\begin{array}{l}\text { Interoperabilidade Mundial } \\
\text { para Acesso por Microondas }\end{array}$ & $\begin{array}{l}\text { Worldwide Interoperability } \\
\text { for Microwave Access }\end{array}$ \\
\hline XPM & Modulação de Fase Cruzada & Cross-Phase Modulation \\
\hline
\end{tabular}




\section{Capítulo 1}

\section{Introdução}

As redes de telecomunicações podem ser classificadas, de acordo com a escala, em redes geograficamente distribuídas (Wide Area Networks - WANs), redes metropolitanas (Metro Area Networks - MANs) e redes locais (Local Area Networks - LANs) [1].

Uma WAN abrange uma grande área geográfica, em geral milhares de quilômetros englobando um país ou continente. As taxas de dados em operação nestas redes variam de dezenas de Gbps a Tbps. As MANs cobrem dezenas de quilômetros, geralmente cidades ou regiões metropolitanas. Suas taxas de transmissão chegam a 40 Gbps. Já as LANs são redes privadas contidas em um único edifício ou em um campus universitário, por exemplo. Sua distância máxima atinge poucos quilômetros e, tradicionalmente, operam com taxas de até $100 \mathrm{Mbps}$, porém em redes mais modernas a taxa chega a 10 Gbps [1].

Entre as MANs e as LANs estão situadas as redes de acesso, que são responsáveis pela conexão da central do provedor de serviço (Central Office - CO) aos assinantes residenciais ou empresas. Essas redes atingem dezenas de quilômetros e suas taxas variam de centenas de Kbps até poucos Mbps. Assinantes residenciais não necessariamente estão incorporados em uma rede local, e, nesse caso, o usuário conecta-se diretamente a rede de acesso.

De acordo com as taxas da hierarquia das redes apresentada acima, fica evidente que as redes de acesso são o maior problema ("gargalo") das redes de telecomunicações. Uma representação esquemática da hierarquia das redes pode ser observada na Figura 1.1. 
As redes de acesso eram conhecidas antigamente como redes de última-milha, mas, devido à relevância que vêm obtendo nos últimos anos, passaram a ser conhecidas como redes de primeira-milha [2].A demanda de largura de banda exigida pelos usuários (sejam eles

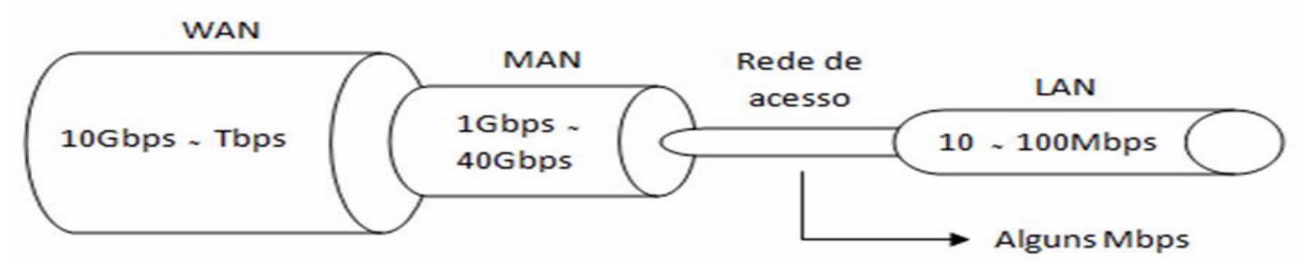

Figura 1.1: Representação das redes de acesso como gargalo da Internet [3]

residências ou empresas) vem aumentando rapidamente e as soluções de acesso banda larga mais utilizadas atualmente (DSL - Linha Digital de Assinante e Modem a Cabo) logo se tornarão insuficientes. As fibras ópticas surgem, então, como uma boa alternativa para atender o aumento de demanda das redes de acesso [4]. Dentre as configurações presentes no cenário mundial atual, a rede óptica passiva (PON - Passive Optical Network) baseada em multiplexação por divisão no tempo (TDM-PON - Time Division Multiplexing - PON) tem recebido grande destaque. Como alternativa, a PON baseada em multiplexação por divisão de comprimento de onda (WDM-PON - Wavelength Division Multiplexing - PON) é capaz de atender uma maior demanda em comparação com a rede TDM-PON. Os países asiáticos têm demonstrado grande interesse por WDM-PONs [5].

Tendo em vista esse cenário, este trabalho foca o estudo nas redes de primeiramilha. Na continuação deste capítulo é apresentada uma revisão sobre as tecnologias para redes de acesso mais difundidas no mundo atualmente.

\subsection{Tecnologias para as redes de acesso}

As redes de acesso mais usuais atualmente podem ser classificadas em: 
- Sem fio,

- $\mathrm{xDSL}$,

- modem a cabo e

- fibra óptica.

A seguir, uma breve descrição a respeito de cada uma delas.

\subsubsection{As redes sem fio}

As redes sem fio possuem o menor custo de implantação dentre as categorias citadas e são representadas pelas tecnologias WiFi [6] e WiMAX [7].

Alguns dos principais padrões de WiFi utilizados atualmente são:

- 802.11b, que utiliza uma freqüência de $2.4 \mathrm{GHz}$ e transmite 11 Mbps a um alcance de $100 \mathrm{~m}$,

- 802.11a, que utiliza freqüência de $5 \mathrm{GHz}$ e em 50 m atinge uma taxa máxima de $54 \mathrm{Mbps}, \mathrm{e}$

- 802.11g, que alia as vantagens dos dois padrões anteriores alcançando taxas de 54 Mbps a distâncias de $100 \mathrm{~m}$.

Devido ao curto alcance, a tecnologia WiFi tem aplicação restrita a aplicações de escala restrita, tais como parques, livrarias e aeroportos [8]. Por outro lado, tecnologia WiMAX foi definida em abril de 2002. Ela provê uma taxa de 70 Mbps em um raio de $5 \mathrm{~km}$. No Brasil, esta tecnologia foi implantada em algumas regiões, como, por exemplo, na cidade de Mangaritiba (Rio de Janeiro) e Parintins (Amazonas) [9]-[11]. Apesar das implementações recentes terem obtido sucesso, o WiMAX não tem tido um grande desenvolvimento em grandes centros urbanos devido a concorrência com o DSL e modem a cabo. A tendência é que a tecnologia fixe seu nicho em zonas rurais, onde o cabeamento não seja viável economicamente. Alguns detalhes sobre a camada física e o controle de acesso ao meio do padrão WiMAX podem ser encontrados na Ref. [12]. 
Apesar da vantagem econômica apresentada pelas redes sem fio descritas acima, elas não possuem largura de banda suficiente para oferecer suporte a aplicações de vídeo, como HDTV (High Definition Television), já que são ponto-multiponto, ou seja, a taxa é compartilhada por vários usuários, em alguns casos até cerca de centenas deles. Vale observar que, como já mencionado, as redes sem fio se constituem em alternativas propícias apenas para aplicações específicas.

Uma alternativa recente que vem sendo investigada pelas operadoras de telefonia celular é o LTE (Long Term Evolution), solução OFDMA (Orthogonal Frequency-Division Multiple Access) móvel pradronizada pelo 3GPP (3rd Generation Partnership Project) [13][15]. O LTE seria a evolução das tecnologias 3G, porém ainda é cedo para determinar a fração de mercado que a tecnologia vai alcançar.

\subsection{2 xDSL e modem a cabo}

A Linha Digital de Assinante, xDSL, é uma tecnologia baseada no fato de que os cabos de cobre das linhas telefônicas conectam praticamente todas as residências e áreas empresariais com uma central telefônica. Dessa forma, companhias telefônicas podem prover acesso banda larga a seus usuários usando parte do espectro que não é utilizado pela transmissão de voz.

A xDSL usa arquitetura ponto-a-ponto e seu principal limitante é o ruído resultante da diafonia entre os cabos metálicos. Sua largura de banda depende do nível de ruído que, por sua vez, depende do comprimento do enlace de cobre. Algumas tecnologias xDSL, como a ADSL (DSL assimétrica), VDSL (DSL de alta velocidade), IDSL (DSL baseada em ISDN), G.SHDSL (DSL simétrica de alta velocidade) e SDSL (DSL simétrica) estão mostradas na Tabela 1.1 [16] com suas respectivas taxas e alcances típicos.

De forma similar às companhias telefônicas, as empresas de TV a cabo encontraram uma forma de prover acesso banda larga a seus usuários através da tecnologia Modem a Cabo. Esta tecnologia utiliza canais de radiofreqüência na infra-estrutura de transmissão das TVs por assinatura. Para reduzir as perdas nos cabos coaxiais e a necessidade de muitos amplificadores em série, as empresas passaram a utilizar fibra óptica nos troncos de distribuição, isto é, na parte mais próxima à central de serviço. Na área de distribuição aos 


\begin{tabular}{|c|c|c|c|}
\hline & Downstream & Upstream & Alcance \\
\hline \multirow{2}{*}{ ADSL } & $8 \mathrm{Mbps}$ & $1 \mathrm{Mbps}$ & $5.5 \mathrm{Km}$ \\
& $1.5 \mathrm{Mbps}$ & $640 \mathrm{Kbps}$ & \\
\hline \multirow{2}{*}{ VDSL } & $51-55 \mathrm{Mbps}$ & $1.6-2.3 \mathrm{Mbps}$ & $0.3 \mathrm{Km}$ \\
& $13 \mathrm{Mbps}$ & $1.6-2.3 \mathrm{Mbps}$ & $1.5 \mathrm{Km}$ \\
\hline IDSL & $144 \mathrm{Kbps}$ & $144 \mathrm{Kbps}$ & $5.5 \mathrm{Km}$ \\
\hline G.SHDSL & $2.3 \mathrm{Mbps}-192 \mathrm{Kbps}$ & $2.3 \mathrm{Mbps}-192 \mathrm{Kbps}$ & $8.52 \mathrm{Km}$ \\
\hline SDSL & $1168 \mathrm{Kbps}$ & $1168 \mathrm{Kbps}$ & $3.65 \mathrm{Km}$ \\
\hline
\end{tabular}

Tabela 1.1: Tecnologias DSL: alcance x taxa [16]

\begin{tabular}{|c|c|c|}
\hline Versão & Downstream & Upstream \\
\hline $\mathbf{1 . x}$ & $38 \mathrm{Mbps}$ & $9 \mathrm{Mbps}$ \\
\hline $\mathbf{2 . 0}$ & $38 \mathrm{Mbps}$ & $27 \mathrm{Mbps}$ \\
\hline $\mathbf{3 . 0}$ - 4 canais & $+152 \mathrm{Mbps}$ & $+108 \mathrm{Mbps}$ \\
\hline $\mathbf{3 . 0}$ - 8 canais & $+304 \mathrm{Mbps}$ & $+108 \mathrm{Mbps}$ \\
\hline
\end{tabular}

Tabela 1.2: Versões do padrão DOCSIS [17]

assinantes, continuou-se usando cabos coaxiais. Esta tecnologia mista de projeto denominase planta Híbrida Óptica-Coaxial (HFC). Diferentemente do DSL, onde a arquitetura física dos cabos de cobre é ponto-a-ponto, a tecnologia Modem a Cabo compartilha o meio, dessa forma a largura de banda é dividida entre todos os usuários da rede.

O DOCSIS (Data Over Cable Service Interface Specifications) define as taxas para downstream e upstream, como pode ser observado na Tabela 1.2 [17]. A versão 1.x é a mais utilizada pelas empresas e, compartilhando-se a largura de banda por algumas centenas de usuários, a taxa individual é relativamente pequena (inferior a 1Mbps). Adicionalmente, esta rede foi construída principalmente para oferecer serviços broadcast, o que dificulta o modelo de comunicação bidirecional de uma rede de acesso.

\subsubsection{Fibra óptica}

Devido à sua alta largura de banda, as fibras ópticas têm sido tradicionalmente usadas como meio físico para transmissão de dados em MANs e WANs [2]. Os elevados custos dos equipamentos ópticos não são um problema, já que estas redes chegam a conectar 
milhões de usuários. Com o surgimento de novos serviços e o aumento na demanda por largura de banda de clientes residenciais e empresas, a fibra óptica tem chegado cada vez mais próxima dos usuários. Tendo em vista que as redes de acesso geralmente conectam algumas dezenas ou centenas de usuários, a implantação da fibra nestas redes torna-se mais cara.

As redes de fibras ópticas de acesso podem ser classificadas em duas categorias de acordo com a distribuição dos cabos ópticos: a arquitetura ponto-a-ponto e a pontomultiponto. Na topologia física ponto-a-ponto, o número de fibras é igual ao número de usuários, o que torna mais difícil a instalação e manutenção, portanto, inapropriada para desenvolvimento em massa. Na arquitetura ponto-multiponto, diversos usuários compartilham uma fibra até um nó remoto $(\mathrm{RN})$, a partir do qual cada cliente dispõe do seu próprio enlace óptico. O RN pode ser passivo ou ativo, dependendo se é eletricamente alimentado ou não. Se requerer suprimento de energia, a arquitetura é chamada de Rede Óptica Ativa $(\mathrm{AON})$. Caso contrário, a arquitetura recebe o nome de Rede Óptica Passiva (PON). As PONs foram inicialmente desenvolvidas na década de 80 (vide [18]) como um método financeiramente viável de compartilhamento da infra-estrutura de fibra para prover telefonia a empresas.

PONs são mais vantajosas do que as AONs em termos de instalação, operação, manutenção da rede e possibilidade de upgrade [19]. A planta externa de uma rede óptica passiva implica em menor gasto de capital já que não há componentes elétricos no campo, tais como switches Ethernet ou amplificadores. Gastos operacionais também são reduzidos na PON, tendo em vista que não há necessidade dos operadores proverem e monitorarem a energia elétrica no campo ou manterem baterias reservas. Adicionalmente, componentes elétricos são passíveis de falha, preocupação adicional que se deve ter com AONs. Desta forma, as redes de acesso estudadas neste trabalho serão as redes ópticas passivas.

Nas PONs, o Terminal de Linha Óptica (Optical Line Terminal - OLT), localizado na central do provedor de serviço $(\mathrm{CO})$, é conectado a várias Unidades de Rede Óptica (Optical Network Units - ONUs) através de um ou vários divisores ópticos, splitters, que estão localizados dentro do RN.

A Figura 1.2 mostra uma das configurações mais utilizadas para implementação 


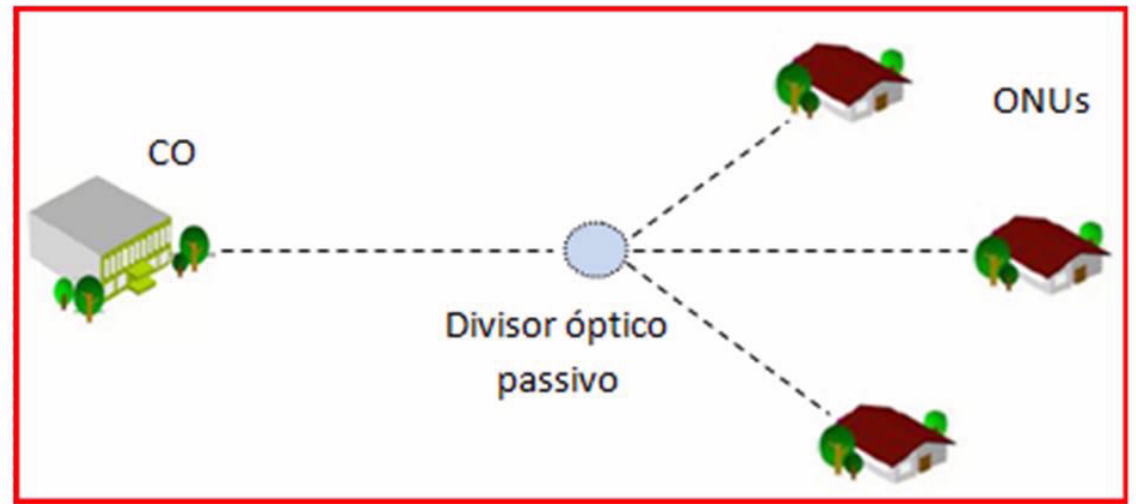

Figura 1.2: Topologia em árvore de uma Rede Óptica Passiva

de uma Rede Óptica Passiva: a topologia em árvore.

As PONs podem ser configuradas no modelo chamado FTTx:

- fibra até a residência (Fiber to the Home - FTTH),

- fibra até o prédio (Fiber to the Building - FTTB),

- fibra até o meio fio (Fiber to the Curb - FTTC) e

- fibra até o armário (Fiber to the Cabinet - FTTCab).

Nesse contexto, a PON pode ser utilizada como a rede convergente de vídeo, voz e dados, serviço denominado como "triple-play", sendo mais baratos ao usuário do que se fossem adquiridos separadamente, vide Figura 1.3.

\subsection{Descrição do trabalho}

Assim sendo, a continuação deste trabalho está organizada da seguinte forma: no capítulo 2 é feita uma discussão sobre as Redes Ópticas Passivas, mais especificamente a TDM-PON e a WDM-PON. Após a comparação entre essas redes, foram investigadas estratégias de migração entre elas e também discutiu-se aspectos relativos a segurança de TDM-PONs. No capítulo 3 são descritas as principais arquiteturas WDM-PON propostas 


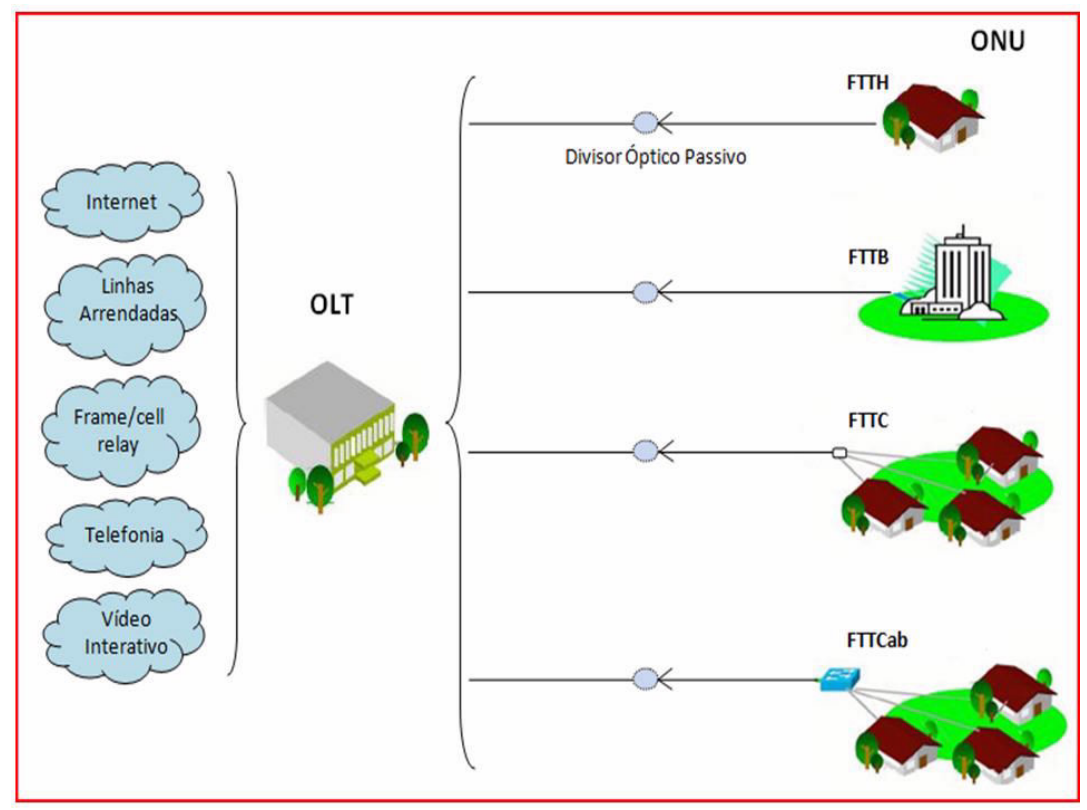

Figura 1.3: Esquemas FTTx (FTTH, FTTB, FTTC e FTTCab) sendo empregados como uma rede convergente de vídeo, voz e dados [20]

até hoje por grupos de pesquisadores e pela própria indústria. No capítulo 4 fez-se uma análise mais profunda sobre topologias recentes derivadas da RITENET, as quais utilizam travamento de diodos lasers Fabry-Pérot através da injeção do sinal de ASE. O software OptiSystem foi a ferramenta computacional utilizada no estudo. Finalmente, o capítulo 5 apresenta as conclusões obtidas. 


\section{Capítulo 2}

\section{Redes Ópticas Passivas}

Este capítulo inicia-se com uma breve discussão sobre TDM-PONs, sendo apresentadas suas três principais tecnologias: BPON, EPON e GPON. Em seguida, na seção 2.2, foi investigado um grave problema de segurança presente nessas redes. Na seção 2.3, as redes WDM-PON, de maior interesse para o trabalho, são descritas. Para efeito de comparação entre as redes estudadas, a seção 2.4 apresenta resultados obtidos através do software OptiSystem. Por fim, na seção 2.5, uma alternativa de migração de TDM-PON para WDM-PON é investigada.

\subsection{TDM-PON}

Atualmente, a solução de acesso óptico mais difundida no mundo é a TDM-PON [21], a qual combina a alta capacidade oferecida pelas fibras ópticas com o baixo custo na instalação e manutenção da infra-estrutura passiva. Muitos países têm adotado a primeira geração de TDM-PONs, que fornece taxas de dados para downstream de até 1,25 Gbps [22].

No downstream a transmissão ocorre em broadcasting, sendo que cada ONU recebe toda a informação provida pelo OLT e filtra os dados que lhe são destinados, como pode ser observado na Figura 2.1. No entanto, precauções relativas à segurança devem ser tomadas para garantir que usuários mal intencionados não tenham acesso a toda informação da rede. A faixa de comprimento de onda utilizada nesse sentido de tráfego varia entre $1480 \mathrm{~nm}$ a $1500 \mathrm{~nm}$. 
No sentido upstream cada ONU terá uma janela temporal pré-determinada e, durante este intervalo, poderá usar toda a largura de banda provida pelo canal óptico. $\mathrm{O}$ splitter, atuando como um combinador de potências, será responsável por combinar as sequências de dados e mandar as informações de todos os usuários ao CO. O esquema está mostrado na Figura 2.2. O OLT é responsável por alocar as janelas temporais de cada usuário, com intuito de evitar colisões no tráfego de upstream. De forma complementar, as ONUs devem negociar com o OLT quando elas podem transmitir seus dados, levando-se em consideração as diferentes distâncias que pode haver entre elas. Nesse contexto, uma característica importante é a Alocação Dinâmica de Largura de Banda (DBA), cujos algoritmos permitem uma melhor eficiência da rede, alocando um número maior de janelas temporais para aqueles usuários com maior intensidade de tráfego. A faixa de comprimento de onda utilizada no upstream varia entre $1260 \mathrm{~nm}$ a $1360 \mathrm{~nm}$.

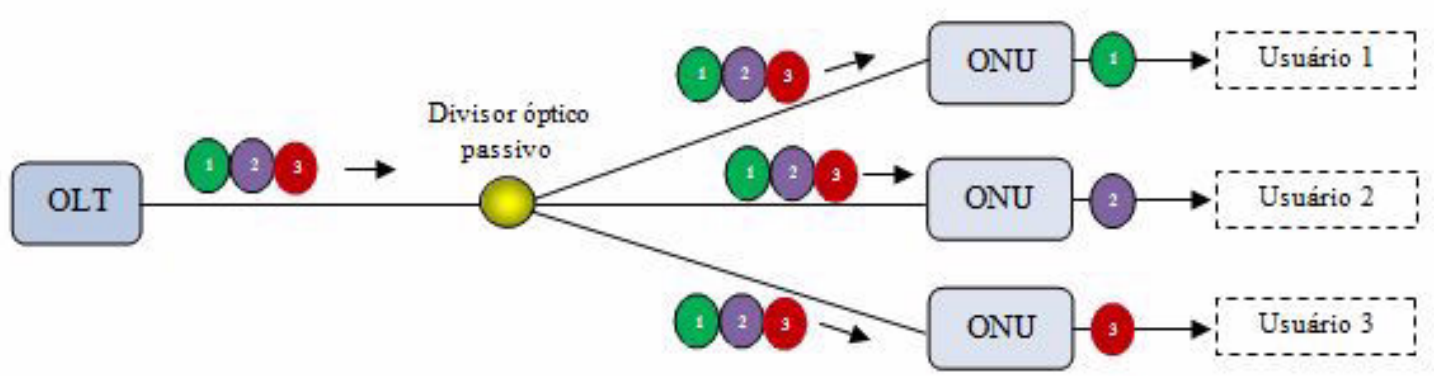

Figura 2.1: Esquema de downstream da TDM-PON

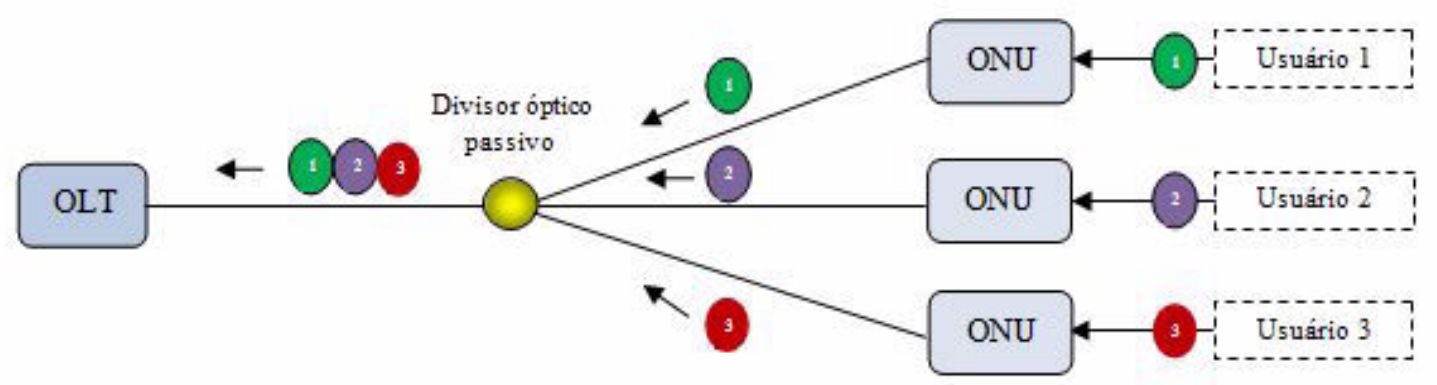

Figura 2.2: Esquema de upstream da TDM-PON 
As tecnologias TDM-PON mais em uso atualmente são:

- Broadband PON (BPON) [23], introduzida anteriormente como ATM PON (Asynchronous Transfer Mode PON - APON),

- Ethernet PON (EPON) [24], e

- Gigabit PON (GPON) [25].

Já existem muitas plantas TDM-PON em operação viabilizadas pelas operadoras NTT (Japão), DT (Alemanha), BT (Inglaterra) e BellSouth (Canadá). Alguns dos maiores parques instalados de PON são os backbones de Tokyo e Osaka da NTT (Japão) [28]. Detalhes sobre a implantação de fibras ópticas para redes de acesso nos Estados Unidos estão descritos em [22] e [29].

\subsubsection{Broadband PON}

A BPON (anteriormente APON) foi proposta pelo grupo FSAN (Full Service Access Network), formado em 1995 por vinte e uma grandes empresas de telecomunicações ao redor do mundo. A tecnologia opera a uma taxa de downstream entre 155 Mbps e 622 Mbps, e de upstream 155 Mbps. Por utilizar o protocolo de comunicação ATM, ela oferece grande qualidade de serviço (QoS). Por outro lado, a eficiência da transmissão é reduzida, já que se utilizam muitos bytes de cabeçalho nas células.

A BPON já pode ser considerada uma tecnologia legada tendo em vista que poucos provedores de serviço dos Estados Unidos ainda a utilizam. Em breve, estas empresas mudarão suas arquiteturas e tecnologias para EPON ou GPON [26].

\subsubsection{Ethernet PON}

Em novembro de 2000, o IEEE 802.3 anunciou um grupo de estudos chamado Ethernet na primeira milha (EFM), que tinha como objetivo utilizar a Ethernet para a rede de acesso do usuário. Os resultados deste grupo de estudos foram ratificados em junho de 2004, tornando-se o padrão IEEE 802.3ah (o EPON) [24]. Esta rede trabalha com pacotes 
de tamanho variável, diferentemente da rede anterior, o que permite grande eficiência no tratamento de tráfego IP.

A EPON provê taxas de 1 Gbps nos dois sentidos usando o comprimento de onda $1490 \mathrm{~nm}$ para downstream e $1310 \mathrm{~nm}$ para upstream. O comprimento de onda $1550 \mathrm{~nm}$ é reservado para serviços adicionais, como o broadcast de vídeo analógico. Considerando que a cada OLT se conectam, tipicamente, 16 ou 32 ONUs, a largura de banda média para cada usuário seria em torno de 60 ou $30 \mathrm{Mbps}$, respectivamente.

Em termos de evolução da EPON, o IEEE lançou a força tarefa P802.3av para considerar a possibilidade de prover 10 Gbps no sentido downstream, e entre 1 e 10 Gbps para upstream [27].

\subsubsection{Gigabit PON}

A GPON teve inicio com o consórcio FSAN em 2001. Dois anos mais tarde os primeiros dois padrões da rede foram aprovados pelo ITU-T: o que diz respeito a requisitos e arquitetura básica (G.984.1) e a camada dependente do meio físico (G.984.2). O método de encapsulamento da GPON (GEM), definido na G.984.3, pode acomodar diferentes formatos de empacotamento, podendo trabalhar somente com pacotes Ethernet, ou somente com pacotes ATM ou ainda com pacotes dos dois tipos simultaneamente. A rede garante grande eficiência no transporte de dados IP, utilizando mais de $95 \%$ da largura de banda disponível no canal de transmissão. A QoS é proporcionada pelo contrato de nível de serviço (Service Level Agreement - SLA), definido em G.984.4.

As taxas para downstream na GPON são 1250 ou $2500 \mathrm{Mbps}$, e para upstream 155, 622, 1250 ou 2500 Mbps. O número de ONUs por OLT são 32 ou 64. Considerando a taxa máxima de 2,5 Gbps dividida entre 64 usuários, a largura de banda média seria 40 Mbps. Dividida entre 32 usuários, a largura de banda média para cada ONU seria 80 Mbps.

Em termos de evolução da GPON, tem-se procurado melhorar o orçamento de potência da rede para que seja possível aumentar seu alcance e/ou aumentar o número de ONUs por OLT. Adicionalmente, estuda-se o incremento da taxa de downstream para 10 Gbps e, para upstream, 5 ou 10 Gbps [19]. 


\subsection{Problemas de segurança em TDM-PONs}

Esta seção tem como objetivo evidenciar um grande problema das redes ópticas passivas baseadas em multiplexação por divisão no tempo: a segurança. Os três problemas principais de segurança em TDM-PONs (vide [30]) são:

- Ataque de falta de serviço

- Escuta não autorizada, conhecido na literatura por "eavesdropping"e

- ONU mascarada.

\subsubsection{Ataque de falta de serviço}

$\mathrm{O}$ ataque de falta de serviço pode ocorrer quando o laser de uma ONU transmitir continuamente sinal de upstream não respeitando sua janela temporal para transmissão. Além disso, dependendo da potência transmitida, todas as outras ONUs podem ter seus dados perdidos. A transmissão contínua do laser pode ter como razão um defeito no dispositivo ou até mesmo uma alteração intencional deste dispositivo. Devido à natureza passiva da rede, a identificação da ONU problemática é difícil e alguns mecanismos têm sido propostos para identificação ou desconexão destas ONUs [31]-[32].

\subsubsection{Escuta não autorizada}

A escuta não autorizada ocorre quando uma ONU consegue interceptar os dados enviados ou recebidos por outros usuários. O padrão EPON não especifica mecanismos de autenticação e criptografia, permitindo que soluções proprietárias o façam, para garantir a segurança da rede. Na literatura, é possível encontrar um desses mecanismos na Ref. [33]. Por outro lado, o padrão GPON recomenda o uso do Padrão de Criptografia Avançado (Advanced Encryption Standard - AES) para a transmissão downstream [25]. Todavia, com relação ao upstream, o GPON considera que não há necessidade de encriptação, uma vez que, a alta direcionalidade dos componentes na rede de distribuição óptica (ODN) impede que uma ONU consiga receber os dados de outra ONU [25]. Porém, diferentememte do que foi 
afirmado, será constatado neste trabalho que o tráfego upstream não é seguro, possibilitando a ocorrência de eavesdropping.

Em linhas gerais, tanto o algoritmo de criptografia AES quanto o algoritmo proposto na Ref. [33] utilizam uma chave, isto é, uma senha para acesso aos dados de downstream. Essa chave é renovada periodicamente e o OLT é responsável por solicitar à ONU que crie uma nova chave. No caso do padrão GPON, quando a OLT envia a mensagem key_request_message, a ONU cria, armazena e envia três vezes consecutivas sua nova chave para o OLT. Note que este envio ocorre sem criptografia, simplesmente supondo que o tráfego em upstream é seguro, porém, na prática, a direcionalidade da ODN é questionável. Segundo operadores de redes americanas, a perda de retorno devido a conectores mal instalados é bastante elevada [34], sendo muito frequente encontrar conectores mal instalados em redes PONs em franco funcionamento [30].

Dessa forma, devido à fenômenos de reflexão na rede, é possível que uma ONU mal intencionada, denominada Maliciosa, possa receber indevidamente o tráfego de upstream de uma outra ONU, que será denominada Vítima. Como os dados trafegando em upstream não estão criptografados, a ONU Maliciosa pode, inclusive, ter acesso a chave da ONU Vítima, sem causar qualquer prejuízo ao tráfego de upstream, impossibilitando ao operador da rede a capacidade de identificar qualquer falha de segurança.

\subsubsection{ONU mascarada}

Por fim, o terceiro problema de segurança em TDM-PONs é conhecido como mascaramento, o qual ocorre quando uma ONU Maliciosa finge ser uma ONU Vítima. Neste caso, se a ONU Maliciosa tem acesso a toda informação de downstream e upstream da ONU Vítima, como discutido na Seção 2.2.2, ela pode efetivamente identificar-se como sendo essa ONU.

\subsubsection{Esquema simulado e resultados}

Como descrito nas Seções 2.2.1 a 2.2.3 os problemas de segurança nas redes TDMPONs envolvem sérias implicações e precisam de um estudo detalhado para uma melhor compreensão dos aspectos a ela interligados. A ferramenta computacional utilizada nas 
simulações para se mensurar até que ponto estes problemas de segurança estão presentes nas redes TDM-PON já instaladas foi o software OptiSystem 8.0, desenvolvido pela empresa Optiwave Systems Inc, Ottawa, Canadá. O programa OptiSystem 8.0 tem como propósito permitir que sejam realizadas simulações de sistemas de telecomunicações, dentre outras aplicações. Para isto, dispõe de várias bibliotecas com diversos componentes utilizados nos sistemas reais, permitindo aos usuários planejar, testar e simular enlaces ópticos na camada de transmissão de redes ópticas modernas [35].

A representação esquemática da rede a ser investigada nessa seção está mostrada na Figura 2.3 [30]. Nela pode-se observar que a ONU Vítima está localizada a 1,6 Km de um splitter de quatro portas e a ONU Maliciosa a cerca de 1,2 Km. O conector, representado pela cor azul escura na Figura 2.3, conecta o divisor óptico passivo à fibra que leva o sinal até o OLT. As taxas de transmissão para análise do tráfego de upstream foram $155 \mathrm{Mbps}$, 622 Mbps e 1,25 Gbps.

Uma das classificações que pode ser feita para conectores é quanto ao tipo de polimento que ele recebe na superfície de contato com a fibra, que pode ser PC (Physical Contact), UPC (Ultra Physical Contact) e APC (Angled Physical Contact) [36]. Os dois últimos tipos são os mais utilizados em redes PON. Quando em perfeito estado, o conector UPC apresenta perda de retorno (ORL) maior que $35 \mathrm{~dB}$ e o APC apresenta perda de retorno maior que $55 \mathrm{~dB}$ (valores disponibilizados por fabricantes [37]). Porém, de acordo com a Ref. [34], um conector UPC mal instalado pode apresentar perda de retorno de somente $15 \mathrm{~dB}$, enquanto um APC mal instalado apresentaria uma ORL pouco maior que 22 dB. Este intervalo de valores para a perda de retorno foi utilizado nas simulações.

As curvas da Figura 2.4 mostram as taxas de erro para as potências recebidas na ONU Maliciosa com diferentes taxas. Em cada taxa foram feitas medidas back-to-back para determinar a sensibilidade do receptor. Em 155 Mbps, por exemplo, a taxa de erro de $2,9 \times 10^{-10}$ (cujo logaritmo é -9.5) é obtida com uma potência recebida de $-36,41 \mathrm{dBm}$. De acordo com as medições back-to-back, esta BER é obtida com uma potência em torno de -36,7 dBm. Percebe-se, com o gráfico, que a relação sinal-ruído desta configuração não será um empecilho para que a ONU maliciosa detecte o sinal de uma ONU vizinha.

Nos gráficos da Figura 2.5 tem-se a BER para a faixa de valores de perda de 


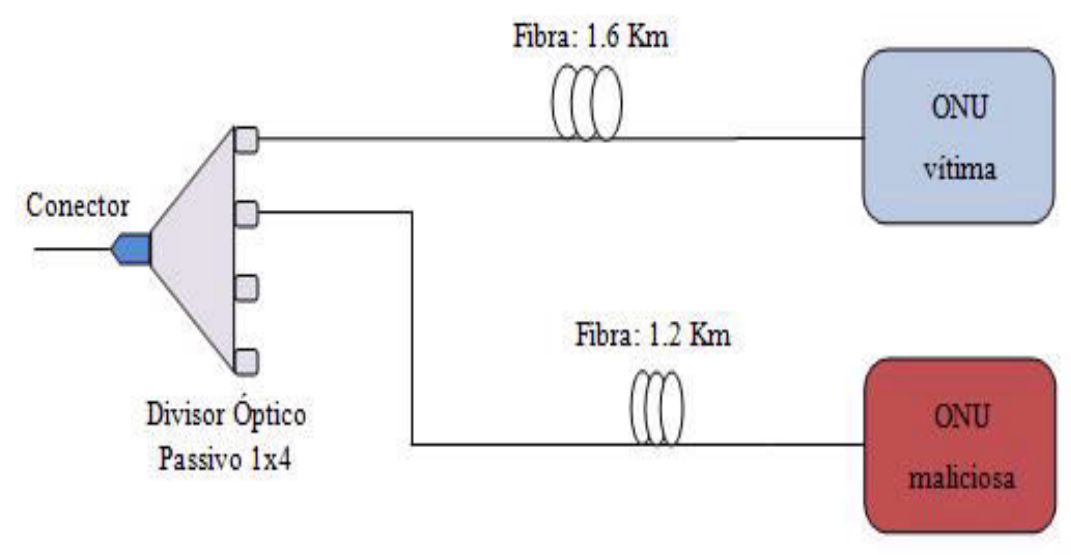

Figura 2.3: Esquema simulado para disposição da ONU vítima e ONU maliciosa.

retorno de conectores mal instalados mencionada anteriormente. A potência enviada pelo transmissor da ONU Vítima é $0 \mathrm{dBm}$. Na situação proposta, com a taxa de $622 \mathrm{Mbps}$, por exemplo, o conector tendo perda de retorno de $17 \mathrm{~dB}$, o receptor da ONU Maliciosa está apto a recuperar o sinal de upstream com uma BER de 2,2×10-10 (cujo logaritmo representado na figura é -9.6).

Para tornar mais evidente o problema, foram elaboradas duas tabelas. Na Tabela 2.1 é mostrada a potência necessária no transmissor da ONU Vítima para que a ONU Maliciosa consiga receber os dados com uma taxa de erro de $10^{-9}$. Três valores de ORL do conector foram considerados: $15 \mathrm{~dB}, 20 \mathrm{~dB}$ e $25 \mathrm{~dB}$. Para efeito de comparação, a Tabela 2.2 mostra a potência máxima no upstream para as classes A, B e C descritas na norma GPON. Observando-se as duas tabelas, percebe-se que uma BER melhor que $10^{-9}$ pode ser atingida quando a ORL do conector for $15 \mathrm{~dB}$ em quaisquer das três taxas (155 Mbps, 622 Mbps e 1,25 Gbps) para potências de upstream da classe A. Com ORL de $20 \mathrm{~dB}$, a BER de $10^{-9}$ poderia ser alcançada também pelas três taxas, sendo que para taxas de $155 \mathrm{Mbps}$ e 622 Mbps seria necessário que a rede fosse enquadrada na classe B, enquanto que para a taxa de 1,25 Gbps a rede deveria ser enquadrada na classe C.

Deve-se observar que taxas de erro de bit maiores que $10^{-9}$ podem ser suficientes para que ONUs Maliciosas possam decifrar a informação de upstream de outras ONUs, o 


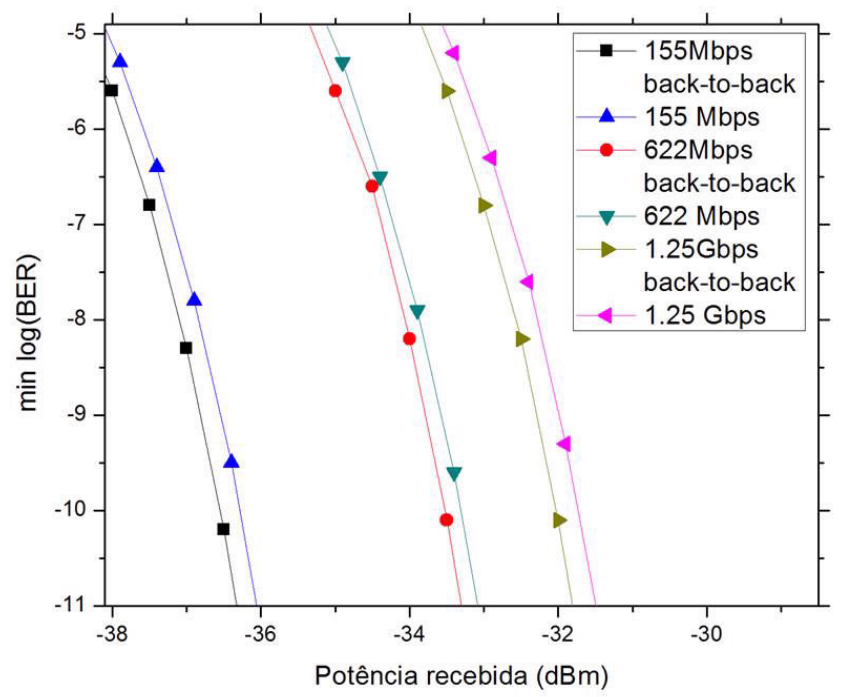

Figura 2.4: BER para potências recebidas pela ONU maliciosa e medições back-to-back

\begin{tabular}{|c|ccc|}
\hline Taxa & \multicolumn{3}{|c|}{ Potência necessária com ORL do conector de } \\
\hline & $\mathbf{1 5} \mathbf{d B}$ & $\mathbf{2 0} \mathbf{d B}$ & $\mathbf{2 5} \mathbf{d B}$ \\
155 Mbps & $-5,3 \mathrm{dBm}$ & $-0,3 \mathrm{dBm}$ & $+4,7 \mathrm{dBm}$ \\
622 Mbps & $-2,3 \mathrm{dBm}$ & $+2,69 \mathrm{dBm}$ & $+7,69 \mathrm{dBm}$ \\
$\mathbf{1 , 2 5} \mathbf{G b p s}$ & $-0,7 \mathrm{dBm}$ & $+4,3 \mathrm{dBm}$ & $+9,3 \mathrm{dBm}$ \\
\hline
\end{tabular}

Tabela 2.1: Potência necessária para atingir uma BER de 10-9

que torna o problema mais crítico. Se necessário, ONUs Maliciosas podem, ainda, utilizar receptores do tipo APD e amplificadores para aumentar a sensibilidade e assim detectar os dados trafegando na rede.

Dessa forma, fica claro que o tráfego em upstream de TDM-PONs não é seguro e há necessidade de criptografia.

\subsubsection{Estudo de novos cenários}

O esquema simulado na Seção 2.2.4 baseava-se, como mencionado, no cenário proposto por [30]. Para complementar as simulações relativas à segurança foram elaborados 


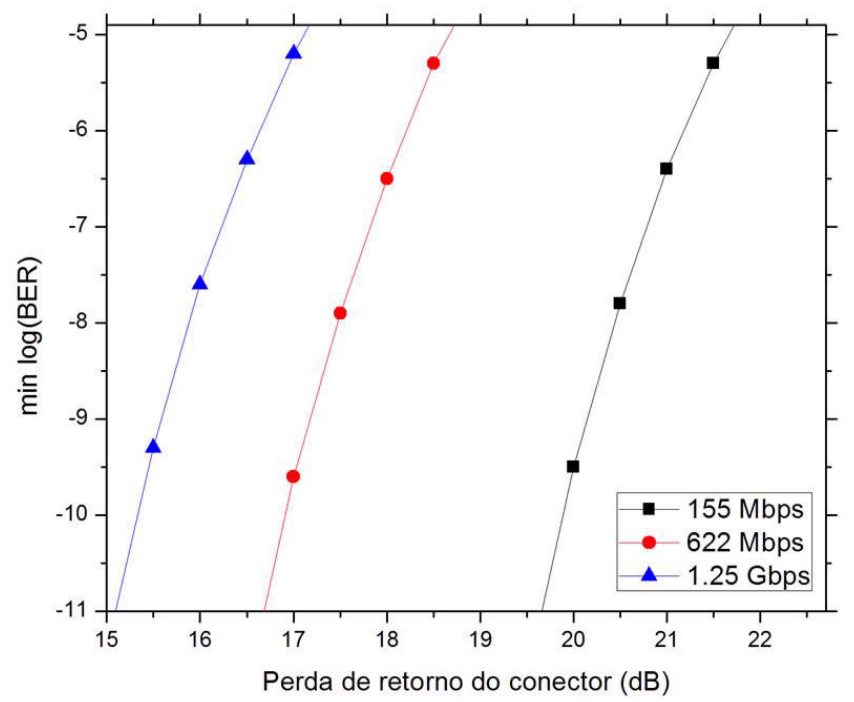

Figura 2.5: Taxa de erro para diversos valores de ORL de conectores mal instalados.

\begin{tabular}{|c|ccc|}
\hline & \multicolumn{3}{|c|}{ Potência máxima } \\
\hline Taxa & Classe A & Classe B & Classe C \\
155 Mbps & $-0 \mathrm{dBm}$ & $+2 \mathrm{dBm}$ & $+4 \mathrm{dBm}$ \\
622 Mbps & $-1 \mathrm{dBm}$ & $+4 \mathrm{dBm}$ & $+4 \mathrm{dBm}$ \\
1,25 Gbps & $+2 \mathrm{dBm}$ & $+3 \mathrm{dBm}$ & $+7 \mathrm{dBm}$ \\
\hline
\end{tabular}

Tabela 2.2: Potência máxima no upstream - norma GPON [25]

novos cenários com splitters de 8, 16 e 32 portas. Porém, antes de mostrar os resultados, uma discussão sobre o orçamento de potência será feita.

Inicialmente, considere o esquema mostrado na Figura 2.3, onde um divisor de 4 portas foi utilizado. O orçamento de potência está mostrado na Tabela 2.3. Considerando uma potência transmitida de $0 \mathrm{dBm}$ pelo transmissor da ONU Vítima, a potência que entra no splitter (sentido upstream) é -0,78 dBm, sendo a perda resultante da atenuação sofrida em 1,6 Km de fibra.

Na saída do splitter (antes do sinal chegar ao conector de cor azul na Figura 2.3), a potência é reduzida para $-8,3 \mathrm{dBm}$. Para compreender a perda inserida por um divisor 


\begin{tabular}{|l|l|}
\hline Potência do transmissor da ONU Vítima & $0 \mathrm{dBm}$ \\
\hline Potência na saída da fibra & $-0,78 \mathrm{dBm}$ \\
\hline Potência na saída do spliter (antes do conector) & $-8,3 \mathrm{dBm}$ \\
\hline Potência refletida pelo conector & $-28,3 \mathrm{dBm}$ \\
\hline Potência na saída do spliter & $-35,8 \mathrm{dBm}$ \\
\hline Potência na saída fibra & $-36,4 \mathrm{dBm}$ \\
\hline BER da ONU maliciosa & $2,9 \times 10^{-10}$ \\
\hline
\end{tabular}

Tabela 2.3: Orçamento de potência para splitter de 4 portas

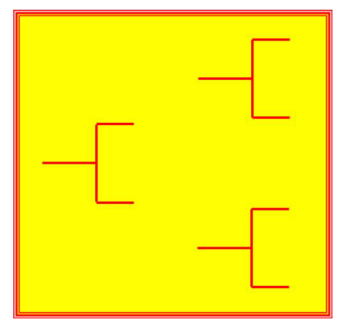

Figura 2.6: Representação de um splitter 1x4 formado por três acopladores

óptico, deve-se imaginá-lo como um conjunto de acopladores. No caso do splitter $1 \mathrm{x} 4$, observe a Figura 2.6, onde o sinal provindo de uma dada porta atravessa dois acopladores. Considerando-se que a perda de um acoplador é $3 \mathrm{~dB}$, já que divide a potência óptica de entrada pela metade em cada uma das portas de saída, a perda gerada pelos dois acopladores é $6 \mathrm{~dB}$. Soma-se a isso a perda de inserção do dispositivo, cujo valor atribuído foi 1,5 dB (valor compatível com dispositivos disponibilizados no mercado [38]). Dessa forma, a perda total sofrida no splitter é $7,5 \mathrm{~dB}$, o que explica a redução de potência do sinal mostrada na Tabela 2.3 .

Ao sair do splitter, a maior fração do sinal atravessa o conector e é transmitida pela fibra até chegar no OLT. Porém, como mencionado, uma porção do sinal é refletida por este conector. Considerando uma perda de retorno de $20 \mathrm{~dB}$ para um dispositivo mal instalado (valor atribuído neste exemplo de orçamento de potência), a potência do sinal que seria refletida seria $-28,3 \mathrm{dBm}$. Novamente, o sinal passa pelo divisor óptico, porém agora no sentido de downstream. A mesma perda de 7,5 dB faz com que o sinal saia em cada uma das quatro portas do splitter com potência de $-35,8 \mathrm{dBm}$. A atenuação em 1,2 Km de fibra 
óptica faz com que o sinal diminua sua potência para $-36,4 \mathrm{dBm}$ e a taxa de erro calculada foi $2,9 \times 10^{-10}$.

Deve-se observar que neste tipo de simulação a perda mais significante é a proporcionado pelo splitter, já que o sinal passa por ele duas vezes. Tendo isso em vista, a análise agora é feita para um cenário com splitter 1x32. A Figura 2.7 mostra a quantidade de acopladores utilizados por este divisor óptico. O sinal provindo de uma porta de entrada passa por cinco acopladores para alcançar a porta de saída, ou seja, a perda devido aos acopladores é de $15 \mathrm{~dB}$. Somada a perda de inserção, o valor total de perda no dispositivo é $16,5 \mathrm{~dB}$.

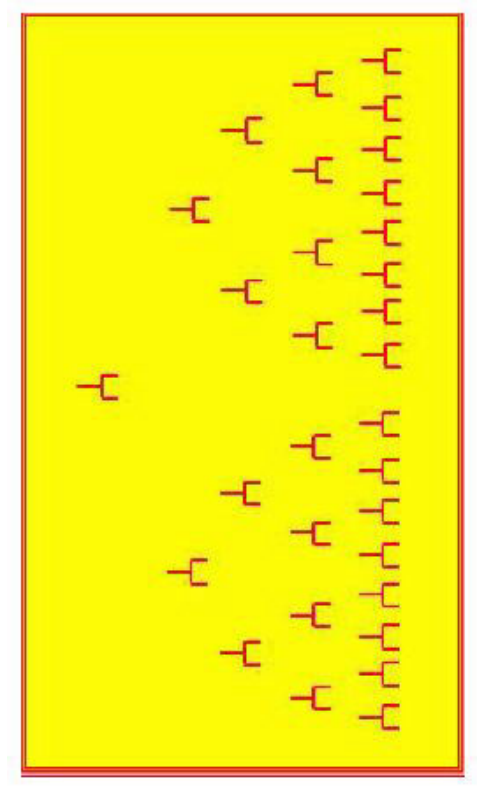

Figura 2.7: Representação de um splitter 1x32 formado por diversos acopladores

A Tabela 2.4 mostra o orçamento de potência para um esquema semelhante ao mostrado na Figura 2.3, porém agora com a utilização de um divisor de 32 portas. A potência que chega na ONU Maliciosa é muito baixa, logo a taxa de erro é $100 \%$.

Como mencionado no início desse Capítulo, um número convencional de ONUs por OLT são 32. Se nas TDM-PONs fossem utilizados somente splitters de 1x32, então, 


\begin{tabular}{|l|c|}
\hline Potência do transmissor da ONU Vítima & $0 \mathrm{dBm}$ \\
\hline Potência na saída da fibra & $-0,78 \mathrm{dBm}$ \\
\hline Potência na saída do spliter (antes do conector) & $-17,3 \mathrm{dBm}$ \\
\hline Potência refletida pelo conector & $-37,3 \mathrm{dBm}$ \\
\hline Potência na saída do spliter & $-53,9 \mathrm{dBm}$ \\
\hline Potência na saída fibra & $-54,5 \mathrm{dBm}$ \\
\hline BER da ONU maliciosa & - \\
\hline
\end{tabular}

Tabela 2.4: Orçamento de potência para splitter de 32 portas

\begin{tabular}{|c|c|c|c|}
\hline $\begin{array}{c}\text { Taxa de } \\
\text { transmissão }\end{array}$ & $\mathbf{1 5 5} \mathbf{M b p s}$ & $\mathbf{6 2 2 M b p s}$ & $\mathbf{1 , 2 5}$ Gbps \\
\hline Potência Máxima & $4 \mathrm{dBm}$ & $4 \mathrm{dBm}$ & $7 \mathrm{dBm}$ \\
\hline BER & $1,2 \times 10^{-3}$ & - & - \\
\hline
\end{tabular}

Tabela 2.5: Orçamento de potência para splitter de 16 portas

como observa-se na Tabela 2.4, não tería-se problemas relativos à reflexão de conectores mal instalados. Porém, em redes TDM-PON já instaladas pode-se encontrar splitters em cascata, ou seja, um divisor óptico ligado a outro na rede. Por exemplo, um splitter de 8 portas conectado a um splitter de 4 portas acomoda 32 ONUs. Deve-se observar que o divisor de interesse é somente aquele ligado a ONU Vítima e a ONU Maliciosa, logo em uma rede em que tem-se um divisor de 8 portas conectado a um divisor de 4 portas, tería-se a situação ilustrada na Figura 2.3.

Por esta razão, foram feitas simulações com splitters de 8 e 16 portas. As Tabelas 2.5 e 2.6 mostram a taxa de erro de bit nestes dois esquemas para as taxas de transmissão de $155 \mathrm{Mbps}, 622 \mathrm{Mbps}$ e 1,25 Gbps. No caso do esquema com divisor óptico de 16 portas, foi utilizada a potência máxima definida pela norma GPON (vide Tabela 2.2) nestas três taxas de transmissão, porém somente com 155 Mbps a ONU Maliciosa pôde detectar o sinal, embora a BER tenha sido bastante elevada $\left(10^{-3}\right)$. Com divisor óptico de 8 portas, a ONU maliciosa já pode detectar o sinal proveniente da ONU Vítima com taxas de erro baixas. 


\begin{tabular}{|c|c|c|c|}
\hline $\begin{array}{c}\text { Taxa de } \\
\text { transmissão }\end{array}$ & $\mathbf{1 5 5}$ Mbps & 622Mbps & $\mathbf{1 , 2 5}$ Gbps \\
\hline Potência & $\begin{array}{c}1 \mathrm{dBm} \\
\max : 4 \mathrm{dBm}\end{array}$ & $4 \mathrm{dBm}$ & $\begin{array}{c}5 \mathrm{dBm} \\
\max : 7 \mathrm{dBm}\end{array}$ \\
\hline BER & $1,1 \times 10^{-9}$ & $1,6 \times 10^{-10}$ & $3,5 \times 10^{-8}$ \\
\hline
\end{tabular}

Tabela 2.6: Orçamento de potência para splitter de 8 portas

\subsection{WDM-PON}

Embora a rede TDM-PON seja uma boa alternativa para prover acesso banda larga ao usuário final, ela tem duas grandes desvantagens: a primeira é relativa a segurança, como mostrado na seção anterior. A outra desvantagem reside no fato da rede não ser escalável devido à perda por divisão de potência nos divisores ópticos, o que limita o número possível de ONUs. Com o objetivo de superar estas dificuldades pode-se, por outro lado, usar multiplexação por divisão de comprimento de onda, aumentando a largura de banda de uma PON e melhorando o orçamento de potência. Estas redes recebem o nome de redes WDM-PONs.

Podem-se identificar na literatura atual três vertentes principais para os sistemas WDM-PON.

- A primeira delas consiste no uso de múltiplos comprimentos de onda, todos localizados dentro da banda-passante dos divisores de potência de uma TDM-PON [39]-[41]. Essa é a alternativa mais imediata para migração de uma rede óptica passiva TDM para uma rede óptica passiva WDM, e um de seus principais centros de estudo é a Universidade de Stanford. Porém, o uso de receptores e/ou transmissores ópticos sintonizáveis impõe dificuldades tanto no ponto de vista tecnológico quanto financeiro. O estudo desta alternativa constitui num tópico de interesse e remete a possíveis futuras investigações.

- A segunda vertente emprega o conceito de WDM-PON para sistemas de ultra-longa distância e é denominada SuperPON. Embora não seja o foco deste trabalho, no próximo capítulo, seção 3.3, será apresentada uma breve discussão sobre essa alternativa. 
- A terceira vertente está mostrada esquematicamente na Figura 2.8. Este conceito de rede WDM-PON, certamente, é o que se impõe na literatura e que se constitui no foco do trabalho [42]-[44]. A topologia lógica é a ponto-a-ponto, diferentemente da PON convencional, e o sistema reúne múltiplos comprimentos de onda tanto no sentido downstream como no upstream. Neste esquema, diferentes ONUs podem operar em diferentes taxas de bits. Logo, uma variedade de serviços pode ser oferecida em uma mesma rede. O elemento principal de uma rede WDM-PON é o Arrayed Waveguide Grating (AWG), que faz o roteamento do sinal óptico de uma porta de entrada para uma dada saída, baseado no comprimento de onda do sinal [21].

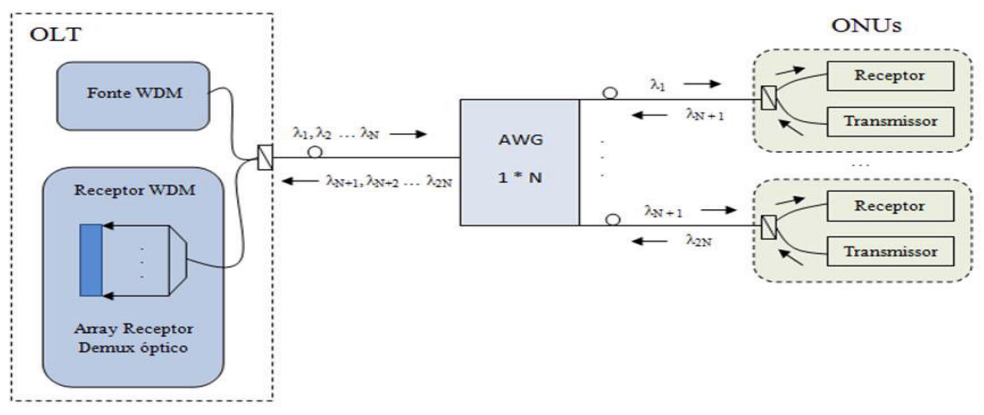

Figura 2.8: Esquema idealizado de uma WDM-PON [45]

Como mostrado na Figura 2.8, uma fonte de múltiplos comprimentos de onda na OLT é usada para transmitir os comprimentos de onda que serão roteados para as diversas ONUs no sentido downstream. Por outro lado, no sentido upstream, a OLT é equipada com um demultiplexador WDM para receber os comprimentos de onda das ONUs. As transmissões downstream e upstream ocorrem nas janelas de $1500 \mathrm{~nm}$ e $1300 \mathrm{~nm}$, respectivamente. Em cada janela, a separação dos comprimentos de onda é por WDM denso, sendo um espaçamento típico entre os comprimentos de onda da ordem de $100 \mathrm{GHz}$.

A rede WDM-PON é a mais promissora solução para o gargalo das redes de telecomunicações [46]-[47]. Porém, antes da implementação de uma rede WDM-PON, é necessário 
que existam estágios intermediários. O preço de uma rede ponto a ponto é muito elevado, e o cenário mundial atual ainda não exige toda a banda fornecida por estas redes, o que acaba inibindo o interesse dos usuários e sua disseminação comercial. O primeiro passo, então, é a diminuição de custos. Com este pensamento, foram propostas algumas arquiteturas de redes WDM-PON que provêem uma elevada largura de banda e ainda possibilitam que, no futuro, com o surgimento de novos serviços, as redes sejam adaptadas para o formato ponto a ponto.

Conforme será descrito em detalhe no próximo capítulo, as arquiteturas WDMPON propostas na literatura, em sua maioria, utilizam uma mesma lógica para o tráfego no sentido downstream: cada ONU recebe um canal de comprimento de onda. Quanto ao upstream, deve-se levar em consideração que o preço dos equipamentos para as ONUs deve ser relativamente baixo. De forma complementar, a utilização dos mesmos equipamentos em todas as ONUs evita dificuldades de gerenciamento e manutenção. Arquiteturas mais recentes têm se preocupado também com a questão da compatibilidade com os sistemas já em uso.

\subsubsection{Por que utilizar WDM-PON ?}

O desenvolvimento do ADSL proporcionou um rápido aumento no número de usuários de redes de banda larga, sendo o principal atrativo inicial ao acesso à Internet. À medida que o número de usuários da rede e a largura de banda aumentam, o conteúdo das páginas web vem deixando de ser baseado em texto e passando a ser baseado em conteúdo multimídia. O estereótipo padrão do usuário de Internet vem também mudando, deixando de apenas navegar na rede e passando a usá-la principalmente para download e compartilhamento deste conteúdo multimídia [48].

O aumento no tráfego de dados acontece em grande escala. Estima-se que essa taxa de crescimento é algo em torno de 100\% por ano desde a década de 90 [49]. Pesquisas de mercado mostram que após o upgrade para uma conexão de banda larga, de $56 \mathrm{Kbps}$ do modem convencional para $1 \mathrm{Mbps}$, por exemplo, o usuário passa 35\% a mais de tempo on line do que antes [50]. A Telcordia previu que, em 2010, 50\% da receita das grandes companhias telefônicas será baseado em serviços de vídeo [51]. 
Como já mencionado, existe uma tendência para o estabelecimento de um serviço triple-play. Há pouco tempo atrás, voz, vídeo e dados eram distribuídos aos usuários em redes separadas, a saber:

- redes telefônicas públicas comutadas (PSTN),

- redes de televisão a cabo (CATV)

- e DSL, principalmente.

No Brasil, empresas como a NET já disponibilizam estes serviços em uma única rede, porém a taxa máxima oferecida é 12 Mbps a um custo de quase $\mathrm{R} \$ 400,00$ mensais [52]. Percebe-se, então, que o principal objetivo da implantação do serviço triple-play, ou seja, a diminuição de custos, ainda não foi alcançada.

Paralelamente a isso, aplicações emergentes, tais como Video on Demand (VoD), HDTV, cinema digital, educação sob demanda (EoD), esquemas de vigilância on line, games on line interativos e transmissão de áudio com alta qualidade, requerem uma alta largura de banda tanto no downstream quanto no upstream. Outros serviços que devem ser atendidos pela próxima geração de redes de acesso estão descritos em [53].

Alguns estudos citam que sejam necessários mais de 75 Mbps para disponibilização de todos esses requisitos aos usuários (vide Tabela 2.7), outros apontam para valores de 100 Mbps bidirecionais [47],[54]. Taxas desta magnitude não podem ser alcançadas pelas tecnologias de acesso xDSL e CATV.

A fibra óptica apresenta-se como a alternativa para as redes de acesso. Embora as TDM-PONs proporcionem um custo menor na instalação e manutenção, elas não exploram completamente a vasta largura de banda oferecida pelas fibras, algo que seria alcançado somente com a tecnologia WDM. Por exemplo, enquanto uma TDM-PON poderia oferecer 2,5 Gbps através de um canal óptico para 32 usuários, uma WDM-PON poderia oferecer 2,5 Gbps para cada cliente através de 32 comprimentos de onda. Adicionalmente, o divisor óptico passivo eleva significativamente a perda efetiva na rede, ao contrário do AWG que insere sua perda de inserção (em torno de $3,5 \mathrm{~dB}$ a $5 \mathrm{~dB}[55],[56]$ ), não ocorrendo divisão de potência. 


\begin{tabular}{|c|c|}
\hline Serviços & $\begin{array}{c}\text { Largura de banda } \\
\text { (Mbps) }\end{array}$ \\
\hline Três canais de HDTV & 60 \\
\hline Internet & 10 \\
\hline Vídeo Conferência (telefone) & 2 \\
\hline Telemetria / controle remoto & 1 \\
\hline Total & $>75$ \\
\hline
\end{tabular}

Tabela 2.7: Largura de banda necessária para alguns serviços [48]

\begin{tabular}{|c|c|c|c|c|}
\hline & & TDM-PON & & WDM-PON \\
\hline & EPON & BPON & GPON & \\
\hline Padrão & IEEE 802.3ah & ITU G.983 & ITU G.984 & Nenhum \\
\hline Protocolo & Ethernet & ATM & GEM/ATM & Não necessário \\
\hline $\begin{array}{c}\text { Largura de } \\
\text { banda máxima }\end{array}$ & $1 \mathrm{Gbps}$ & $622 \mathrm{Mbps}$ & 2.488 Gbps & $\begin{array}{c}\text { Ilimitada } \\
\text { (restrições físicas } \\
\text { do equipamento) }\end{array}$ \\
\hline Usuários/PON & 16 & 32 & 64 & $\begin{array}{l}\text { Limitado pelo } \\
\text { número de } \\
\text { portas do AWG }\end{array}$ \\
\hline $\begin{array}{l}\text { Largura de } \\
\text { banda média } \\
\text { por usuário }\end{array}$ & $60 \mathrm{Mbps}$ & 20Mbps & 40Mbps & $\begin{array}{c}\text { Ilimitada } \\
\text { (restrições físicas } \\
\text { do equipamento) }\end{array}$ \\
\hline Vídeo & $\mathrm{RF} / \mathrm{IP}$ & $\mathrm{RF}$ & $\mathrm{RF} / \mathrm{IP}$ & $\mathrm{RF} / \mathrm{IP}$ \\
\hline Custo relativo & Muito baixo & Baixo & Médio & Alto \\
\hline $\begin{array}{l}\text { Capacidade } \\
\text { de upgrade }\end{array}$ & Difícil & Difícil & Difícil & Fácil \\
\hline
\end{tabular}

Tabela 2.8: Principais características das tecnologias PON $[57,58]$

Para efeito de comparação, a Tabela 2.8 resume algumas das principais características das redes TDM-PON e WDM-PON [57],[58].

Arquiteturas híbridas TDM/WDM PON logo serão necessários para suprir a demanda exigida por um número cada vez maior de usuários e, no passo seguinte, a WDMPON será a tendência natural para as redes de acesso. O grande empecilho atualmente para implantação dessas redes é o elevado custo de seus equipamentos. Porém, esquemas 
viáveis vêm sendo propostos na literatura, como será discutido no Capítulo 4.

\subsection{GPON x WDM-PON}

No decorrer da presente seção, o software OptiSystem 8.0 será empregado para uma análise comparativa entre redes TDM-PON e uma versão idealizada da rede WDMPON. Versões mais realistas das redes WDM-PON serão discutidas nos próximos capítulos.

\subsubsection{Rede WDM-PON}

A rede WDM-PON investigada nesta seção está representada esquematicamente na Figura 2.8. Nela pode-se observar que, no OLT estão presentes uma fonte WDM e um receptor WDM.

Para um melhor entendimento,

1. A fonte WDM pode ser representada por um array de 32 lasers DFB ("Distributed Feedback Laser") com modulação NRZ ("Non Return to Zero"), onde são considerados:

- Comprimento de onda central de 1550 nm e espaçamento de $100 \mathrm{GHz}$.

- Taxas simétricas para downstream e upstream de 1,25 Gbps, 2,5 Gbps e 10 Gbps, e

- Taxas de $2^{7}$ bits para o gerador de sequência de bit pseudo-randômico (PRBS).

2. O receptor WDM é composto por um demultiplexador capaz de separar cada um dos 32 comprimentos de onda utilizados no upstream e encaminhá-los para seus respectivos fotodetectores PIN, cuja responsividade é da ordem de 1 A/W. A Figura 2.9 mostra, à esquerda, o espectro obtido na saída de um único laser, e à direita, o espectro na saída do multiplexador.

Alguns outros parâmetros de importância para a simulação são discutidos a seguir.

- A distância entre o OLT e o AWG é de $20 \mathrm{Km}$.

- Os valores considerados de atenuação e dispersão na fibra bidirecional para 


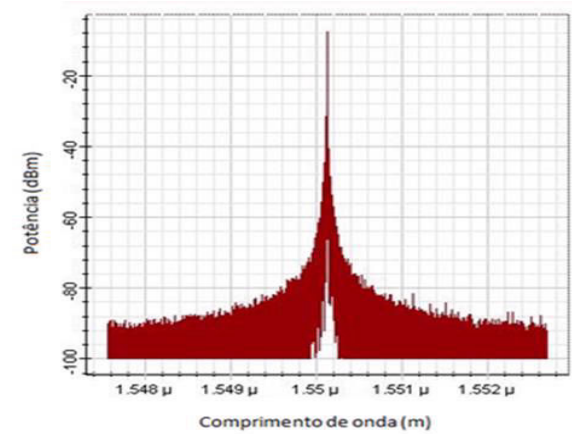

(a)

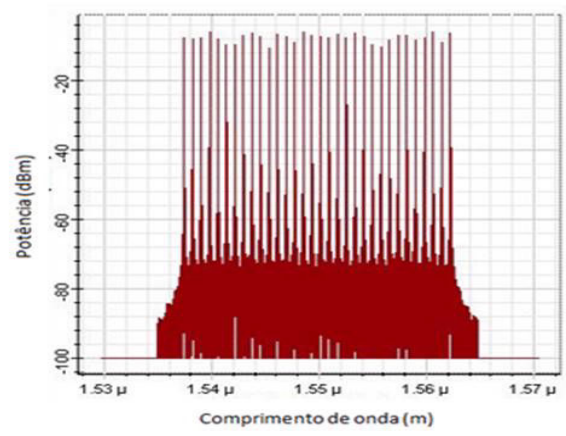

(b)

Figura 2.9: Espectro de saída (a) de um laser, (b) do multiplexador do OLT

- o comprimento de onda de $1550 \mathrm{~nm}$ são de 0,2 dB/Km e 16,75 ps/(nm.km), respectivamente, e para

- o comprimento de onda de $1310 \mathrm{~nm}$, utilizada para o upstream, são de 0,5 dB/Km e $0 \mathrm{ps} /(\mathrm{nm} . \mathrm{km})$, respectivamente.

Para tornar os cálculos mais realistas, a simulação incluiu os efeitos não lineares, dos quais destacamos:

- Modulação de Fase Cruzada (XPM),

- Automodulação de Fase (SPM),

- Espalhamento Raman (SRS),

- espalhamento Brillouin (SBS) e

- Mistura de Quatro Ondas (FWM).

No entanto, observou-se que a influência desses efeitos nas simulações não foi detectada. 
Um outro ponto que merece destaque é a utilização do recurso que simula, no programa OptiSystem 8.0, o uso do AWG na rede. De fato, na rede real, o AWG localizado no nó remoto $(\mathrm{RN})$ apresenta 1x32 portas, entretanto o OptiSystem 8.0 não disponibiliza um AWG 1x32 portas, fornecendo apenas um de 32x32 portas. Sendo assim, para a utilização dos recursos disponíveis no software de simulação, deve-se selecionar corretamente a porta de entrada do dispositivo, considerando-se o sentido upstream, no qual determinado comprimento de onda deve entrar. Fazendo-se, portanto, a combinação correta da porta de entrada com o comprimento de onda, é possível que todos os canais ópticos saiam em uma mesma porta. Dessa forma, as outras N-1 portas não são utilizadas e o dispositivo comporta-se como sendo um AWG 1xN, não acarretando em restrições na sua utilização.

Relativo ao AWG, cabe comentar os seguintes parâmetros:

- Largura de banda por canal de $70 \mathrm{GHz}$,

- Perda de inserção de 3,5 dB,

- Perda de retorno de $-65 \mathrm{~dB}$ e

- Filtro retangular (todos esses valores compatíveis com AWGs disponíveis no mercado $[55]-[56])$.

Especificamente, cada porta de saída do AWG na direção de downstream apresenta um comprimento de onda diferente que será encaminhado para a respectiva ONU. Além disso, cada ONU está equipada com um fotodetector PIN para receber o sinal de downstream, e um laser DFB é colocado em cada cliente. Os 32 comprimentos de onda de upstream atuam na janela de $1310 \mathrm{~nm}$ e são espaçados em $100 \mathrm{GHz}$. Eles são multiplexados no AWG e percorrem a fibra até chegar ao OLT. Vale ressaltar que a periodicidade do AWG permite que seja utilizado por diferentes janelas espectrais.

A Figura 2.10 mostra o diagrama de olho obtido pelo programa Optisystem 8.0 para o sinal de downstream da ONU 1, considerando a potência de $-13 \mathrm{dBm}$ do laser no OLT a uma taxa de 1,25 Gbps.

Como pode ser observado analisando-se a Figura 2.10, o diagrama de olho apresenta aspecto relativamente satisfatório e, de acordo com o software, corresponde a taxa de 


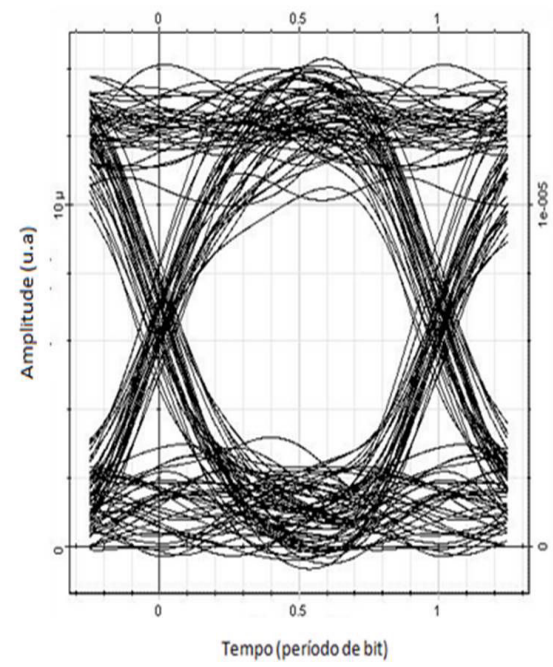

Figura 2.10: Diagrama de olho para ONU 1

erro de bit (BER) de $10^{-12}$, valor típico recomendado atualmente para transmissão livre de erro.

A Figura 2.11 mostra o gráfico da varredura de potências transmitidas em $20 \mathrm{Km}$ de fibra, utilizando-se para tanto o canal que apresenta o pior desempenho, ou seja, a maior taxa de erro de bit entre todos os 32 canais no sentido downstream. Como esperado, uma menor taxa de erros de bit requer uma maior potência. Sendo assim, para prover uma BER de $10^{-12}$, tem-se que, para uma taxa de:

- 1,25 Gbps, requer uma potência de $-13,5 \mathrm{dBm}$,

- 2,5 Gbps, requer uma potência de $-12,0 \mathrm{dBm}$, e

- $10 \mathrm{Gbps}$, requer uma potência de - 9,2 dBm.

De um ponto de vista mais específico, de modo a validar as simulações realizadas, foi efetuado o cálculo do orçamento de potência para o comprimento de onda de 1537,4 $\mathrm{nm}$ com taxa de 2,5 Gbps no sentido downstream. De fato, como pode ser observado na Tabela 2.9, após $20 \mathrm{~km}$ de fibra a potência é reduzida em $4,3 \mathrm{~dB}$, o qual pode ser considerado um resultado consistente levando-se em conta a atenuação sofrida por este comprimento de 


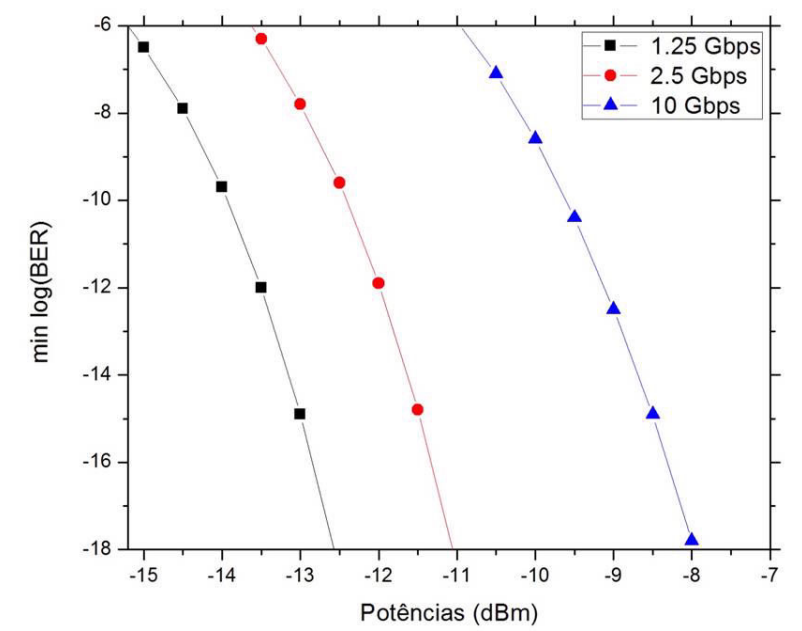

Figura 2.11: Varredura de potências para 1,25 Gbps, 2,5 Gbps e 10 Gbps

\begin{tabular}{|c|c|c|c|c|}
\hline$\lambda$ & $\begin{array}{c}\text { Potência no } \\
\text { transmissor } \\
(\mathrm{OLT})\end{array}$ & $\begin{array}{c}\text { Potência na } \\
\text { saída da } \\
\text { fibra }(20 \mathrm{~km})\end{array}$ & $\begin{array}{c}\text { Potência na } \\
\text { saída do } \\
\text { AWG }\end{array}$ & $\begin{array}{c}\text { Taxa de } \\
\text { erro de } \\
\text { bit (ONU) }\end{array}$ \\
\hline $1537,4 \mathrm{~nm}$ & $-12,5 \mathrm{dBm}$ & $-16,8 \mathrm{dBm}$ & $-20,3 \mathrm{dBm}$ & $1,2 x 10^{-10}$ \\
\hline
\end{tabular}

Tabela 2.9: Orçamento de potência

onda. A perda de inserção do AWG é de $3,5 \mathrm{~dB}$, dessa forma a potência foi reduzida de -16,8 dBm para -20,3 dBm na saída do dispositivo. Finalmente, através de medições back-to-back para verificar a sensibilidade do receptor, observou-se que para uma potência de $-20,3 \mathrm{dBm}$ a BER encontrada foi $1,7 \times 10^{-10}$, resultado compatível com o apresentado na Tabela 2.9.

A Figura 2.12 mostra o comportamento de cada um dos 32 comprimentos de onda utilizados, com uma taxa de 2,5 Gbps em $20 \mathrm{Km}$, para as mesmas potências do resultado anterior.

O padrão ITU-T G.984 define algumas classes de redes PON de acordo com a perda na fibra, potência enviada, sensibilidade do receptor e BER estipulada. Para a Classe A, a perda total na rede de distribuição está na faixa de 5,0 a 20,0 dB. Dessa forma, a rede WDM-PON simulada em $20 \mathrm{Km}$ pode se enquadrar nesta classe. A potência mínima de um transmissor no OLT a uma taxa de 1,25 Gbps definida para esta classe é -4 dBm. Para 


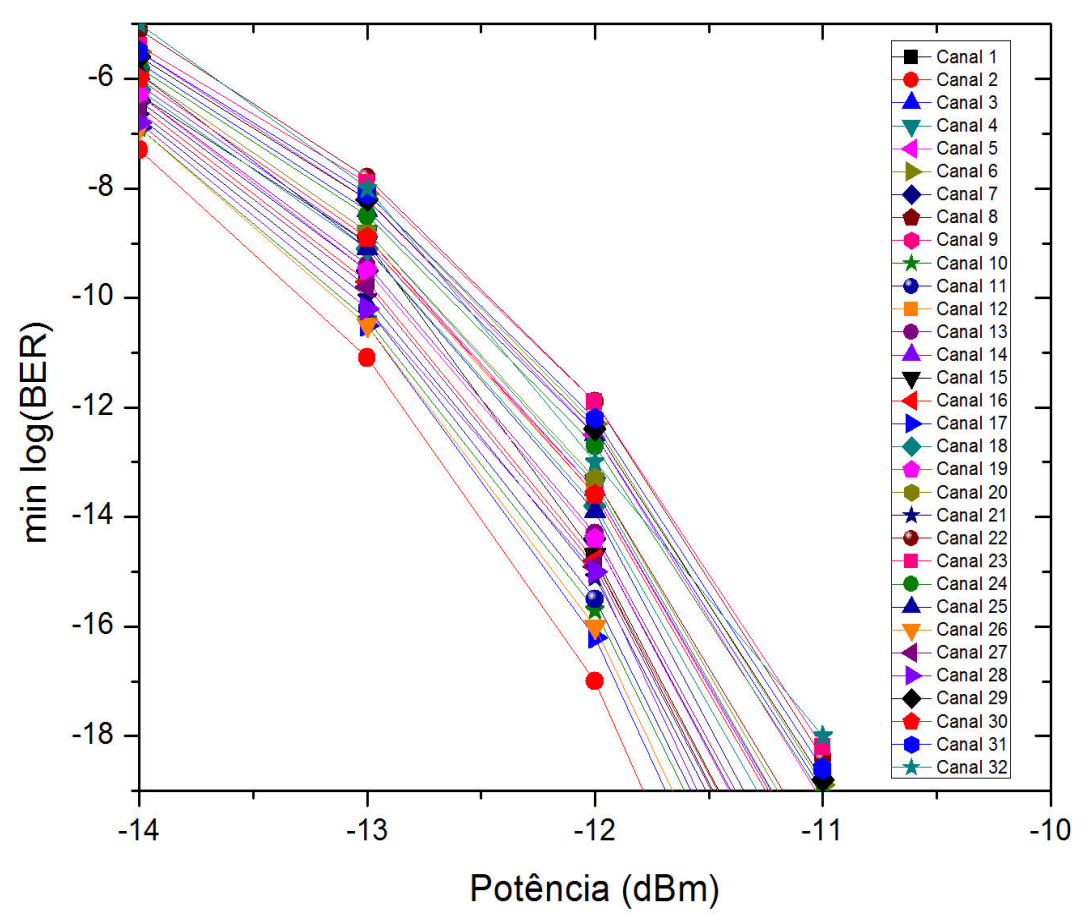

Figura 2.12: BER dos 32 canais a 2,5Gbps em 20Km

avaliar o alcance da rede WDM-PON, fez-se uma varredura de distâncias com os lasers do array no OLT operando a -4,0 dBm. Os resultados estão mostrados na Figura 2.13, na qual o canal com pior desempenho é mostrado.

De acordo com a Figura 2.13, considerando-se o valor de BER máximo $10^{-12}$ e taxa de 2,5 Gbps, por exemplo, pode-se alcançar uma distância de aproximadamente $58 \mathrm{Km}$. Os gráficos foram feitos considerando-se o sentido downstream, sendo importante ressaltar que para o upstream, banda de $1300 \mathrm{~nm}$, deve-se levar em consideração que o valor da atenuação é maior, logo o alcance é menor. Adicionalmente, vale à pena observar que a inserção de efeitos não-lineares nos sistemas investigados não influenciaram o comportamento dos canais. 


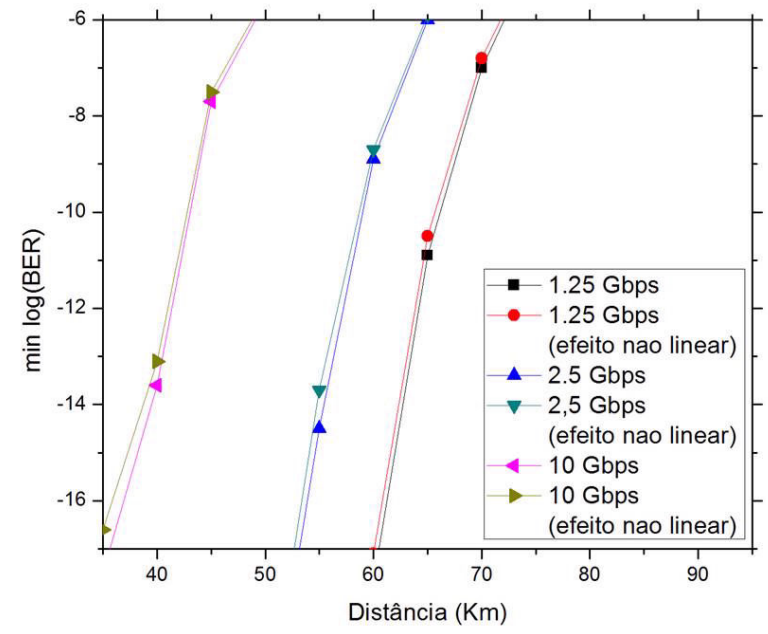

Figura 2.13: Varredura de distâncias com potência de $-4,0 \mathrm{dBm}$

\subsubsection{GPON}

A estrutura da rede GPON analisada nesta seção, e simulada a partir do software Optsystem 8.0, assemelha-se à rede WDM-PON descrita na seção anterior, na qual um OLT é conectado a 32 ONUs, porém, agora através de um divisor óptico passivo, em lugar do AWG.

A seguir, são descritos os parâmetros de interesse para a simulação completa da rede:

- No OLT é utilizado um laser DFB com comprimento de onda de $1490 \mathrm{~nm}$, modulação NRZ e gerador PRBS com $2^{8}$ bits.

- Na ONU, para o upstream, é usado um laser semelhante operando em $1310 \mathrm{~nm}$.

- A fibra óptica é a mesma da simulação anterior.

- Foram utilizadas as taxas de transmissão de:

$-1,25$ Gbps,

$-2,5$ Gbps e 
-10 Gbps.

Como já discutido no Capítulo 2, redes TDM-PON compartilham a largura de banda no tempo, de modo que, enviando-se 1,25 Gbps para 32 ONUs, tem-se como taxa individual 40 Mbps.

O splitter localizado no RN possui perda de inserção de $1,5 \mathrm{~dB}$, valor compatível com dispositivos disponibilizados no mercado [38]. Esse dispositivo divide a potência no sentido downstream, fazendo com que o requerimento da potência enviada pelo OLT seja bem maior do que na WDM-PON, como pode ser observado na Figura 2.14. Para obter-se uma taxa de erro de $10^{-12}$ a 1,25 Gbps na GPON a potência enviada no transmissor do OLT necessita ser cerca de $-1,0 \mathrm{dBm}$, enquanto que na rede WDM-PON essa potência seria aproximadamente de $-13,5 \mathrm{dBm}$.

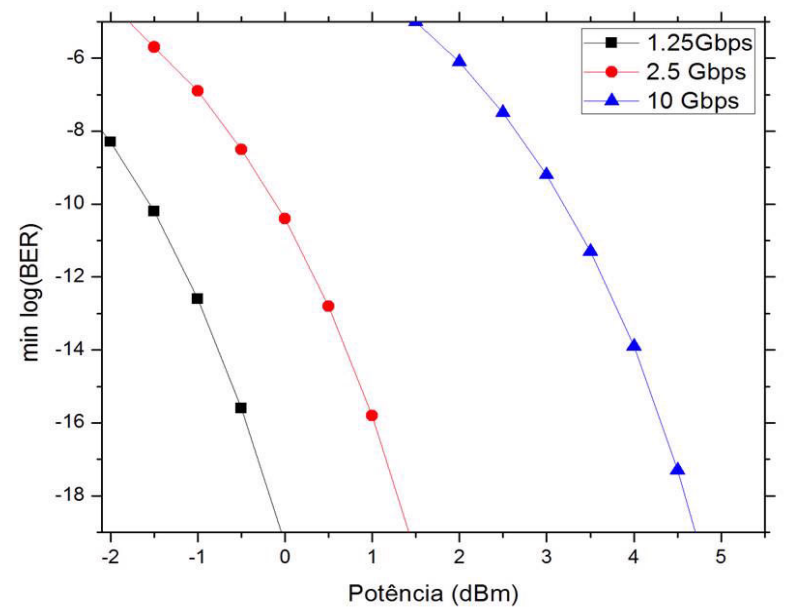

Figura 2.14: Varredura de potências para GPON em 20Km

A Figura 2.15 ilustra como é tratada a questão do compartilhamento de tempo no sentido upstream, onde cada um dos 32 canais recebe uma janela temporal, como mostrado no Visualizador Óptico no Domínio do Tempo (OTDV), e o splitter, atuando como um combinador de potência, é o responsável por juntar toda a informação e enviá-la ao OLT.

A Figura 2.16 mostra o espectro de saída do divisor no sentido upstream. 


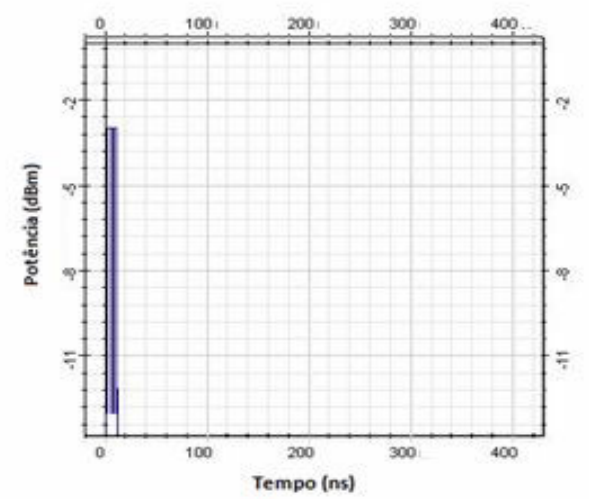

(a)

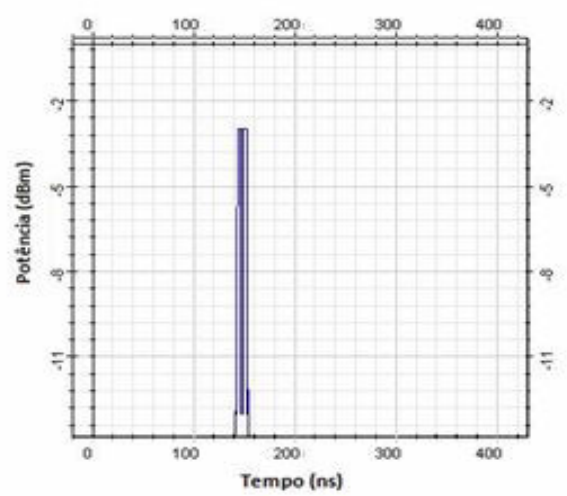

(b)

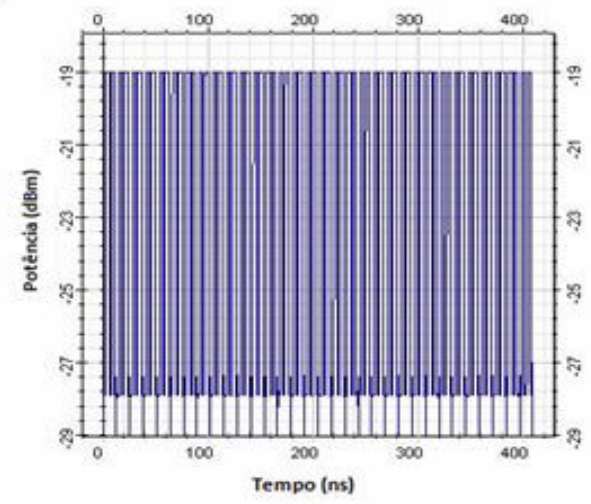

(c)

Figura 2.15: OTDV na saída (a) da ONU 1, (b) da ONU 12 e (c) do splitter.

Percebe-se que existe uma potência residual no comprimento de onda $1490 \mathrm{~nm}$, utilizado no downstream, devido à perda de retorno do dispositivo, no caso, $65 \mathrm{~dB}$. Implicações a respeito dessa perda de retorno foram discutidas anteriormente.

Comparando-se o esquema WDM-PON apresentado na seção 2.4.1 com o esquema GPON mostrado nesta seção pode-se concluir que para uma mesma taxa de transmissão, a potência a ser transmitida pelo laser de uma TDM-PON deve ser bem maior que a transmitida pelo laser da WDM-PON. Como já mencionado, essa diferença é ocasionada principalmente pelo dispositivo utilizado no nó remoto (divisor óptico passivo ou AWG). De forma complementar, as taxas efetivas de cada ONU em um esquema TDM-PON são relativamente menores do que as taxas que podem ser alcançadas pelas ONUs em sistemas 


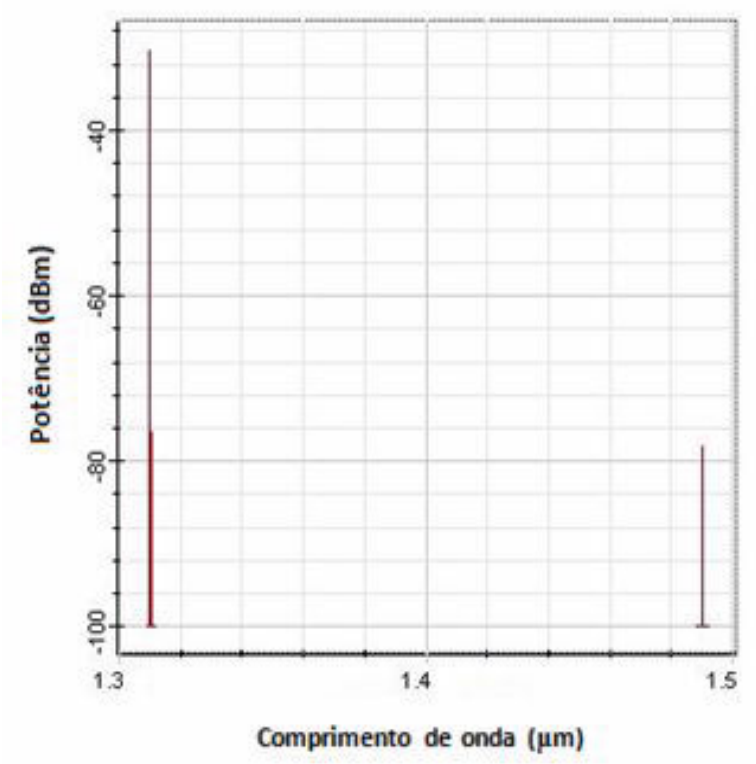

Figura 2.16: Espectro de saída do splitter no sentido upstream

WDM-PON.

\subsection{MigraçãoTDM-PON para WDM-PON}

Um esquema de migração de TDM-PONs para a WDM-PON de interesse para este trabalho foi proposto por Choi et al [59]. Na rede já instalada, mostrada na Figura 2.17, o divisor conecta 8 ONUs. As faixas de comprimento de onda utilizadas no downstream e no upstream são 1480 - 1500 nm e 1260 - 1360 nm, respectivamente. Dessa forma, para o upgrade, devem-se utilizar bandas diferentes. A TDM-PON em questão pode ser BPON, EPON ou GPON.

Para realização desse esquema de migração sem mudar substancialmente a estrutura da rede já instalada foi empregado um dispositivo de três portas que combina/divide banda de comprimento de onda, representado no artigo citado e aqui no trabalho pela sigla WC. No esquema de migração, ele está presente no OLT e no $\mathrm{RN}\left(\mathrm{WC}_{1}\right.$ e $\left.\mathrm{WC}_{2}\right)$, como mostra a Figura 2.18. A perda inserida para cada WC foi de 1 dB. A banda C $(1540,94$ 


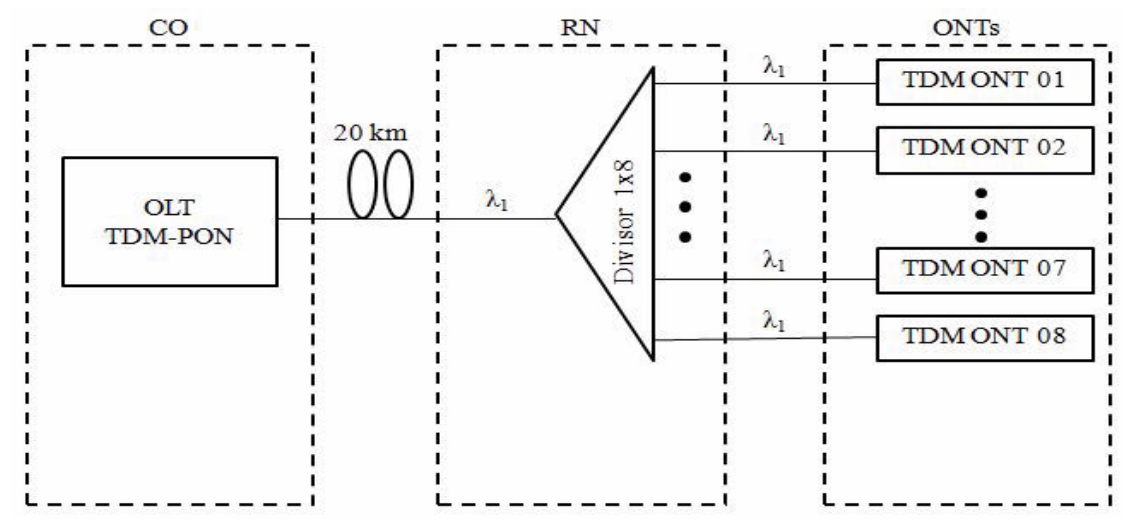

Figura 2.17: Rede TDM-PON já instalada com OLT conectado a 8 ONUs

$\mathrm{nm}$ - 1546,89 nm) e a banda L (1589,76 nm - 1595,89 nm) foram utilizadas para prover os comprimentos de onda de upstream e downstream, respectivamente.

Para o upgrade, inseriu-se no OLT uma fonte óptica gerando 16 novos comprimentos de onda, que através do $\mathrm{WC}_{1}$ integram-se ao $\lambda_{1}$ e são lançados na fibra. No $\mathrm{RN}$, o $\mathrm{WC}_{2}$ separa os novos comprimentos de onda e os envia para a porta de entrada do AWG, enquanto o $\lambda_{1}$ continua conectando-se ao divisor óptico passivo. Dessa forma, ter-se-ia um aumento do número de usuários aproveitando-se o máximo possível da estrutura já instalada.

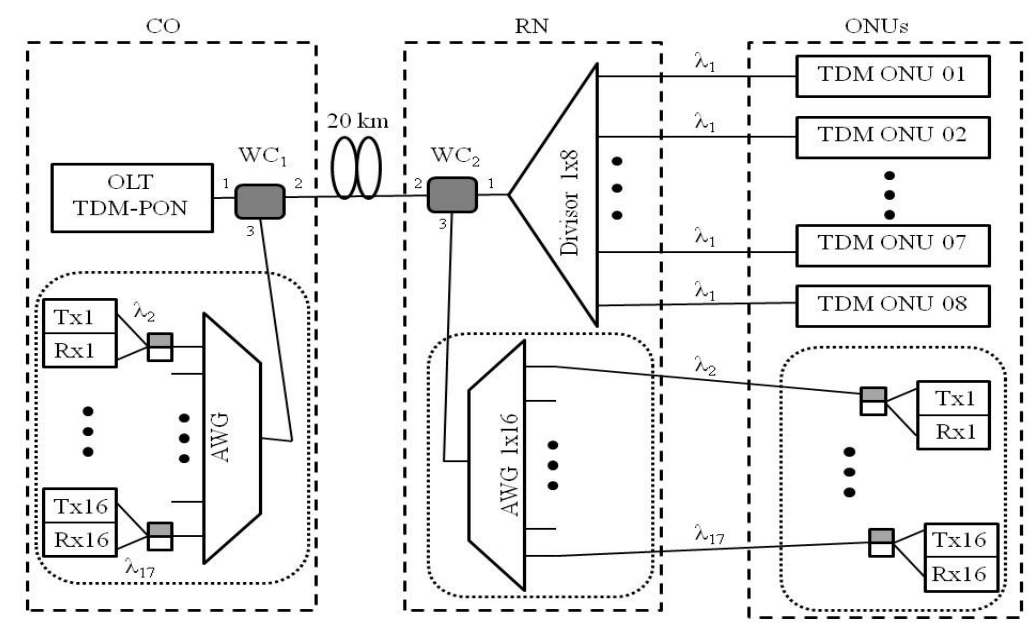

Figura 2.18: Esquema de migração de TDM-PON para WDM-PON 
Quando um usuário antigo desejar receber os serviços de próxima geração (que precisam de um $\lambda$ dedicado), sua conexão correspondente na fibra de distribuição pode ser trocada do divisor para o AWG, como se pode observar na Figura 2.19 na ONU antiga que recebe o $\lambda_{8}$.

Caso o usuário deseje usufruir dos serviços correntes (até então providos pelo divisor) e também os serviços de nova geração, será então necessário acrescentar-se mais 2 WCs, um no RN e outro na própria ONU, como se pode observar na segunda ONU antiga, que recebe o $\lambda_{1}$ e $\lambda_{2}$.

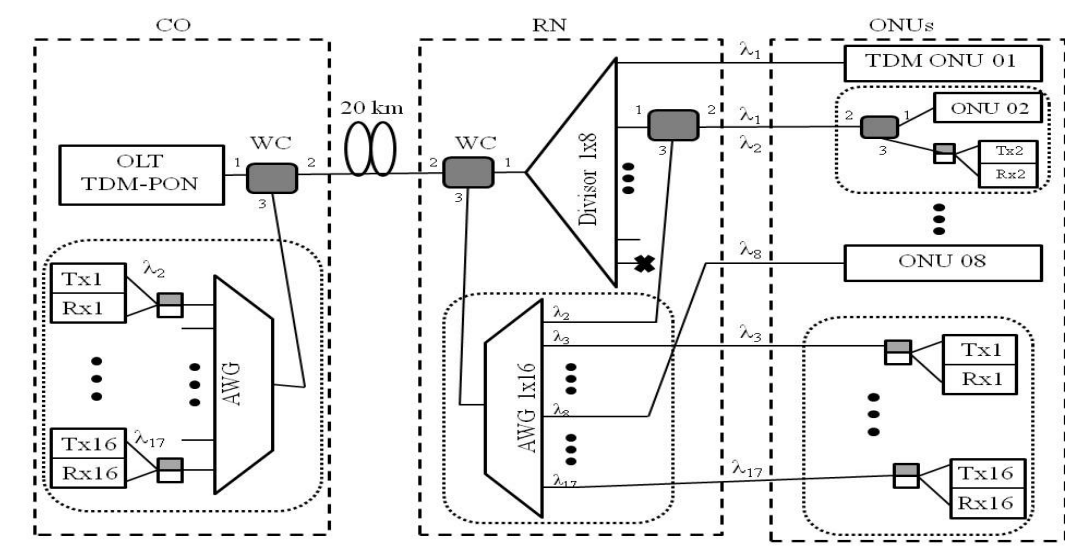

Figura 2.19: Esquema de migração de TDM-PON para WDM-PON com duas propostas de upgrade para ONUs antigas

Alternativamente, outra forma de upgrade pode ser implementada para as ONUs já instaladas utilizando-se um esquema semelhante. Um dos comprimentos de onda novos gerado pela fonte óptica inserida no OLT passará a pertencer a mesma banda do comprimento de onda gerado pelo OLT TDM-PON (no caso, o $\lambda_{2}$ ). Como pode ser observado na Figura 2.20, dois comprimentos de onda vão passar pelo $\mathrm{WC}_{2}$ em direção ao splitter: o $\lambda_{1}$, que já era utilizado anteriormente para prover os serviços legados, e o $\lambda_{2}$. Os demais comprimentos de onda gerados vão seguir do $\mathrm{WC}_{2}$ para o $\mathrm{AWG}$, sendo utilizados pelas ONUs novas. Dessa forma, este esquema de upgrade além de adicionar novos usuários com canais ópticos dedicados, duplica a largura de banda dos clientes antigos. 


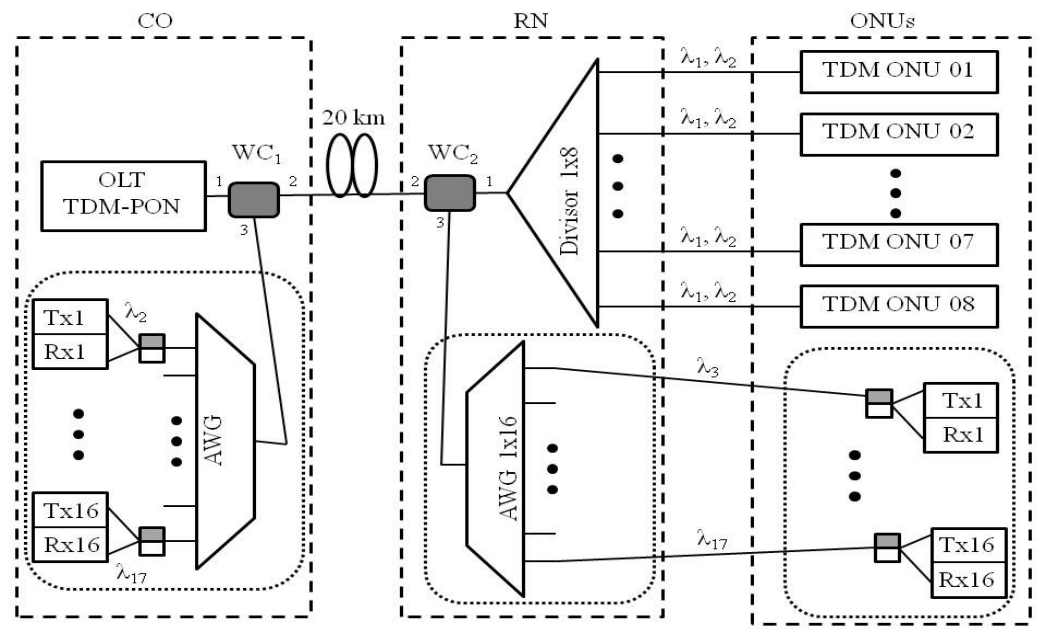

Figura 2.20: Alternativa de upgrade com esquema duplicando largura de banda das ONUs legadas 


\section{Capítulo 3}

\section{WDM-PON: componentes e topologias}

Como discutido no capítulo anterior, a literatura tem buscado propor e aperfeiçoar arquiteturas que tornem os sistemas WDM-PON mais viáveis economicamente. Dessa forma, após análise de uma rede WDM-PON ideal, efetuada no capitulo anterior, este capítulo descreve as principais arquiteturas, mostrando as propostas originais e suas variações recentes. Porém, antes de descrever as arquiteturas existentes, serão discutidos na Seção 3.1 alguns aspectos relativos aos seus principais componentes: o AWG e a fonte óptica multi-comprimento de onda. Por fim, na Seção 3.3 será abordado brevemente uma descrição de uma outra vertente WDM-PON: a SuperPON.

\subsection{Principais componentes da rede WDM}

\subsubsection{Array Waveguide Grating (AWG)}

O Array Waveguide Grating (AWG) é um dispositivo que exerce a função de roteador passivo de comprimento de onda e assume um papel essencial nas redes WDMPON. O AWG é um dispositivo passivo que provê o roteamento fixo de um sinal óptico a partir de uma dada porta de entrada para uma determinada porta de saída, baseado no comprimento de onda do sinal. Múltiplos comprimentos de onda de uma entrada podem ser 
separados em diferentes portas de saída pelo AWG, podendo ainda combinar vários canais de diferentes entradas em uma mesma saída. Uma grande vantagem do dispositivo é que ele pode ser utilizado nas duas direções simultaneamente, exercendo os papéis de multiplexador e demultiplexador, como mostra a Figura 3.1. Nesta figura, da esquerda para a direita, os canais do set WDM na porta de entrada são separados nas portas de saída, ocorrendo o inverso no sentido oposto. Isso mostra uma importante propriedade do AWG: a dependência da resposta óptica com o comprimento de onda.

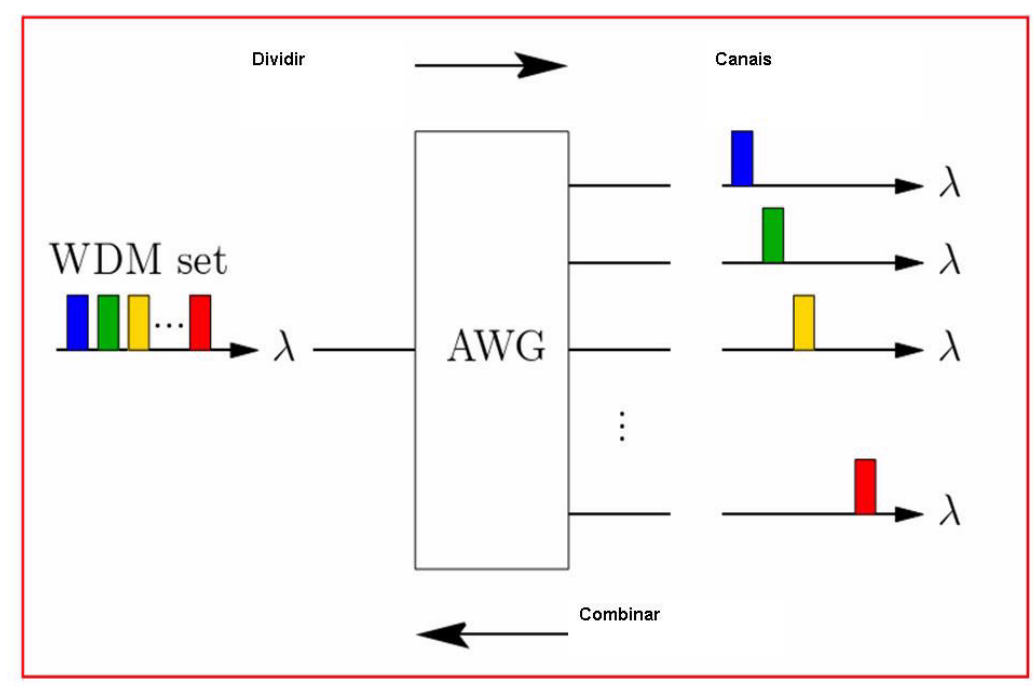

Figura 3.1: Característica bidirecional do AWG [60].

O AWG é construído a partir de uma tecnologia de guia de onda planar (Planar Lightwave Circuit-PLC) e possui perda de inserção entre 3.5 e 5 dB [55],[56]. Ele possui uma estrutura muito complexa, tipicamente muitos centímetros quadrados de área, compreendendo múltiplos guias de onda. Suas dimensões básicas são determinadas principalmente pelos seguintes parâmetros [61]:

- espaçamento do guia de onda receptor,

- comprimento da região de propagação livre (Free Propagation Region - FPR),

- incremento do comprimento do vetor de guia de onda (Arrayed Waveguide - AW), 
- largura da abertura do AW

- e região espectral livre (Free Spectral Range - FSR).

No projeto de um AWG, além de tais características, outras questões importantes devem ser levadas em conta, tais como: diafonia (crosstalk), perda de inserção e perda dependente de polarização, discutidas em [62].

Uma segunda propriedade muito importante do AWG é o seu comportamento periódico, mostrado na Figura 3.2. Dois sinais ópticos consecutivos que entram na porta $x$ e são roteados para a porta $y$ separam-se por um intervalo de comprimento de onda fixo, a região espectral livre (FSR). Este intervalo é determinado pela construção do AWG. Dessa forma, considerando um comprimento de onda $\lambda_{0}$, as saídas de uma dada porta $y$ seriam: $\lambda_{0}, \lambda_{0}+F S R, \lambda_{0}+2 F S R$, e assim por diante. Para a porta de saída $y+1$, os canais roteados a partir da porta $x$ sofrem um deslocamento de $\Delta \lambda$ comparados a $y$. Dessa forma, os comprimentos de onda na porta $y+1$ são $\lambda_{0}+\Delta \lambda, \lambda_{0}+\Delta \lambda+F S R, \lambda_{0}+\Delta \lambda+2 F S R$, e assim por diante [21].

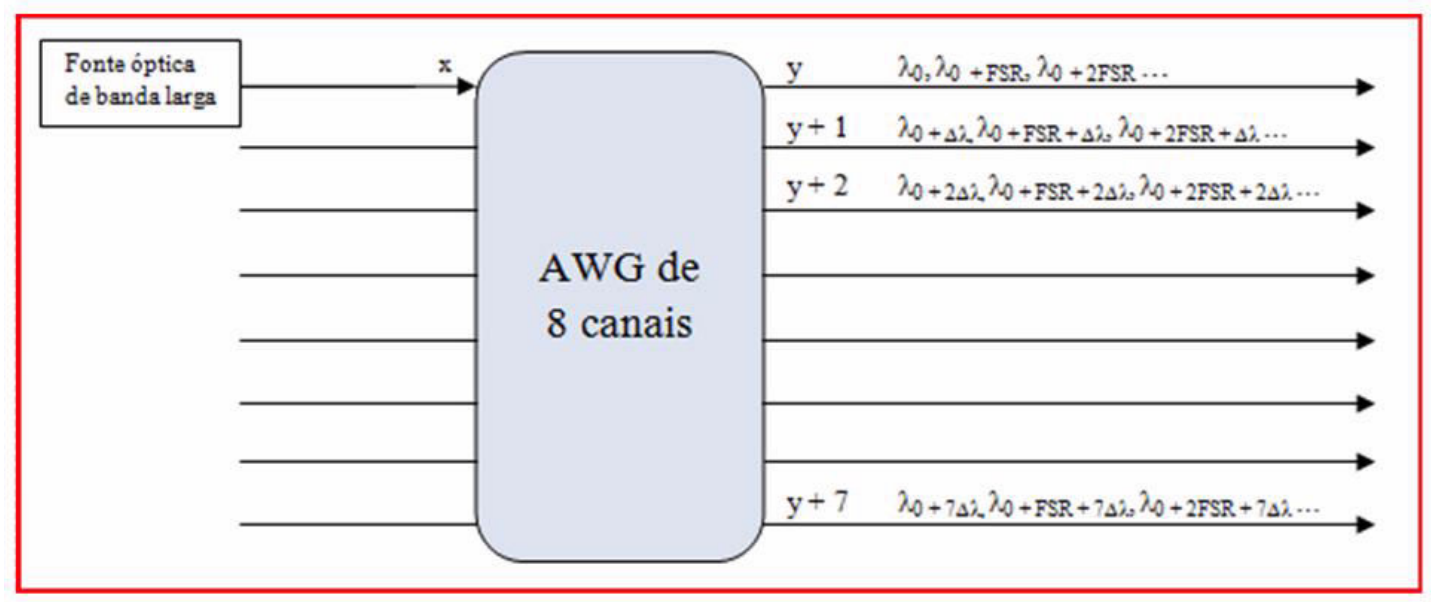

Figura 3.2: O comportamento periódico do AWG

Analisando internamente um AWG, pode-se dividi-lo em cinco partes, como mostra a Figura 3.3. A parte 1 representa os guias de onda de entrada (na figura, por questão de simplicidade, apenas um guia é representado). A luz que entra por esses guias é acoplada 
no vetor de guias de onda através de uma região de propagação livre (FPR), onde ocorre difração (parte 2). Os guias de onda do vetor (parte 3) possuem diferentes comprimentos (a diferença nos comprimentos de guias de ondas adjacentes é constante), implicando em mudanças de fase diferentes para os comprimentos de onda que passam por essa região. Na saída do guia, a luz atravessa outra FPR (parte 4), cuja ação combinada com o vetor de guias ópticos proporciona a separação espacial dos comprimentos de onda, que são encaminhados para os guias de onda de saída (parte 5).

Além de atuar como multiplexador e demultiplexador, o AWG pode exercer diversas funções, tais como: OADM (Optical Add-Drop Multiplexer - multiplexador óptico que insere e retira comprimentos de onda) [63], OXC (Optical Cross-Connect - comutador óptico) [63] e compensador de dispersão [64]. Porém a função mais importante desse dispositivo, no que diz respeito às WDM-PONs, é o roteamento de comprimentos de onda $\mathrm{NxN}$ $[65],[66]$.

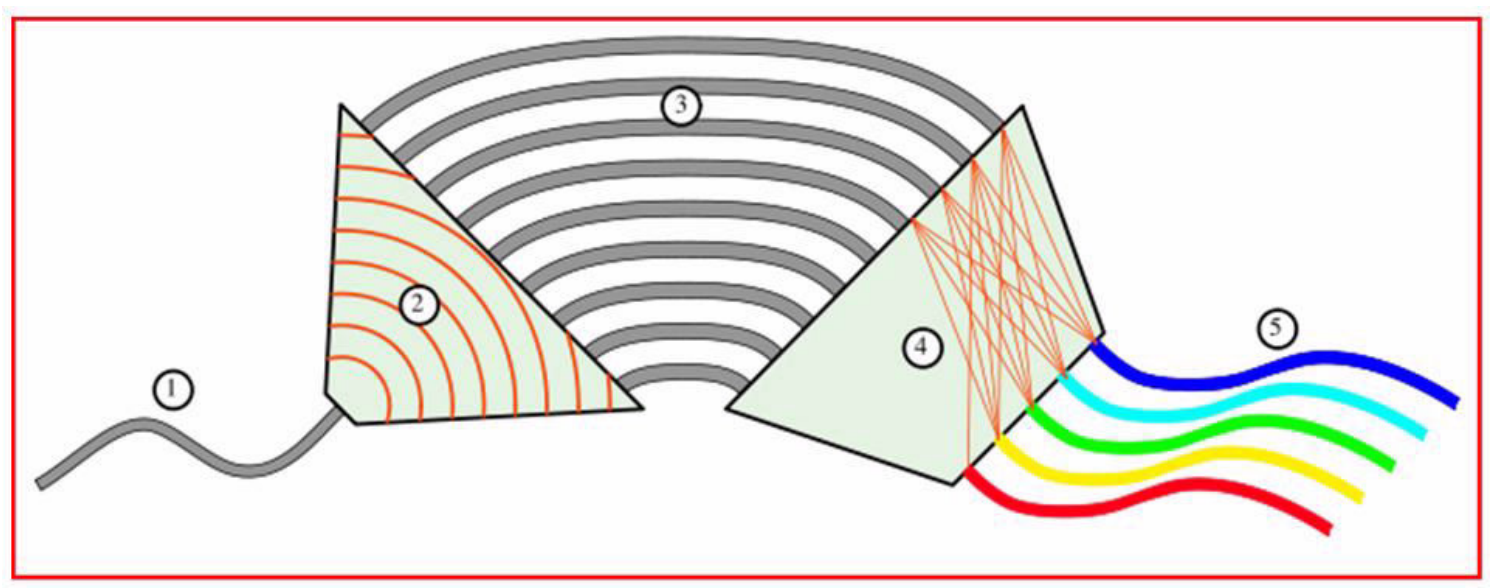

Figura 3.3: Estrutura interna do AWG

\subsubsection{Fonte óptica multi-comprimento de onda}

A fonte óptica multi-comprimento de onda é um dos dispositivos mais importantes na implementação de uma rede WDM-PON. Algumas propostas na literatura para construção desta fonte incluem o vetor de lasers $\mathrm{DFB}$, o laser multi-frequência e fontes óp- 
ticas sintonizáveis em comprimento de onda [67]-[69]. Porém, estas alternativas apresentam custo elevado, tornando-se inapropriadas para produção comercial em massa.

Uma opção que vem sendo amplamente estudada atualmente é o travamento (injection-locking) de diodos lasers Fabry-Pérot (F-P LD) através da injeção do sinal de ASE (Emissão Espontânea Amplificada) de um EDFA (Amplificador de Fibra Dopada com Érbio). O conceito de travamento por injeção de laser é bem antigo (vide [70]), e, desde que foi proposto como uma fonte de baixo custo para WDM-PON, muitos sistemas e resultados experimentais foram publicados [71]-[72], inclusive por grandes empresas, como a Samsung [73] e institutos de pesquisa como o KAIST [74]. Em 2005, um modelo teórico de travamento por injeção de F-P LDs foi proposto baseado nas equações de taxa para o diodo laser semicondutor [75].

Injetando-se uma banda estreita de um sinal de ASE devidamente filtrado em um laser Fabry-Pérot é possível obter-se uma saída monomodo, ao contrário da saída multimodo convencional de um F-P LD. A Fig. 3.4 mostra a configuração da fonte WDM. Observe que o AWG localizado dentro da fonte óptica é responsável pelo fatiamento espectral (spectral slicing), de modo que cada F-P LD receba uma pequena parte do espectro do sinal de ASE.

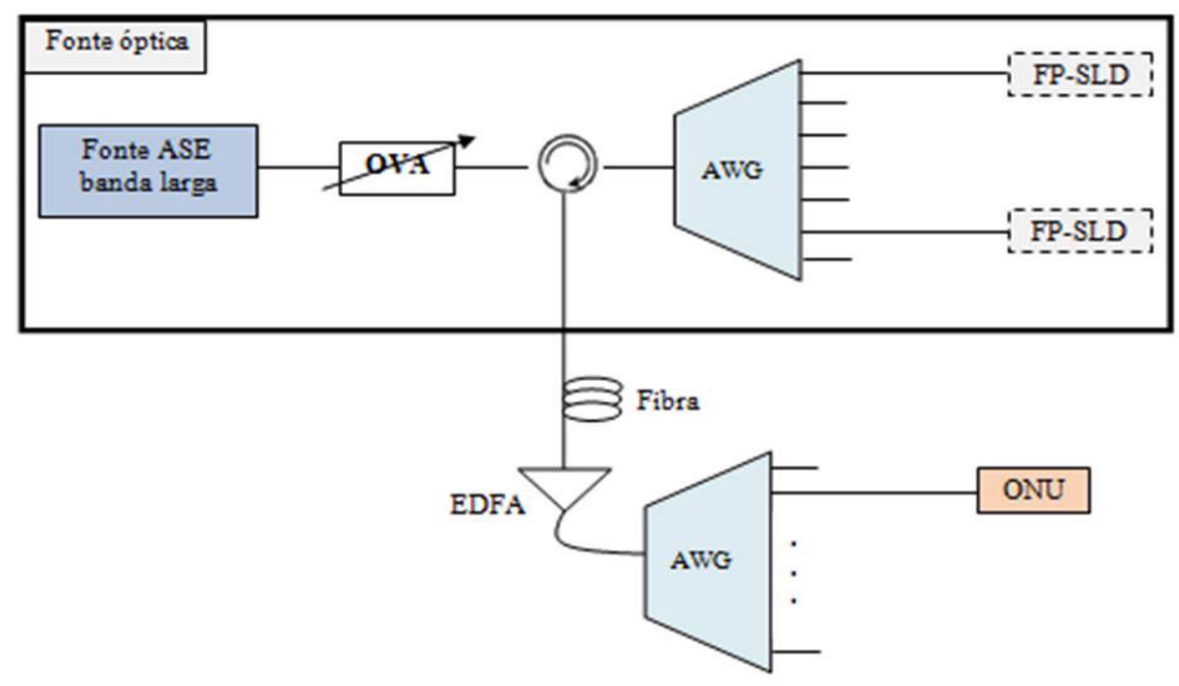

Figura 3.4: Fonte óptica baseada no esquema de travamento por injeção de F-P LD [76] 
Sem a injeção de ASE no F-P LD, a saída multimodo do laser é mostrada na Fig. 3.5-a. Depois que a luz é filtrada pelo AWG, pode-se observar a presença de um pico monomodo. Entretanto, os dados não podem ser transmitidos com sucesso, como se pode ver no diagrama de olho (completamente fechado). Isso se deve ao fato de que a potência de um modo particular flutua aleatoriamente com o tempo, flutuação essa gerada pela propriedade aleatória da emissão espontânea acoplada a cada modo. Injetando-se no laser uma fonte de luz banda larga fatiada espectralmente (BLS), a saída do F-P LD torna-se praticamente monomodo, Fig. 3.5-b, resultando em um ótimo diagrama de olho.

Comparada às alternativas supracitadas, esta fonte WDM apresenta um menor custo, já que se utiliza somente uma fonte ASE, um AWG e vários lasers Fabry-Pérot idênticos, sendo, então, uma boa alternativa para o downstream [77]. Um esquema semelhante a esse pode ser usado também para prover o tráfico de upstream, fazendo com que todas as ONUs possuam os mesmos dispositivos para modulação (ou seja, seriam utilizados transmissores ópticosindependentes do comprimento de onda) e todas as fontes ópticas estariam localizadas nas ONUs, de onde provêm as portadoras ópticas a serem moduladas. Este esquema será tratado na seção 3.2.3 e investigado mais detalhadamente no próximo capítulo. A seguir, serão descritas as principais arquiteturas WDM-PON.

\subsection{Arquiteturas WDM-PON}

\subsubsection{Composite PON}

Uma das primeiras arquiteturas implementadas para resolver a questão da redução de custos mencionada anteriormente nas PONs convencionais foi a Composite PON (CPON) [78]. Esta arquitetura utiliza roteamento WDM para distribuir os sinais downstream, que trafegam na banda $1550 \mathrm{~nm}$, e faz combinação de potência para os sinais upstream, que trafegam em TDM na banda $1300 \mathrm{~nm}$. Dessa forma, a descida assemelha-se ao WDM-PON ponto a ponto, enquanto que a subida assemelha-se a TDM-PON. Como o tráfego nesses dois sentidos é separado por CWDM, a arquitetura necessita apenas de uma fibra, embora tenha sido proposta inicialmente com duas fibras [79]-[80].

A Figura 3.6 mostra cada ONU possuindo um receptor e um transmissor de com- 


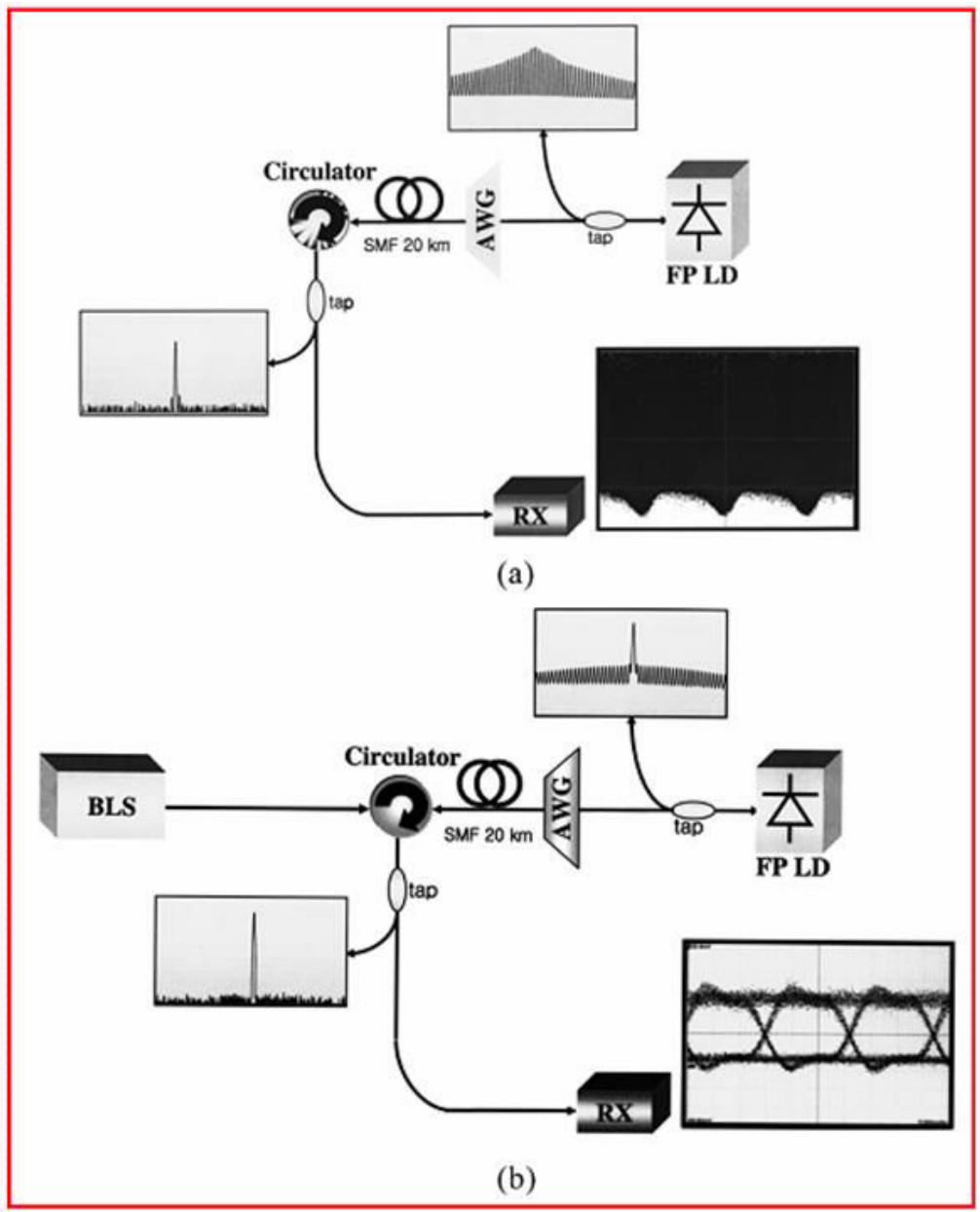

Figura 3.5: Espectro de saída e o diagrama de olho: (a) antes do travamento de comprimento de onda, (b) e depois do travamento de comprimento de onda [77].

primento de onda único (no caso, um laser Fabry-Pérot). Na direção de upstream utiliza-se um protocolo TDMA, obrigando o OLT ser equipado com um receptor no modo rajada (sendo este desnecessário na ONU devido ao fato de no downstream a transmissão ser contínua). O receptor no modo rajada sincroniza os sinais dos relógios das ONUs que estão localizadas em diferentes distâncias do OLT, sendo capaz de lidar com diversos níveis de potência.

Em [81] é proposto um protocolo de controle de acesso ao meio (MAC) para CPON. O esquema de rede adotado para utilização do protocolo possui 4 comprimentos de onda espaçados por $400 \mathrm{Ghz}$, com taxa na descida de $622 \mathrm{Mbps}$ e na subida de $155 \mathrm{Mbps}$, sendo 


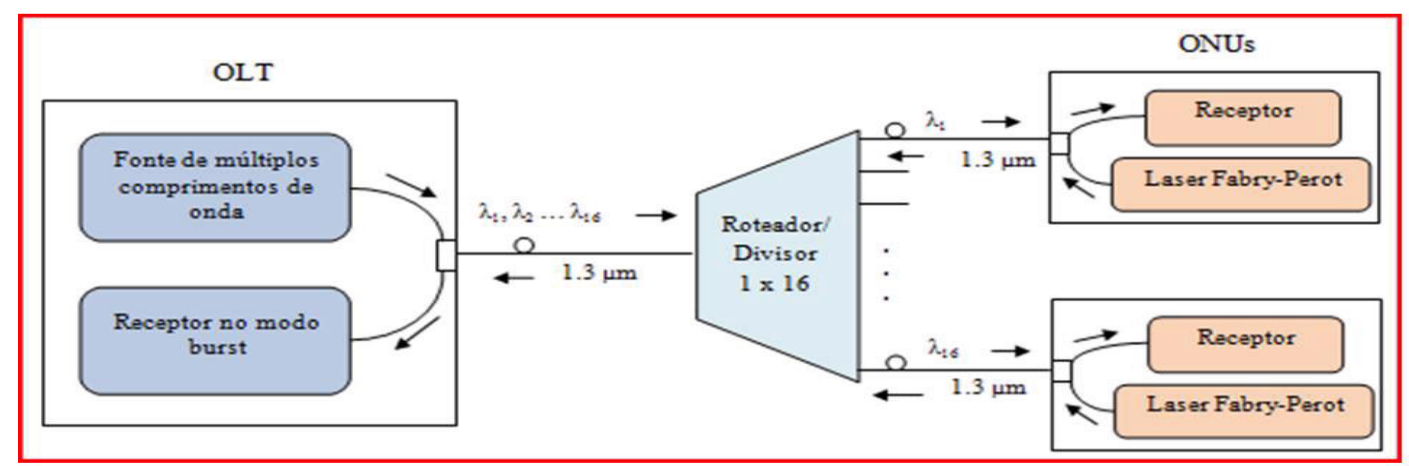

Figura 3.6: Diagrama esquemático de uma rede CPON [78]

utilizadas 16 ONUs.

\subsubsection{Local Access Router Network (LARNET)}

A LARNET é uma arquitetura WDM-PON baseada na utilização de uma fonte banda larga de baixo custo nas ONUs, como, por exemplo, os diodos emissores de luz (LEDs) [82]. Estes dispositivos, que emitem um espectro largo de comprimentos de onda, apresentam como grande vantagem o preço, já que são equipamentos bem mais baratos do que os lasers.

Cada porta de entrada do AWG, considerando o sentido upstream, recebe um espectro largo e seleciona uma faixa do espectro para encaminhá-la à porta de saída (fatiamento espectral). Dessa forma, na saída, diversas faixas do espectro são observadas, cada qual sendo enviada por uma ONU.

Nesta arquitetura, cada ONU tem sua própria portadora óptica para upstream e, diferentemente da arquitetura CPON, todas as ONUs têm o mesmo dispositivo. Desse modo, são utilizados transmissores ópticos colorless, isto é, transmissores que podem ser utilizados em quaisquer ONUs do sistema independentemente do seu comprimento de onda específico de operação. 
Como desvantagens da LARNET podem-se citar: a alta perda por fatiamento (slicing loss), que ocorre quando a luz do LED é transmitida através dos roteadores; a diafonia gerada pelo AWG (já que no fatiamento espectral ele permite pequenos níveis de potência de comprimentos de onda não desejados em cada canal) e também pelo demultiplexador na OLT; e a distância da OLT para cada ONU, que é consideravelmente reduzida devido à falta de orçamento de potência gerada pelo fatiamento espectral no AWG. Como se pode observar, o orçamento de potência nesta arquitetura é muito prejudicado.

Uma variação da arquitetura LARNET utilizando-se LEDs e EDFAs foi demonstrada em [83]. Como proposto em [84], lasers Fabry-Pérot também podem ser usados em redes PON como fonte banda larga para fatiamento espectral. Alternativamente, podese usar também um LED superluminescente (SLED) [85] ou a emissão espontânea de um EDFA [86].

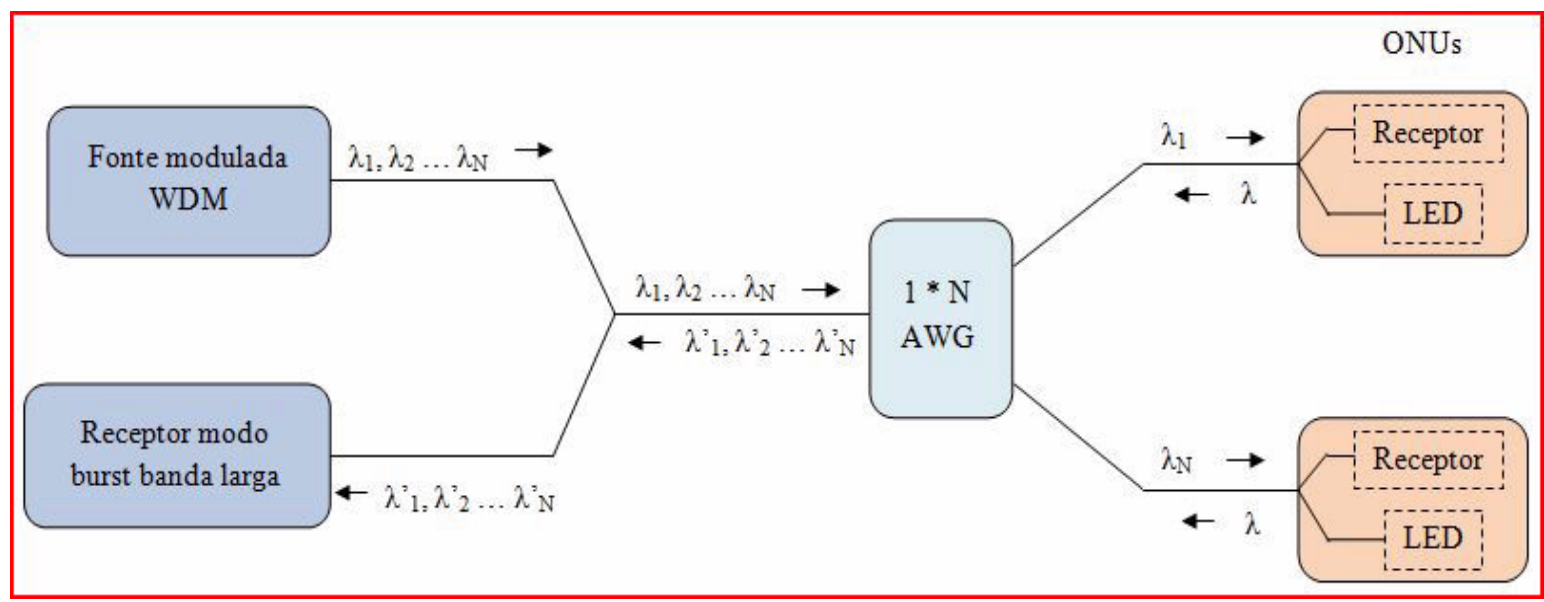

Figura 3.7: LARNET [45]

\subsubsection{Remote Interrogation of Terminal Network (RITENET)}

A RITENET surge como uma alternativa para diminuir o custo das ONUs ao excluir a necessidade de uma fonte óptica em cada uma delas [87]. Parte do sinal de downstream é modulado na ONU e mandado de volta para o OLT, processo denominado loop-back. Nesta porção do sinal óptico, o usuário insere seus dados e os envia. A outra 
parte do sinal de downstream contém, evidentemente, a informação que será detectada por um receptor da ONU.

Na proposta original, o sinal vindo do OLT foi dividido para downstream e upstream por divisão de tempo e, como o mesmo canal óptico foi usado nos dois sentidos de tráfego, a arquitetura precisava ter duas fibras separadas. Em [88], pode-se encontrar um refinamento deste esquema. A Fig. 3.8 mostra o esquema original da RITENET.

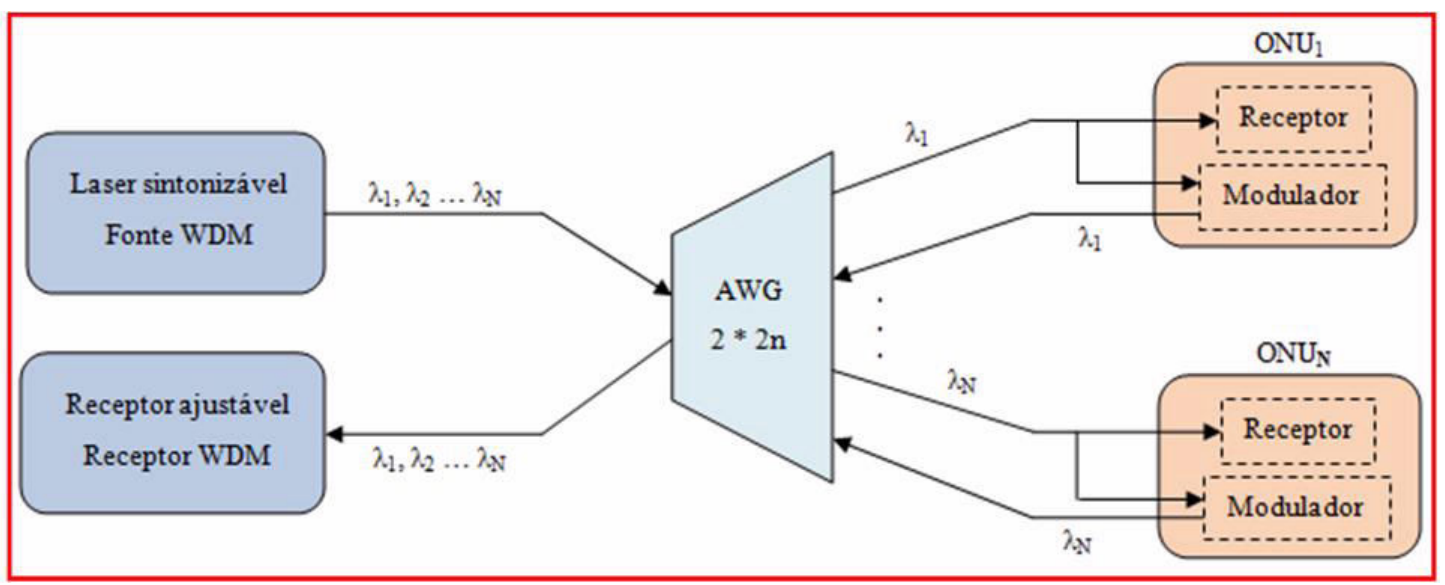

Figura 3.8: RITENET [45]

Como todas as fontes ópticas estão localizadas no OLT, a LARNET é também referenciada como WDM-PON baseada em fontes ópticas centralizadas (centralized light sources - CLS). Variações da WDM-PON baseada em CLS têm ganhado atenção nos últimos anos e utilizam, para o upstream, moduladores ópticos alimentados por sinal de uma fonte compartilhada [89]-[91]. Deve-se observar que todo o aparato para transmissão está localizado no OLT, tornando o custo das ONUs reduzido.

Uma destas variações utiliza o travamento por injeção de laser Fabry-Pérot, que já foi discutido anteriormente como uma boa alternativa para fonte óptica multi-comprimento de onda para o OLT. Agora, esta técnica é aplicada no sentido de upstream [92]. O sinal de travamento é localizado no OLT, enquanto o Fabry-Pérot a ser travado está situado na ONU. Dessa forma, uma série de lasers idênticos e de baixo custo pode ser utilizada para gerar quaisquer comprimentos de onda, implementando assim um esquema colorless (vide 
Fig. 3.9).

Na Coréia do Sul, onde está implantada comercialmente uma WDM-PON, o travamento por injeção de lasers F-P LD foi utilizado tanto no downstream (banda E, 1426 -1449 $\mathrm{nm}$ ), quanto no upstream (banda C, 1534-1559 nm) [93]-[94]. Dessa forma, uma série de lasers idênticos e de baixo custo foram utilizados para prover uma taxa de 100 Mbps.

A utilização de F-P LDs nas ONUs, no entanto, contraria o conceito de fontes ópticas centralizadas. Pode-se, então, utilizar a técnica de travamento de F-P LDs de forma que a rede seja ainda CLS: todos os lasers estariam localizados no OLT e as ONUs possuiriam moduladores Mach-Zehnder, por exemplo. Uma comparação essas duas opções será investigada no próximo capítulo.

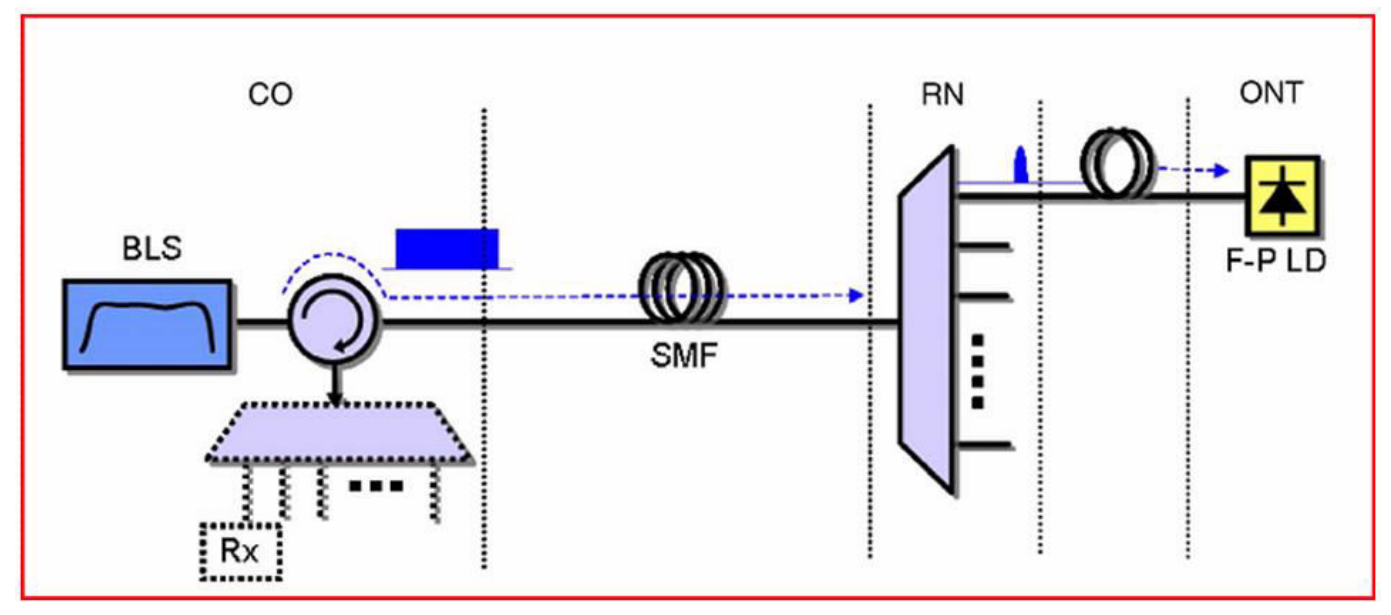

Figura 3.9: Travamento por injeção de FP-LD no upstream [93]

Outra alternativa é a utilização de amplificador óptico semicondutor reflexivo (RSOA) nas ONUs [90], [95]. Um dos primeiros trabalhos utilizando RSOAs nas ONUs remodulando o sinal de downstream para obtenção do sinal de upstream foi publicado em 2005 [96]. Três anos mais tarde, esquema semelhante foi proposto em [97] utilizando-se F-P LDs nos OLTs como fonte de onda contínua para injeção nos RSOAs das ONUs, provendo uma taxa de 2,5 Gbps para upstream. Um RSOA para este tipo de aplicação pode ser encontrado em [98] com o nome de SOA-RL-OEC-1550.

Pode-se, ainda, utilizar o modulador de eletro-absorção reflexivo (REAM) nas 
ONUs (um dispositivo desse tipo pode ser encontrado em [98] com o nome de R-EAM1550). Com este modulador, taxas de modulação de dados de 10 Gbps (ou até mesmo 40 Gbps) são possíveis, porém, diferentemente do esquema com RSOAs, nenhuma amplificação é feita nas ONUs [91], [99].

\subsubsection{WDM-PON multi-estágios}

As arquiteturas LARNET e RITENET sofrem duas limitações principais: dificuldade quanto a escalabilidade do número de ONUs depois que a rede é instalada e limitação da quantidade de usuários devido ao número de portas suportadas por um AWG. A arquitetura WDM-PON com multi-estágios [100]-[101] surge como uma alternativa para superação destas limitações. Ela faz uso das propriedades de roteamento dos AWGs para colocá-los em cascata, de modo que seja possível utilizar um dado comprimento de onda para mais de um usuário.

Na rede, os AWGs têm o mesmo número de entradas e saídas, numeradas de 1 a $M$. Quando um comprimento de onda entra a partir de uma dada entrada $i$ e é roteado para uma dada saída $j$, o AWG comporta-se como um filtro periódico passa-banda, e sua função de transferência de potência tem picos de repetição em um intervalo fixo de comprimento de onda, o FSR. A função de transferência para a entrada $i+1$ para uma dada saída $j$ tem a mesma forma da função de transferência anterior (para $i$ ), mas é deslocado no eixo do comprimento de onda pelo intervalo $\Delta \lambda$. Como no AWG o mesmo comprimento de onda pode ser usado em portas diferentes sem que ocorra interferência (outra propriedade importante do dispositivo), é possível que o mesmo comprimento de onda seja utilizado por ONUs diferentes.

A Fig. 3.10 representa o esquema de uma WDM-PON com múltiplos estágios conectando $U$ ONUs a um CO. A estrutura é composta por $k$ estágios interconectados por enlaces de fibra óptica. Em cada estágio existe um AWG e todos eles são iguais. Dado o número de ONUs que devemos conectar e o número de comprimentos de onda que queremos transmitir a partir do $\mathrm{CO}$, pode-se determinar todas as possíveis arquiteturas variando o número de estágios, o número de AWGs por estágio, o número de entradas usadas e o número de comprimentos de onda roteados por uma dada porta (esparsidade) do AWG. 


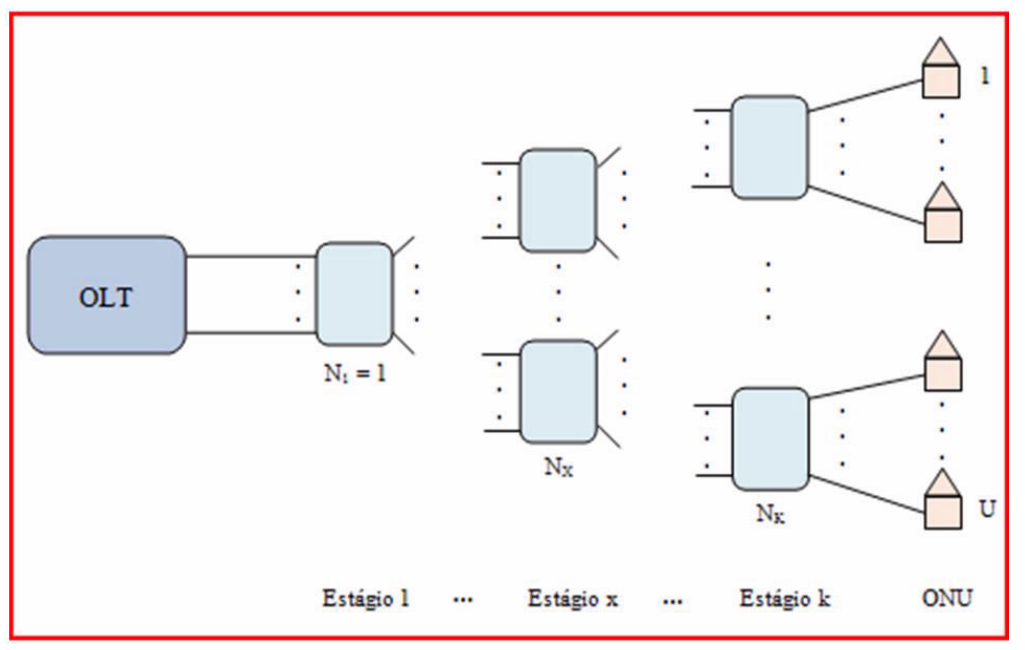

Figura 3.10: Múltiplos estágios [100]

Entre todas essas possibilidades, deve-se encontrar a combinação ótima de parâmetros, isto é, que minimize os custos (as técnicas de programação linear podem ser utilizadas).

A função de roteamento do AWG é definida como [101]:

$$
j=1+\left(i-1+\left|\frac{f-1}{C}\right|\right) \bmod M
$$

onde $i, j$ e $f$ representam a porta de entrada, porta de saída e o comprimento de onda, respectivamente; $M$ representa o tamanho do AWG, $C$ a esparsidade (definida acima), e mod o módulo; e $i, j \in[1, M]$ e $f \in[1, \infty]$. O módulo $M$ na equação é conseqüência da propriedade periódica do dispositivo (FSR). Esta função de transferência do dispositivo foi utilizada nas simulações com o software OptiSystem.

Para exemplificar a facilidade no escalonamento proposta por esta arquitetura, tem-se o exemplo da Fig. 3.11. Inicialmente, 2 lasers comunicam-se com 8 ONUs através de um AWG $2 \times 8$. Para adicionar mais usuários à rede reutilizando a arquitetura instalada, pode-se adicionar 8 novos AWGs $1 \times 4$, tendo-se agora um total de 32 ONUs. Cada laser que fornecia 4 comprimentos de onda, passa a oferecer 16 canais ópticos. A nomenclatura utilizada para definir cada canal é a seguinte: em $\lambda_{3}^{1}$, o subscrito 3 denota o número do comprimento de onda e o sobrescrito 1 denota a fonte, ou seja, comprimento de onda 3 da fonte 1. Dessa forma, as $\mathrm{ONU}$ s originais $\left(\mathrm{ONU}_{1}\right.$ a $\left.\mathrm{ONU}_{8}\right)$ continuam usando os mesmos 
comprimentos de onda que usavam antes do upgrade $\left(\lambda_{1}^{1}\right.$ a $\lambda_{4}^{1}$ e $\lambda_{1}^{2}$ a $\left.\lambda_{4}^{2}\right)$.

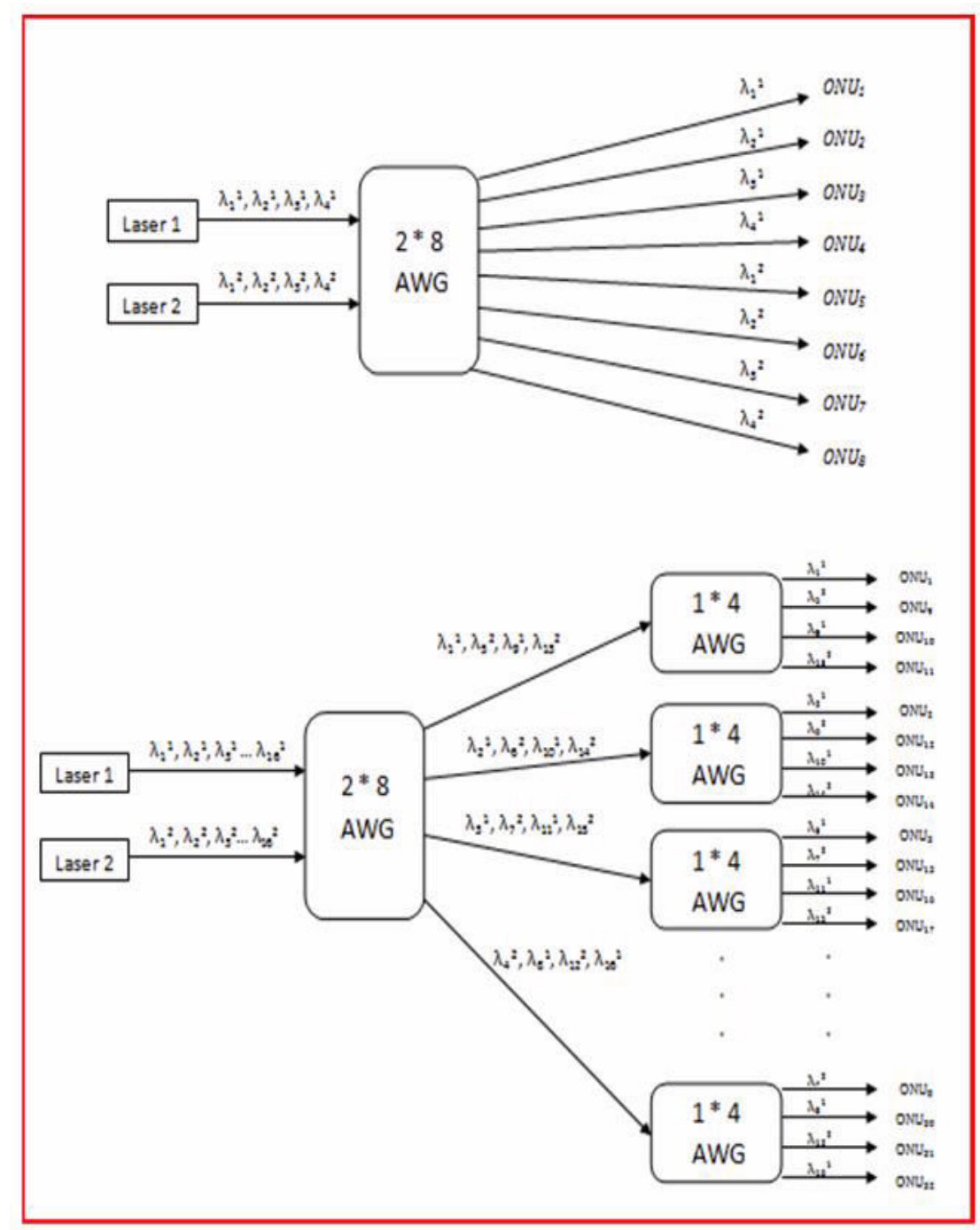

Figura 3.11: Exemplo de escalabilidade na arquitetura Multi-Estágios [21]

\subsubsection{Comparação entre as arquiteturas}

A Tabela 3.1 [46] apresenta algumas características das arquiteturas supracitadas para efeito de comparação. As siglas $L B$ e $N u$ representam a largura de banda máxima de downstream e o número de usuários, respectivamente. 


\begin{tabular}{|c|c|c|c|c|}
\hline Parâmetro & CPON & LARNET & RITENET & Multi-Estágios \\
\hline Configuração & Estrela & Estrela & Estrela & $\begin{array}{c}\text { Barramento } \\
\text { Estrela }\end{array}$ \\
\hline $\begin{array}{c}\text { Compartilha- } \\
\text { mento da fibra }\end{array}$ & $\begin{array}{c}\text { Compar- } \\
\text { tilhado ou } \\
\text { separado }\end{array}$ & $\begin{array}{c}\text { Compar- } \\
\text { tilhado }\end{array}$ & $\begin{array}{c}\text { Compar- } \\
\text { tilhado ou } \\
\text { separado }\end{array}$ & $\begin{array}{c}\text { Compar- } \\
\text { tilhado ou } \\
\text { separado }\end{array}$ \\
\hline $\begin{array}{c}\text { Compartilha- } \\
\text { mento do } \lambda \text { de } \\
\text { downstream }\end{array}$ & $1 \lambda /$ ONU & $1 \lambda /$ ONU & $\begin{array}{c}\text { Compar- } \\
\text { tilhado }\end{array}$ & $1 \lambda /$ ONU \\
\hline $\begin{array}{c}\text { Compartilha- } \\
\text { mento do } \lambda \text { de } \\
\text { upstream }\end{array}$ & $\begin{array}{c}\text { Compar- } \\
\text { tilhado }\end{array}$ & $\begin{array}{c}\text { Compar- } \\
\text { tilhado }\end{array}$ & $\begin{array}{c}\text { Compar- } \\
\text { tilhado }\end{array}$ & $1 \lambda /$ ONU \\
\hline $\begin{array}{c}\text { Largura de } \\
\text { banda do } \\
\text { upstream }\end{array}$ & LB / Nu & LB / Nu & LB / Nu & LB \\
\hline
\end{tabular}

Tabela 3.1: Comparativa das arquiteturas WDM-PON. Fonte: [46]

Em resumo, com base na análise das diversas arquiteturas, a literatura recente têm se dedicado ao estudo de dispositivos colorless, nos quais, segundo [102], podem ser classificados em dois esquemas: emisão local e suprimento remoto de comprimento de onda, mostrados na Tabela 3.2.

\subsection{SuperPON}

Como mencionado capítulo anterior, uma das vertentes encontrada na literatura para sistemas WDM-PON emprega a idéia de redes de longo alcance. Uma breve discussão a seu respeito será feita a partir de agora.

A associação ACTS-PLANET (Advanced Communication Technologies and Services - Photonic Local Access Network) foi criada em meados da década de 90 com o objetivo de definir uma rede de acesso óptica de baixo custo para atender as necessidades e desenvolvimentos dentro das telecomunicações nos próximos anos [103]-[104]. A arquitetura 


\begin{tabular}{|c|c|c|c|c|}
\hline & \multicolumn{2}{|c|}{ Emissão Local } & $\begin{array}{l}\text { Suprimento } \\
\text { comprimento }\end{array}$ & $\begin{array}{l}\text { remoto de } \\
\text { de onda }\end{array}$ \\
\hline & $\begin{array}{c}\text { Fonte } \\
\text { Óptica } \\
\text { sintonizável }\end{array}$ & $\begin{array}{c}\text { Fatiamento } \\
\text { espectral }\end{array}$ & $\begin{array}{l}\text { Travamento } \\
\text { por injeção }\end{array}$ & Loop back \\
\hline $\begin{array}{l}\text { Configura- } \\
\text { ção da } \\
\text { ONU }\end{array}$ & $\begin{array}{c}\text { Receptor } \\
\text { e laser } \\
\text { sintonizável }\end{array}$ & $\begin{array}{l}\text { Receptor } \\
\text { e fonte } \\
\text { banda lar- } \\
\text { ga (BLS) }\end{array}$ & $\begin{array}{l}\text { Receptor } \\
\text { e Fabry- } \\
\text { Pérot }\end{array}$ & $\begin{array}{c}\text { Receptor, } \\
\text { modulador e } \\
\text { amplificador }\end{array}$ \\
\hline $\begin{array}{l}\text { Número } \\
\text { de fibras }\end{array}$ & 1 & 1 & 1 ou 2 & 1 ou 2 \\
\hline $\begin{array}{c}\text { Coerência } \\
\text { da luz do } \\
\text { sinal de } \\
\text { upstream }\end{array}$ & Coerente & Incoerente & $\begin{array}{c}\text { Depende } \\
\text { da condi- } \\
\text { ção de tra- } \\
\text { vamento e } \\
\text { o tipo de luz } \\
\text { de alimen- } \\
\text { tação }\end{array}$ & $\begin{array}{l}\text { Depende } \\
\text { do tipo } \\
\text { de luz de } \\
\text { alimen- } \\
\text { tação }\end{array}$ \\
\hline $\begin{array}{l}\text { Taxa de } \\
\text { transmis- } \\
\text { são típi- } \\
\text { ca }\end{array}$ & $\begin{array}{l}10 \text { Gbps } \\
\text { ou mais }\end{array}$ & 2,5 Gbps & 2,5 Gbps & $\begin{array}{c}2,5 \text { Gbps } \\
(1 \text { fibra }) \text { ou } \\
10 \text { Gbps } \\
(2 \text { fibras })\end{array}$ \\
\hline $\begin{array}{l}\text { Dificulda- } \\
\text { des } \\
\text { técnicas }\end{array}$ & $\begin{array}{l}\text { Custo de } \\
\text { implemen- } \\
\text { tação }\end{array}$ & $\begin{array}{l}\text { - Ruído da } \\
\text { BLS } \\
\text { - Tolerân- } \\
\text { cia a } \\
\text { dispersão }\end{array}$ & $\begin{array}{c}\text { - Back } \\
\text { reflection } \\
\text { - SNR da } \\
\text { luz de } \\
\text { alimentação } \\
\text { - Não } \\
\text { travamento }\end{array}$ & $\begin{array}{l}\text { - Back } \\
\text { reflection } \\
\text { - SNR da } \\
\text { luz de } \\
\text { alimentação }\end{array}$ \\
\hline
\end{tabular}

Tabela 3.2: Opções para implementação de WDM-PONs utilizando ONUs colorless. Fonte: [102] 
escolhida foi chamada de SuperPON. No projeto original, ela atende 2048 ONUs e cobre uma área de $100 \mathrm{~km}$ por meio do uso de amplificadores ópticos. O sistema de transporte de dados era baseado em células ATM (lembrando a ATM PON), sendo que para downstream utiliza-se TDM (com uma taxa de transmissão de 2,5 Gbps) e para upstream utiliza-se um protocolo TDMA (com uma taxa de $311 \mathrm{Mbps}$ ). A arquitetura não é propriamente passiva, já que utiliza componentes ativos (como amplificadores ópticos) entre o OLT e as ONUs. Porém essa desvantagem é compensada com o alcance e número de usuários da rede.

Nos últimos anos têm-se buscado simplificar a hierarquia das redes de telecomunicações integrando a rede de acesso diretamente à rede backbone [46]. Nesse contexto, a SuperPON destaca-se por possibilitar uma rede de longo alcance. Algumas arquiteturas recentes refinam a proposta original utilizando somente multiplexação por divisão no tempo [105]-[106], porém necessitam de amplificadores ópticos e compensadores de dispersão para aumentar a distância na transmissão.

Alternativamente, duas propostas têm sido estudadas para esta arquitetura: um modelo híbrido de DWDM-TDM PON de longo alcance [107] e um modelo exclusivamente DWDM para SuperPONs [108].

O primeiro esquema, proposto em 2006, agrega 17 TDM-PONs, cada uma com taxa de upstream de 10 Gbps. A fonte colorless escolhida para as ONUs foi um modulador de eletro-absorção semicondutor integrado com amplificadores ópticos semicondutores (EAMSOA). Considerando que cada PON fosse composta por 256 usuários, o esquema agregaria 4352 clientes. O esquema proposto está mostrado na Fig. 3.12.

A segunda alternativa, chamada DWDM-PON de longo alcance, foi proposta em 2007. A arquitetura é, basicamente, um esquema WDM-PON ponto a ponto bidirecional com 64 para downstream e mais 64 para upstream (espaçamento de 50 Ghz entre os comprimentos de onda de cada banda) utilizando o travamento por injeção de lasers Fabry-Pérot. Cada canal opera a uma taxa de mais de 100 Mbps e o alcance da fibra é de $70 \mathrm{Km}$. 


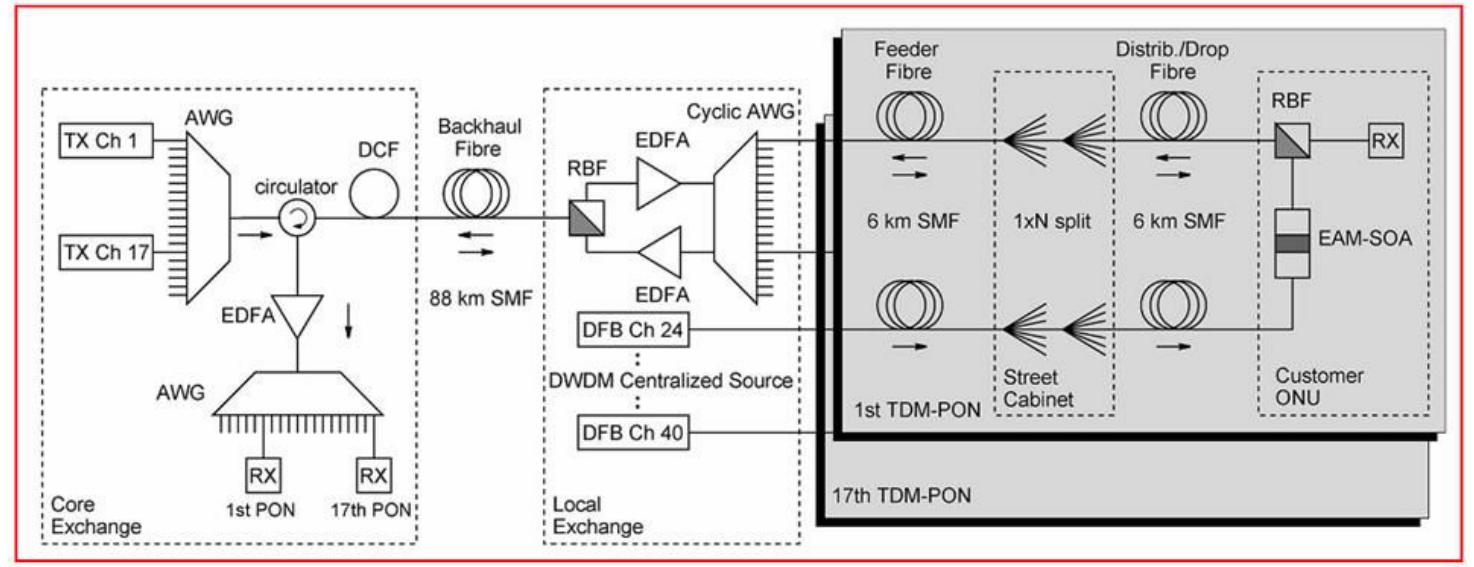

Figura 3.12: DWDM-TDM PON de longo alcance [107] 


\section{Capítulo 4}

\section{Estudo de Arquiteturas Baseadas}

\section{no Travamento Óptico de Lasers}

\section{Fabry-Pérot}

Como já discutido no capítulo anterior, o fato de não precisar de uma fonte óptica na ONU fez com que a RITENET ganhasse certo destaque perante as demais arquiteturas citadas no capítulo anterior. Dessa forma, foi feito um estudo para maior aprofundamento sobre a arquitetura e suas variações na literatura recente. A ferramenta utilizada na simulação foi o software OptiSystem 8.

O capítulo está dividido em quatro partes: inicialmente investigou-se a RITENET em sua proposta original [87]; em seguida, é apresentada uma variação da proposta inicial, na qual o F-P LD a ser travado encontra-se na ONU[109],[110]; na terceira seção foi discutida outra variação, na qual utiliza-se o travamento de lasers Fabry-Pérot através da injeção externa de sinal de ASE para obter uma rede baseada em fontes ópticas centralizadas; por fim, simulou-se uma rede com a quantidade máxima de modos que o OptiSystem permite utilizar. 


\subsection{Proposta original da RITENET}

Inicialmente foi investigada uma rede semelhante à arquitetura RITENET original na qual, no OLT, 32 lasers emitem luz de forma contínua (CW) para prover o sinal de upstream. Os comprimentos de onda (localizados na banda $1550 \mathrm{~nm}$ ), atravessam $20 \mathrm{~km}$ de fibra óptica e, ao chegarem no AWG, são demultiplexados. Cada um deles é encaminhado a uma ONU específica. Na ONU está presente um modulador Mach-Zehnder (assim como em [87]) que recebe o sinal, realiza a modulação com os dados do usuário (sinal de upstream) e manda de volta para o OLT em esquema loop-back. No processo de subida, o sinal percorre novamente $20 \mathrm{~km}$ de fibra e o AWG é responsável por realizar a multiplexação dos 32 comprimentos de onda provindos das ONUs.

O caso de interesse está representado esquematicamente na Figura 4.1. Na arquitetura RITENET original, de forma intercalada no domínio do tempo, a portadora é enviada pelo OLT alternadamente com modulação (isto é, contendo os dados de downstream) e não modulada. No esquema investigado, no sentido OLT-ONU, apenas a porção não modulada foi utilizada, ou seja, considerou-se apenas o sinal de upstream. As taxas de transmissão utilizadas foram $622 \mathrm{Mbps}, 1,25$ Gbps, 2,5 Gbps e 10 Gbps.

A Figura 4.2 mostra a taxa de erro como função da potência necessária emitida pelos lasers CW no OLT, de forma que o gráfico mostra apenas o comportamento da ONU que apresenta o pior desempenho. Como pode ser observado, para a taxa 622 Mbps é necessário que a potência transmitida pelo laser CW do OLT seja aproximadamente $-5,5$

$\mathrm{dBm}$ a fim de que se possa obter uma BER de $10^{-12}$. Para obtenção dessa mesma taxa de erro em 10 Gbps, uma potência de aproximadamente $0,8 \mathrm{dBm}$ seria necessária no laser do OLT.

Como mencionado no capítulo anterior, a arquitetura RITENET provê uma rede baseada em fonte óptica centralizada, já que os transmissores encontram-se no OLT. Porém, ela apresenta como desvantagem a necessidade de que a central do provedor de serviço disponha de um elevado número de lasers em estoque, tendo em vista que cada ONU usaria um laser específico. Dessa forma, duas alternativas foram investigadas nas seções 4.2 e 4.3. A primeira delas, mostrada a seguir, utiliza lasers Fabry-Pérot idênticos 


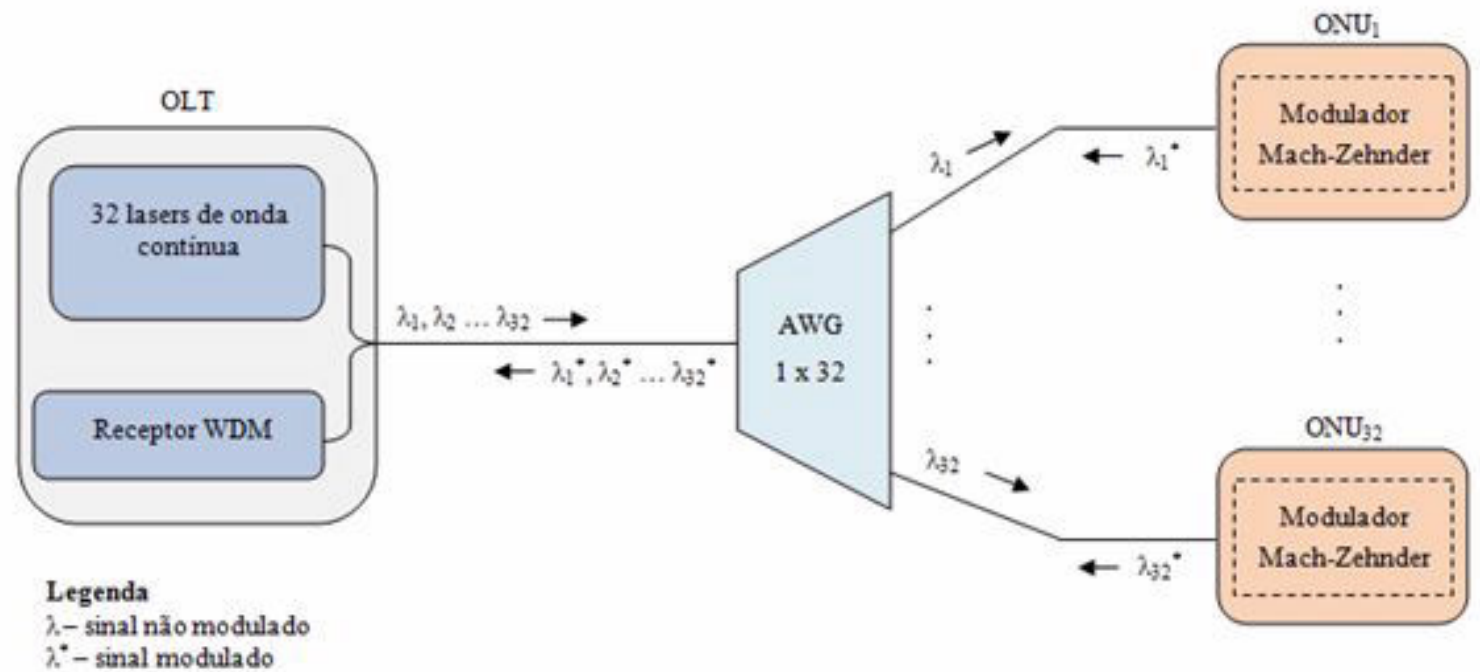

Figura 4.1: Representação esquemática da arquitetura RITENET proposta originalmente por [87]

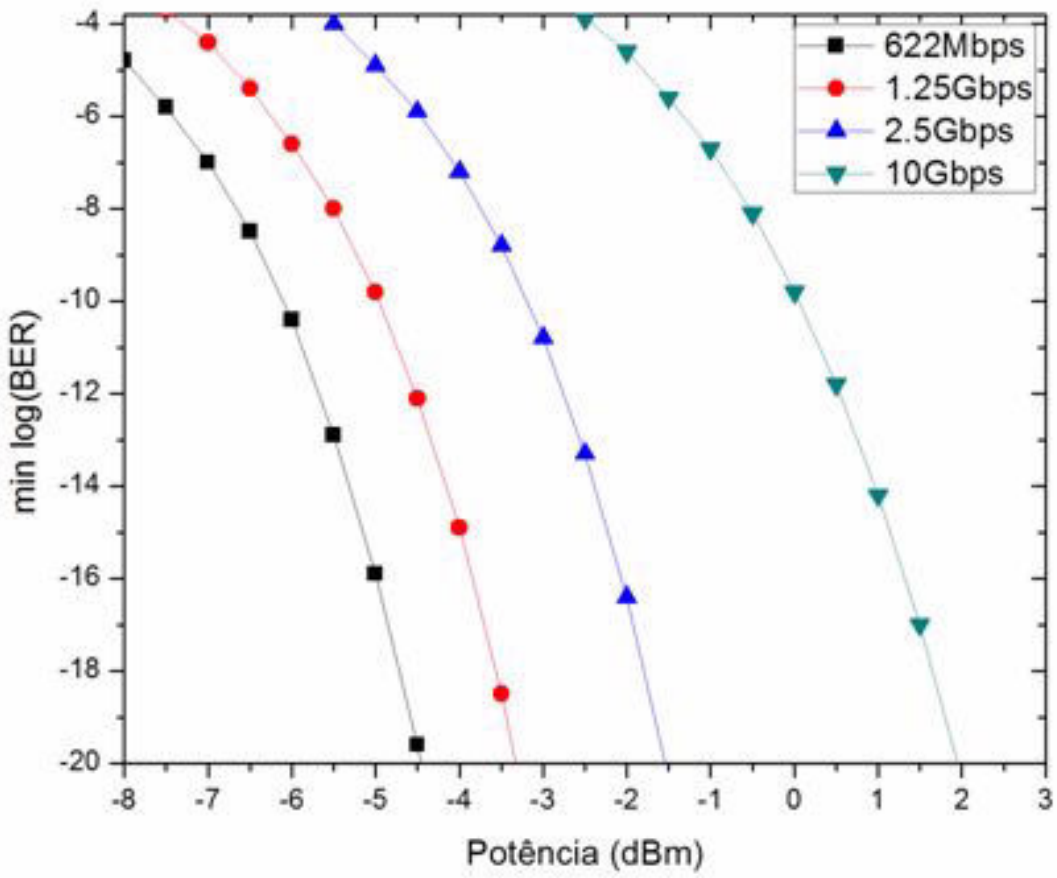

Figura 4.2: Taxa de erro versus a potência do laser CW no OLT em $20 \mathrm{~km}$ de fibra 
nas ONUs, na qual o comprimento de onda específico de atuação é determinado pelo sinal externo que irá travar o laser.

\subsection{Rede com F-P LD na ONU}

Nesta arquitetura é empregada a técnica de travamento de um laser Fabry Pérot por injeção de um sinal externo [111]. Quando a frequência central da fonte óptica externa estiver próxima a um dos modos do Fabry-Pérot, a potência óptica emitida pelos demais modos é suprimida, enquanto ocorre ganho em potência do modo escolhido. Dessa forma, o laser passa a oscilar praticamente em monomodo, travando o dispositivo semicondutor.

Por meio do software OptiSystem, o resultado do emprego dessa técnica pode ser analisado nas figuras abaixo. A Figura 4.3 mostra o espectro de saída de um laser FabryPérot de 9 modos, cujo modo central está localizado em 1550 nm. Injetando-se o sinal de um laser CW com comprimento de onda central $1550 \mathrm{~nm}$, o modo de interesse do F-P LD é travado (Figura 4.4a). Devido à significativa diferença de potência entre o modo travado e os demais modos, pode-se considerar a saída do F-P LD aproximadamente monomodo. De forma similar, pode-se travar qualquer um dos modos como pode ser visto na Figura 4.4b, na qual escolheu-se para travamento o primeiro modo lateral da esquerda, indicado por $\mathrm{m}$ $=-1$.

Os parâmetros dos F-P LDs utilizados nas simulações estão mostrados na Tabela 4.1. Esses valores são compatíveis com trabalhos encontrados na literatura [75]. Estudos recentes sobre algumas características do F-P LD travado, tais como refletividades requeridas, corrente de polarização, modulação e ruído, podem ser encontrados em [112]-[114].

Uma alternativa mais viável do que utilizar vários lasers $\mathrm{CW}$ como fonte de sinal

óptico externo para realizar o travamento é a utilização da emissão espontânea, ASE, de um EDFA. Fatiando-se devidamente o sinal banda larga da ASE, somente uma pequena parte do espectro é encaminhada ao F-P LD. Se a frequência central dessa fatia do espectro estiver em fase e for próxima à frequência de um dos modos do F-P LD, esse modo será travado. Para o fatiamento espectral, pode-se utilizar, por exemplo, o AWG. 


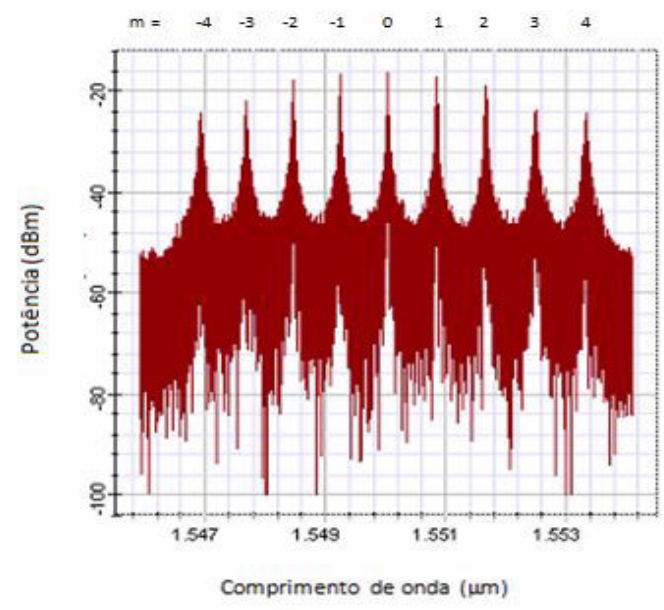

Figura 4.3: Espectro de saída de um Fabry-Pérot com 9 modos sem a injeção de sinal óptico externo. O modo central é referenciado como $\mathrm{m}=0$, os modos à sua esquerda são numerados negativamente e os modos à direita são numerados positivamente

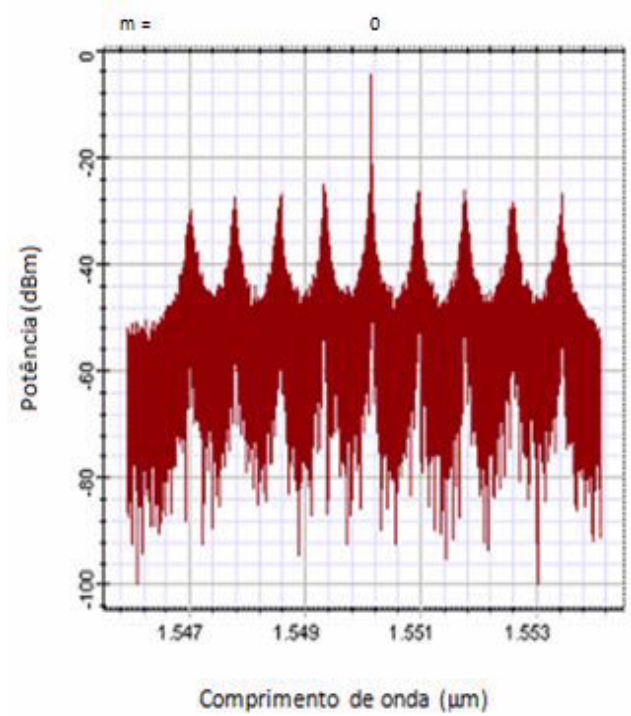

(a)

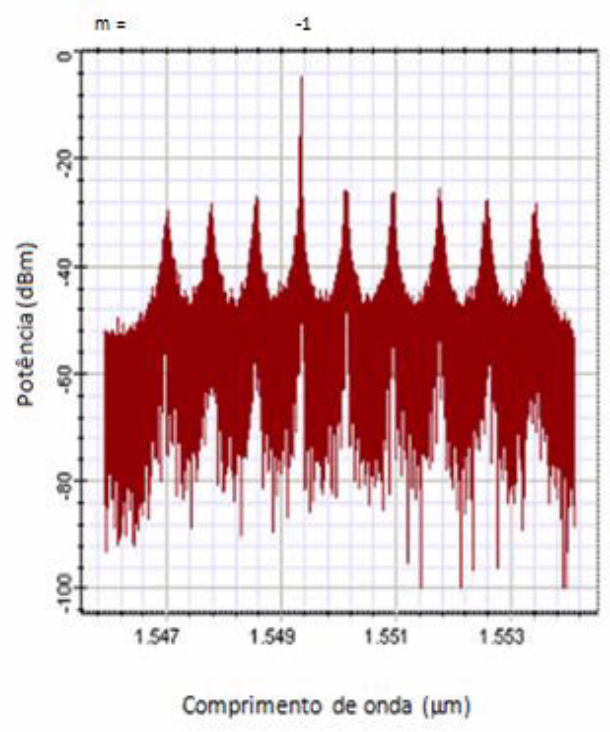

(b)

Figura 4.4: Espectro de saída de um Fabry-Pérot com 9 modos com a injeção de sinal óptico externo (a) travamento do modo central $(\mathrm{m}=0),(\mathrm{b})$ travamento do primeiro modo lateral à esquerda $(\mathrm{m}=-1)$ 


\begin{tabular}{|c|c|c|}
\hline Parâmetros & Símbolos & Valores \\
\hline Comprimento da Cavidade & $\mathrm{L}$ & $428 \mu \mathrm{m}$ \\
Largura da Região Ativa & $\mathrm{W}$ & $15 \mu \mathrm{m}$ \\
Espessura da Região Ativa & $\mathrm{D}$ & $0,2 \mu \mathrm{m}$ \\
Volume da Região Ativa & $\mathrm{V}$ & $1284 \mu \mathrm{m}^{3}$ \\
Fator de Confinamento Óptico & $\Gamma$ & 0,5 \\
Índice de Grupo & $\mathrm{n}_{g}$ & 4 \\
Índice efetivo da Região Ativa & $\mathrm{n}_{r}$ & 3,5 \\
Pernas Internas & $\alpha_{i n t}$ & $1 \times 10^{-3}(\mu \mathrm{m})^{-1}$ \\
Refletividade na Face Frontal & $\mathrm{R}_{f}$ & 0,01 \\
Refletividade na Face Traseira & $\mathrm{R}_{b}$ & 0,3 \\
Comprimento de onda do modo central & $\lambda_{0}$ & $1550 \mathrm{~nm}$ \\
Velocidade da luz no vácuo & $\mathrm{C}$ & $3 \times 10^{8} \mathrm{~m} / \mathrm{s}$ \\
Densidade de Portadores Eletrônicos & $\mathrm{n}_{t r}$ & $1 \times 10^{3}(\mu \mathrm{m})^{-3}$ \\
na transparência & $\mathrm{i}$ & $30 \mathrm{~mA}=1,3 \mathrm{I}_{t h}$ \\
Corrente de Polarização & $\Delta \lambda_{D}$ & $3,5 \mathrm{THz}=28 \mathrm{~nm}$ \\
Largura de Ganho de 3dB & $\mathrm{A}_{n r}$ & $1 \times 10^{8} \mathrm{~s}^{-1}$ \\
Coeficiente de Recombinação Não-Radiativa & $\mathrm{B}$ & $1 \times 10^{-10} \mathrm{~cm}^{3} \mathrm{~s}^{-1}$ \\
Coeficiente de Recombinação Radiativa & $\mathrm{C}_{a u g}$ & $4 \times 10^{-29} \mathrm{~cm}^{6} \mathrm{~s}^{-1}$ \\
Coeficiente Auger & $\mathrm{M}_{\text {m-ésimo modo }}$ & $(-4 \ldots 0 \ldots 4)$ \\
Espaçamento modal & $\Delta \lambda_{L}$ & $100 \mathrm{GHz}=0,8 \mathrm{~nm}$ \\
Eficiência Quântica Diferencial & $\eta$ & 0,4 \\
\hline
\end{tabular}

Tabela 4.1: Valores utilizados nas simulações e disponibilizados pela literatura [75] 


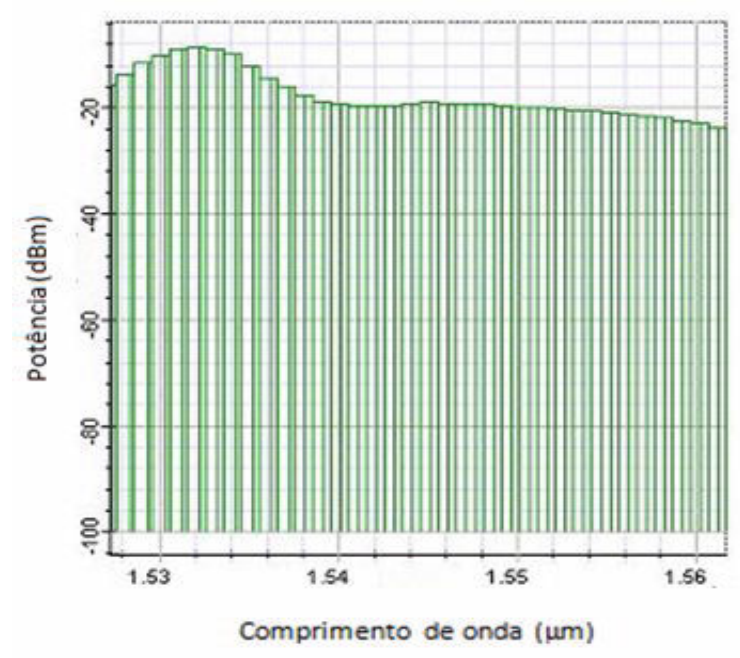

Figura 4.5: Espectro banda larga de um sinal de ASE gerado a partir de componente do software OptiSystem

O espectro banda larga de uma ASE obtido a partir da utilização da ferramenta computacional OptiSystem está mostrado na Figura 4.5. A obtenção desse sinal foi possível através do componente do software chamado "EDFA Measured", com o qual foi possível obter um espectro de ASE semelhante ao utilizado nas Referência [75].

O AWG pode fatiar esse sinal de forma que tenhamos, por exemplo, na porta de saída 1 do dispositivo o espectro mostrado na Figura 4.6a e na porta de saída 5 do AWG o espectro mostrado na Figura 4.6b. As portas de saída do AWG são encaminhadas a lasers Fabry-Pérot idênticos. A fração do espectro da Figura 4.6a utilizado como sinal óptico externo do F-P LD correspondente produz o espectro de saída mostrado na Figura 4.6c. Analogamente, a injeção do sinal mostrado na Figura 4.6b no F-P LD correspondente, produz o espectro de saída mostrado em $4.6 \mathrm{~d}$.

Tendo em vista as informações acima, a primeira variação da arquitetura RITENET investigada emprega F-P LDs nas ONUs. Isto é, a ONU possui como fonte óptica o laser Fabry-Pérot que será travado a partir do sinal de ASE de um EDFA localizado no OLT. Dessa forma, todas as ONUs possuiriam fontes ópticas idênticas (esquema colorless), porém a arquitetura não é centralizada. 


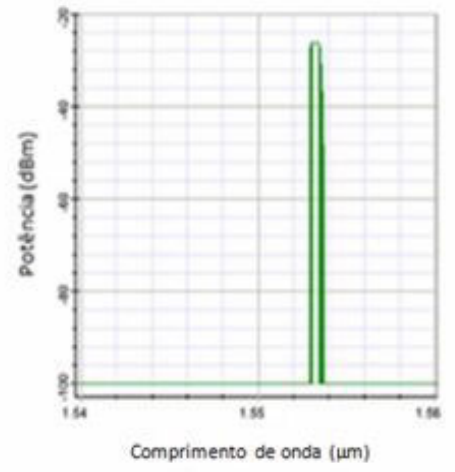

(a)

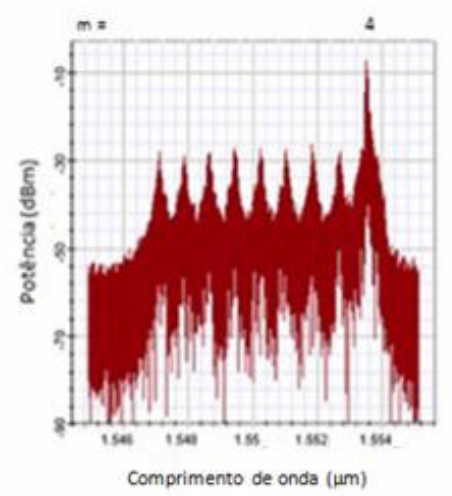

(c)

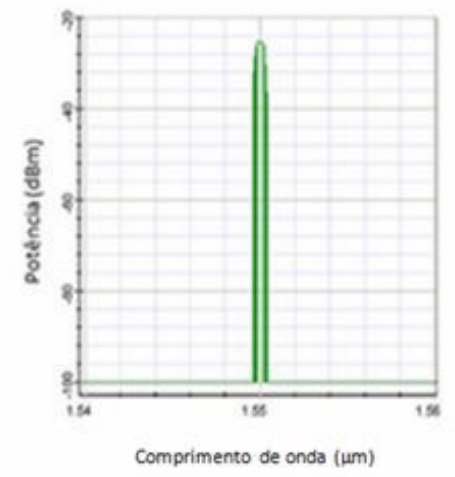

(b)

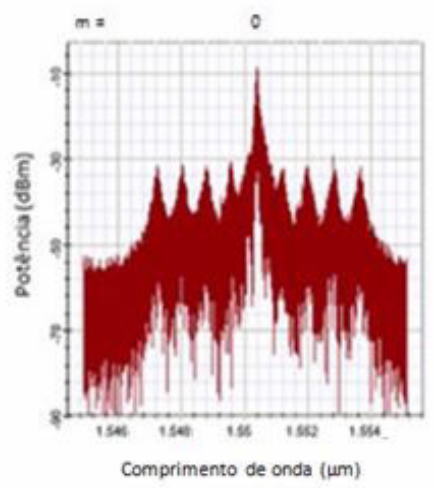

(d)

Figura 4.6: (a) sinal da ASE fatiado que sai na porta 1 do AWG, (b) sinal da ASE fatiado que sai na porta 5 do AWG, (c) modo lateral do F-P LD $(\mathrm{m}=4)$ travado com o sinal de "a", (d) modo central do F-P LD $(\mathrm{m}=0)$ travado com o sinal de "b" 


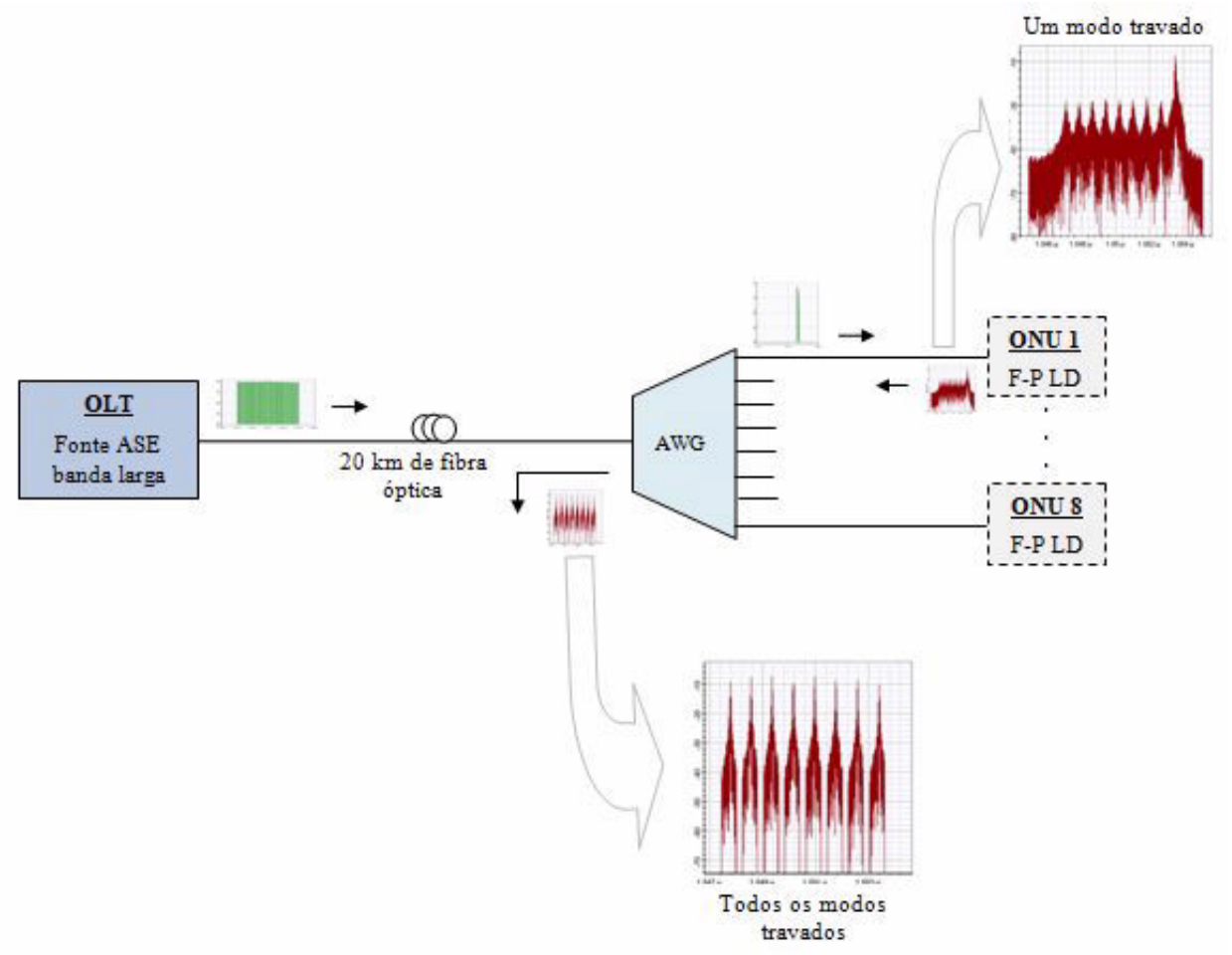

Figura 4.7: Representação esquemática da rede contendo 8 ONUs equipadas com lasers Fabry-Pérot idênticos

No esquema investigado, mostrado na Figura 4.7, o sinal de ASE gerado no OLT percorre a fibra óptica e é fatiado espectralmente pelo AWG. Cada ONU recebe, então, uma estreita fatia do espectro que será responsável por travar um dos modos do F-P LD. Como o laser encontra-se nas instalações do usuário, a modulação é direta. Após a modulação, o sinal de upstream de cada ONU percorre o caminho de volta para o OLT.

Os F-P LDs utilizados na simulação seguem o padrão descrito anteriormente e o sinal de ASE é o mesmo mostrado na Figura 4.5. Nesse esquema foi utilizada a taxa de transmissão de 1,25 Gbps e 622 Mbps e o resultado está mostrado nas Figuras 4.8 e 4.9.

Como pode ser observado pela Figura 4.8, para a taxa de 1,25 Gbps, nem mesmo o modo central consegue atingir uma taxa de erro satisfatória a uma distância de $20 \mathrm{~km}$. Para esse modo, uma BER de $10^{-12}$ é alcançada apenas com a distância de $5 \mathrm{~km}$. Para a taxa de transmissão de $622 \mathrm{Mbps}$ (Figura 4.9), uma BER de $10^{-12}$ é alcançada pelo modo 


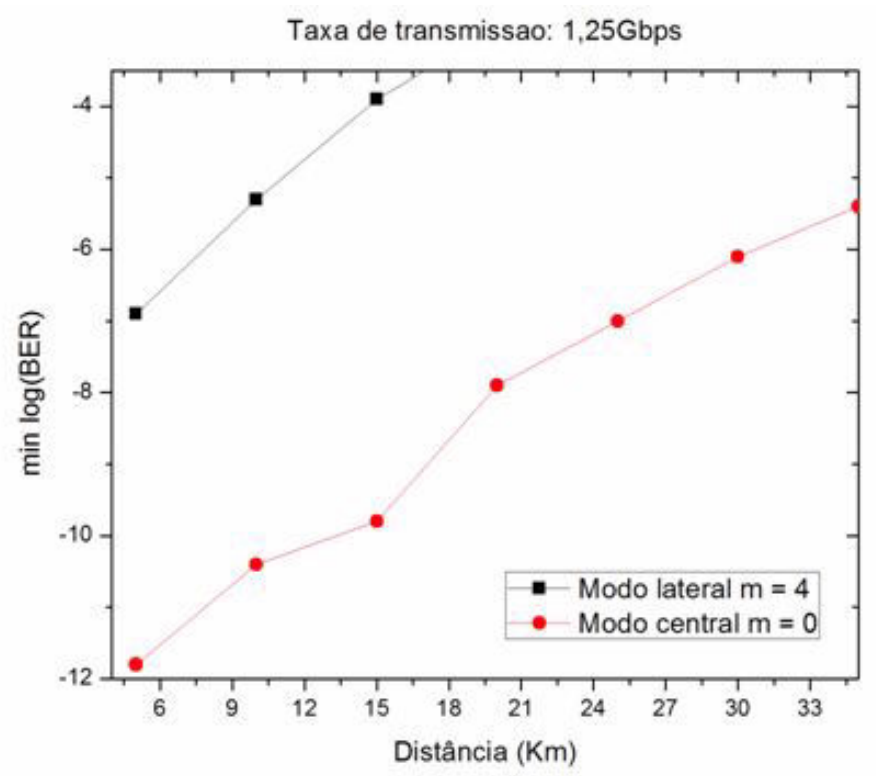

Figura 4.8: BER como função da distância considerando-se uma taxa de transmissão de 1,25 Gbps no esquema com F-P LDs situados nas ONUs. São mostrados os modos central $\mathrm{m}=0$ e lateral $\mathrm{m}=4$

central quando sua respectiva ONU está localizada a uma distância de aproximadamente $30 \mathrm{Km}$. Considerando o modo lateral $\mathrm{m}=4$, essa mesma taxa de erro é obtida a uma distância de aproximadamente $17 \mathrm{Km}$.

Alternativamente, o esquema de travamento pode ser utilizado com F-P LDs idênticos localizados no OLT e as ONUs sendo equipadas apenas com moduladores Mach-Zehnder (ou RSOAs), em esquema semelhante ao mostrado na Seção 4.1, como será mostrado a seguir.

\subsection{Rede de Fonte Óptica Centralizada}

O esquema investigado nessa seção está mostrado na Figura 4.10 e utiliza o travamento de F-P LDs através da injeção do sinal de ASE fatiado para prover uma arquitetura baseada em fontes ópticas centralizadas. A portadora não modulada é enviada pelo OLT e pecorre $20 \mathrm{Km}$ de fibra até chegar na ONU, onde será modulada com os dados de upstream através de um modulador Mach-Zehnder. Dessa forma, assim como na seção anterior, a rede 
Taxa de transmissao: $622 \mathrm{Mbps}$

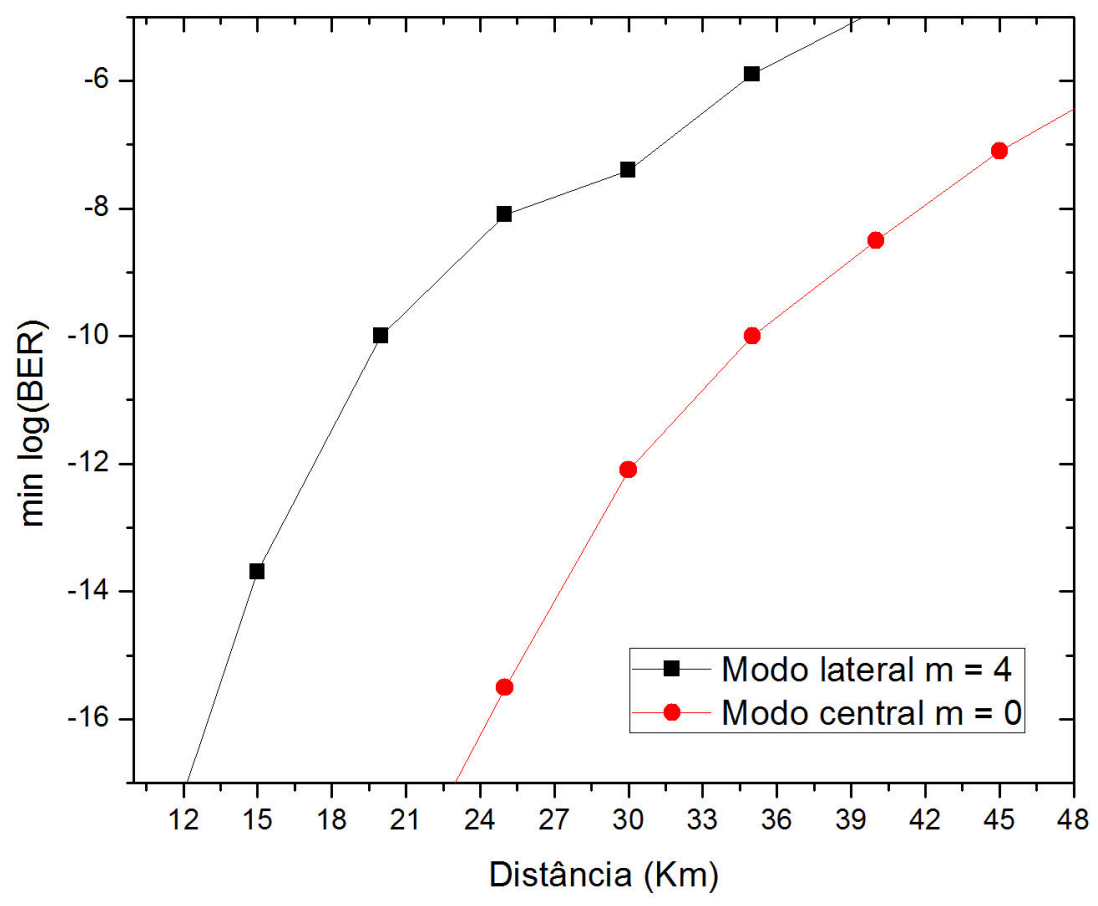

Figura 4.9: BER como função da distância considerando-se uma taxa de transmissão de 622 Mbps no esquema com F-P LDs situados nas ONUs. São mostrados os modos central $\mathrm{m}=0$ e lateral $\mathrm{m}=4$ 


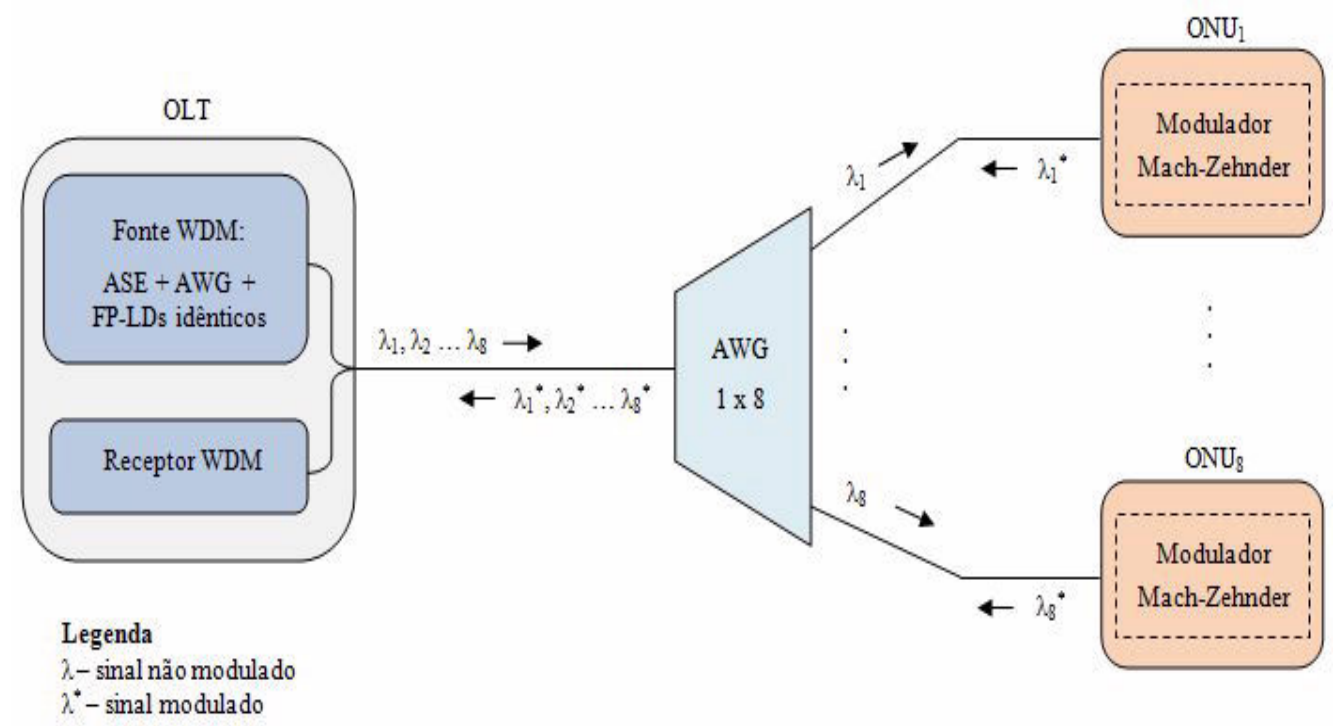

Figura 4.10: Representação esquemática da rede CLS simulada

também apresenta ONUs com esquema colorless. A Figura 4.11 mostra em detalhes a fonte WDM presente no OLT, que é composta pela fonte ASE, um AWG e 8 lasers Fabry-Pérot idênticos travados em modos distintos.

Para demonstrar o avaliar da rede, foi feita uma varredura de distâncias considerandose o modo central e o modo lateral mais afastado. Os resultados estão mostrados nas Figuras 4.12, 4.13 e 4.14, com taxas de transmissão de $622 \mathrm{Mbps}, 1,25$ Gbps e 2,5 Gbps, respectivamente.

Para 622 Mbps (Figura 4.12), uma taxa de erro de $10^{-12}$ pode ser obtida pelo modo central a uma distância de aproximadamente $46 \mathrm{~km}$. Enquanto que, para o modo lateral $\mathrm{m}=4$, a distância máxima para atingir tal BER seria aproximadamente $37 \mathrm{~km}$. Dessa forma, tendo em vista que ONUs podem se localizar a diferentes distâncias do OLT, pode-se alocar os modos centrais para ONUs mais distantes. No caso da taxa de $622 \mathrm{Mbps}$, a distância máxima que uma ONU poderia estar do OLT seria $46 \mathrm{~km}$.

Para 1,25 Mbps (Figura 4.13), a ONU associada ao modo central pode estar situada a uma distância de até $38 \mathrm{~km}$ para atingir uma taxa de erro de, no máximo, $10^{-12}$. Para atingir essa mesma taxa de erro, a ONU correspondente ao modo lateral $\mathrm{m}=4$ deve estar 


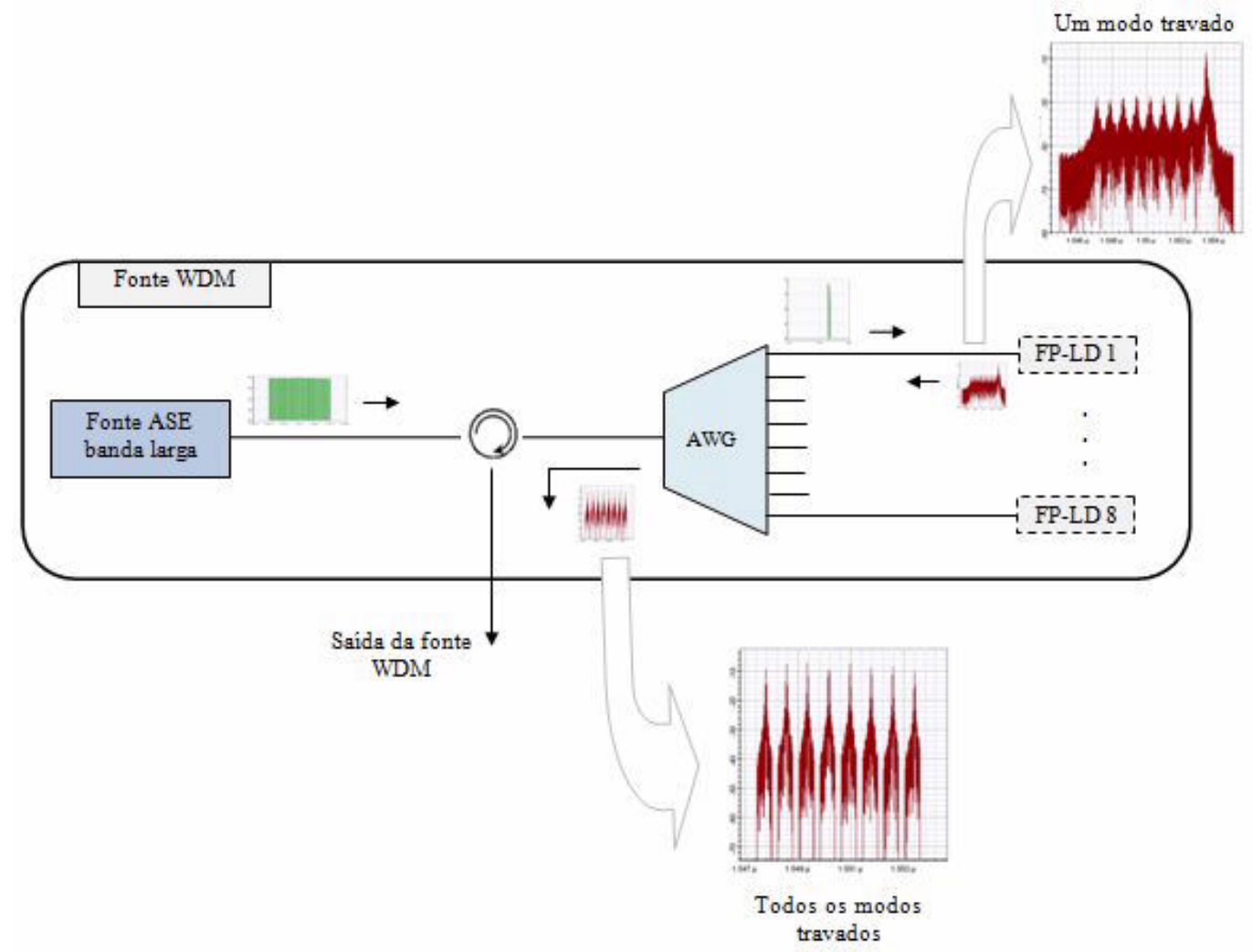

Figura 4.11: Representação esquemática da fonte WDM 


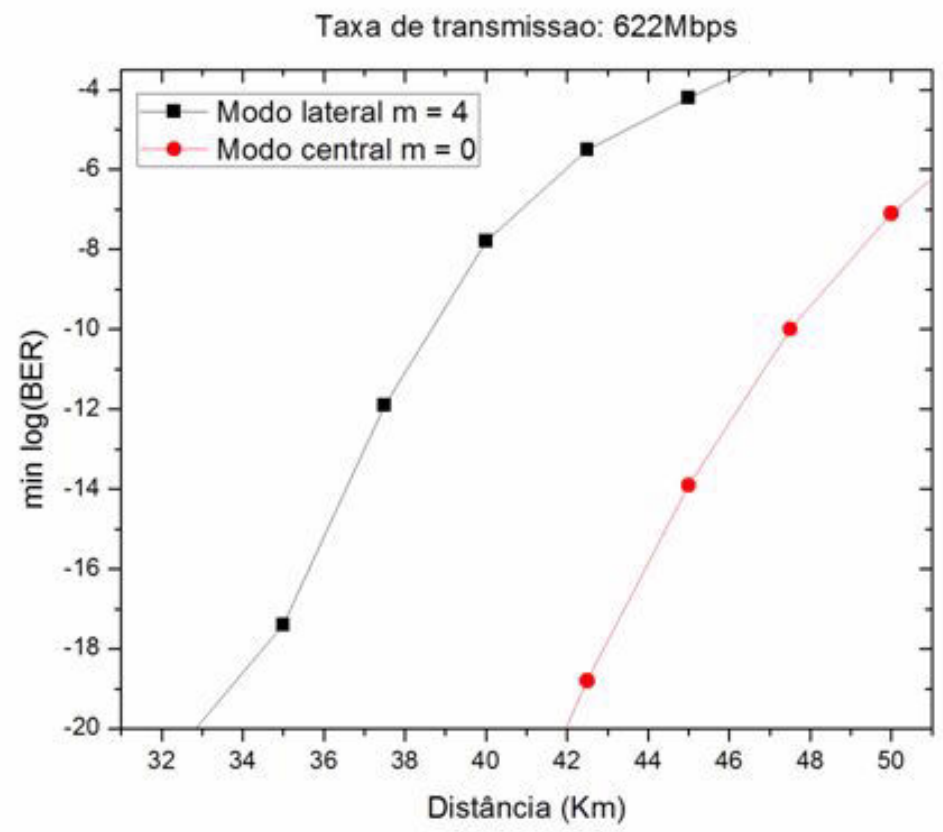

Figura 4.12: Taxa de erro como função da distância considerando-se uma taxa de transmissão de $622 \mathrm{Mbps}$ na rede CLS

distante do OLT de, no máximo, $29 \mathrm{~km}$.

E, como pode ser observado na Figura 4.14, com a taxa de 2,5 Gbps a ONU associada ao modo central pode estar situada a uma distância máxima de $26 \mathrm{~km}$ para uma BER menor do que $10^{-12}$. Enquanto que, para o modo lateral $\mathrm{m}=4$, a distância máxima é reduzida para apenas $9 \mathrm{~km}$.

A rede investigada nesta seção, assim como a rede mostrada na seção 4.2, utilizam dispositivos colorless nas ONUs. Enquanto a rede CLS emprega modulares Mach-Zehnder idênticos nas ONUs, a outra alternativa descrita emprega lasers Fabry Pérot idêntidos como fonte óptica das ONUs. O fato da rede ser centralizada acarreta em uma grande vantagem quanto a gerenciamento e manutenção, já que estes processos seriam facilitados pelo fato de que, caso ocorresse algum problema nos lasers ou no EDFA (fonte ASE), tudo seria resolvido no próprio OLT, sem a necessidade do deslocamento de técnicos ao nó remoto ou à casa do usuário. Quanto ao gerenciamento do estoque de componentes, as duas redes investigadas são viáveis, tendo em vista que o provedor de serviço não precisa se preocupar 


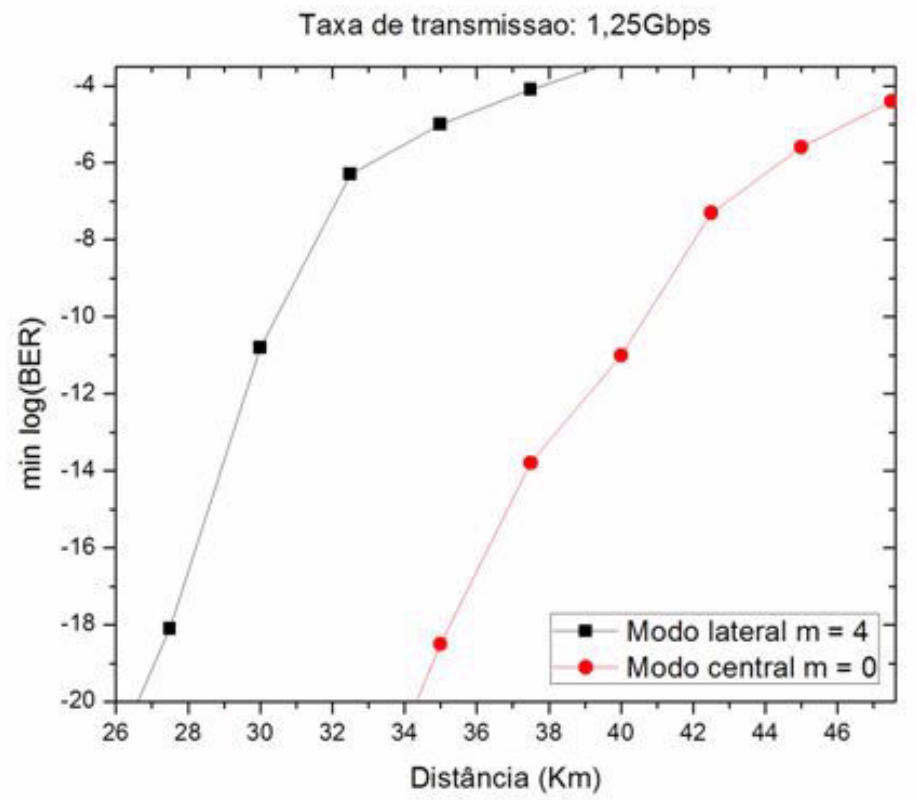

Figura 4.13: Taxa de erro como função da distância considerando-se uma taxa de transmissão de 1,25 Gbps na rede CLS

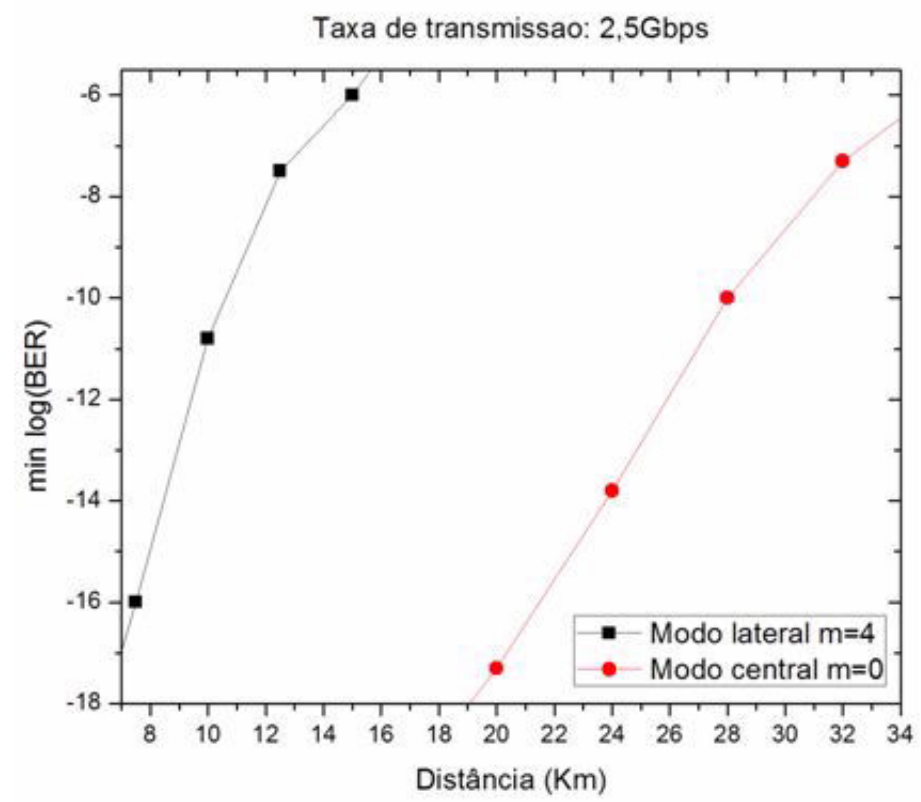

Figura 4.14: Taxa de erro como função da distância considerando-se uma taxa de transmissão de 2,5 Gbps na rede CLS 
em ter guardado n lasers diferentes para suprir eventuais defeitos. Seriam necessários apenas algumas unidades do mesmo laser. Uma desvantagem da rede CLS é a modulação externa exercida pelo Mach-Zehnder, o que aumenta o custo deste esquema em comparação ao esquema apresentado na seção 4.2. Por fim, como pôde ser percebido na comparação entre os resultados das duas seções, a rede CLS obteve um melhor desempenho, indicando ser uma melhor alternativa para implementação de um sistema WDM-PON.

\subsection{Rede CLS com 21 modos}

Nos esquemas investigados nas seções 4.2 e 4.3 foram utilizados F-P LDs com 9 modos. Nesta seção é estendida a análise realizada nas seções anteriores para um número de modos igual a 21, que corresponde ao número máximo de modos permitidos pelo software Optisystem na versão 8.0.

A Figura 4.15 mostra o espectro de saída de um Fabry-Pérot não travado com 21 modos. Dessa forma, utilizando a mesma nomenclatura adotada anteriormente, os modos mais afastados do modo central são identificados como $\mathrm{m}=-10$, indicando o modo mais afastado localizado a esquerda do modo central, e $\mathrm{m}=10$, indicando o modo mais afastado localizado a direita do modo central.

Os F-P LDs foram utilizados para prover uma rede baseada em fontes ópticas centralizadas, de forma similar a rede mostrada na seção anterior. Fixada a distância em $20 \mathrm{~km}$, o comportamento de alguns modos está mostrado na Figura 4.16. As taxas de transmissão consideradas foram $622 \mathrm{Mbps}, 1,25$ Gbps e 2,5 Gbps.

Como pode ser observado pela figura, o modo central $(\mathrm{m}=0)$ está centrado no comprimento de onda $1550 \mathrm{~nm}$ e apresenta desempenho satisfatório nas três taxas de transmissão utilizadas. Em $622 \mathrm{Mbps}$, sua BER é inferior a 10 ${ }^{-20}$; em 1,25 Gbps sua BER é inferior a $10^{-15}$; e em 2,5 Gbps, sua BER é aproximadamente $10^{-12}$.

Esse desempenho, porém, não é repetido nos demais modos. Por exemplo, o modo $\mathrm{m}=-7$, centrado no comprimento de onda $1555,6 \mathrm{~nm}$, só apresenta uma taxa de erro inferior a $10^{-12}$ quando a taxa de transmissão é 622 Mbps. Para o modo mais afastado $\mathrm{m}=-10$, a taxa de erro é superior a $10^{-12}$ em qualquer uma das taxas de transmissão consideradas. 


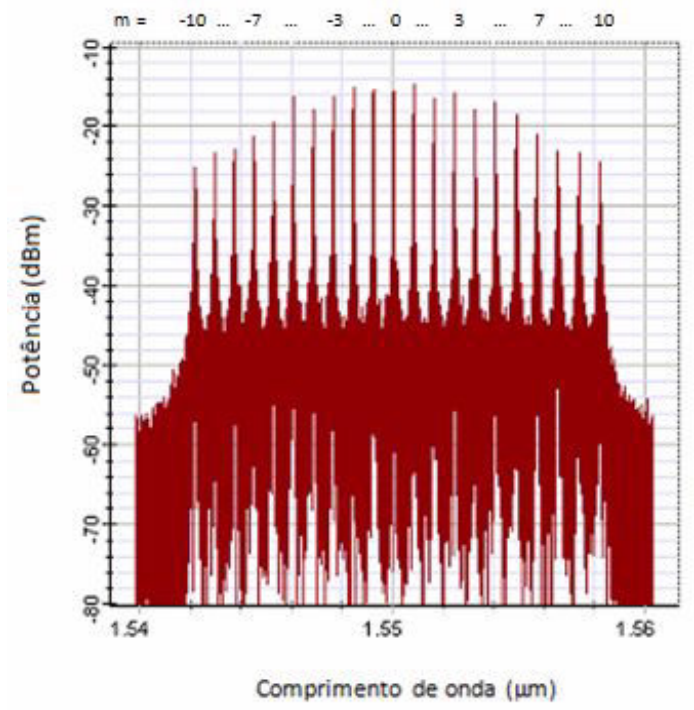

Figura 4.15: Espectro de saída de um Fabry-Pérot com 21 modos sem a injeção de sinal óptico externo

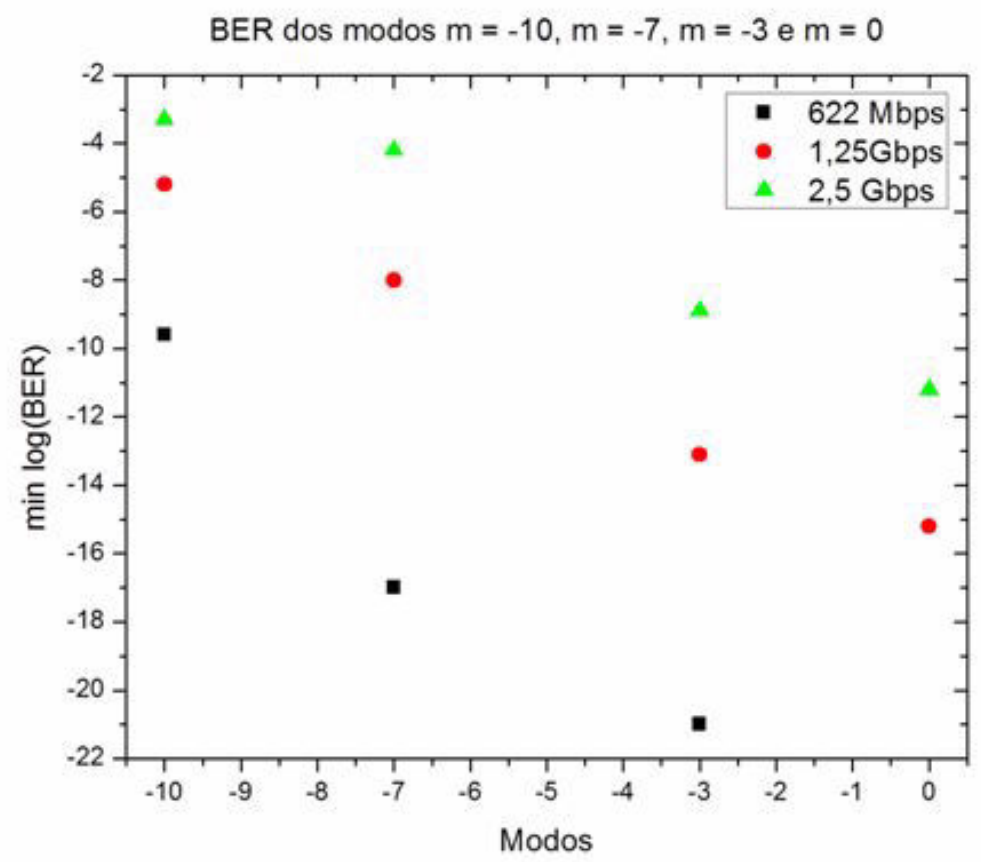

Figura 4.16: Taxa de erro dos modos $\mathrm{m}=-10, \mathrm{~m}=-7, \mathrm{~m}=-3$ e $\mathrm{m}=0$ considerando as taxas de transmissão de $622 \mathrm{Mbps}, 1,25$ Gbps e 2,5 Gbps 
Dessa forma, para utilização de altas taxas de transmissão, o número de modos não pode ser grande, tendo em vista que os modos laterais mais afastados apresentam potência consideravelmente reduzida em comparação ao modo central.

Para finalizar a discussão do capítulo, uma ressalva importante deve ser feita: em sistemas que utilizam o loop-back, o parâmetro de fibra óptica "Rayleigh backscattering"assume um papel importante. Esse parâmetro define a quanto da potência incidente é refletido de volta pela própria fibra. Apesar de o parâmetro ter sido considerado nas simulações realizadas utilizando o OptiSystem, uma investigação aprofundada sobre o retroespalhamento Rayleigh é uma sugestão interessante para um trabalho futuro. 


\section{Capítulo 5}

\section{Conclusão}

A fibra óptica certamente será a solução para as redes de acesso e este trabalho fornece subsídios para evidenciar isso. Dentre as possibilidades com fibra, as redes ópticas passivas reunem vantagens que as tornam mais viáveis do que as redes ópticas ativas. Como mencionado, sistemas PON utilizando multiplexação por divisão no tempo já estão em uso no mercado de telecomunicações.

A TDM-PON, porém, pode não ser suficiente para atender a demanda futura das redes de acesso. Dessa forma, procurou-se estabelecer neste trabalho a necessidade de PONs utilizando multiplexação por divisão de comprimento de onda. A WDM-PON apresenta aspectos vantajosos em relação à TDM-PON em termos de largura de banda, transparência de protocolo, segurança, baixa latência, não necessidade de divisão de potência, dentre outros. Inclusive, a questão da segurança em TDM-PONs foi investigada e concluiu-se que o tráfego de upstream dessas redes não é seguro, isto é, haveria a necessidade de criptografia (algo não implementado nas diversas redes TDM-PON já instaladas).

Simulações relativas às TDM-PONs e WDM-PONs foram feitas com intuito de comparar estas alternativas. Embora este segundo tipo de rede óptica apresente algumas vantagens, principalmente no que diz respeito a largura de banda, o preço de instalação é um fator limitante a sua implantação. Dessa forma, este trabalho buscou elucidar algumas arquiteturas WDM-PON presentes na literatura que são mais viáveis economicamente. As pesquisas nessa área estão em plena ascensão, como pode ser percebido pela referencias 
mencionadas.

Quanto a estas arquiteturas, fica clara a necessidade de transmissores ópticos colorless. Isso ocorre porque o uso de lasers sintonizáveis atualmente disponíveis comercialmente para transmissão em redes em WDM de longa distância é inconveniente em WDM-PONs devido ao elevado custo. Por outro lado, cada ONU não pode ser equipada com lasers de comprimento de onda fixo, já que tornaria complicada e custosa a questão do gerenciamento do estoque de lasers. Dessa forma, como foi mostrado, a literatura está convergindo para o uso de transmissores idênticos atuando em todas as ONUs.

Adicionalmente, outra característica interessante é que a rede seja baseada em fontes ópticas centralizadas, de forma que todo o aparato para transmissão esteja localizado no OLT. Uma alternativa de rede CLS foi investigada utilizando-se o travamento de lasers Fabry-Pérot através da injeção de sinal de ASE. Essa rede foi comparada com uma rede semelhante, porém que não utiliza esquema CLS, e os resultados indicaram que o desempenho da rede baseada em fontes ópticas centralizadas é mais satisfatório.

Alguns tópicos que podem dar continuidade a este trabalho são: estudo da vertente WDM-PON voltada para migração TDM-PON para WDM-PON denominada SUCCESS (Stanford University Access); investigação das redes SuperPONs como alternativa de integração das redes de acesso à rede backbone; estudo detalhado do parâmetro "retroespalhamento Rayleigh"e suas implicações em esquemas loop back; e investigação de arquiteturas RITENET utilizando RSOAs. 


\section{Referências Bibliográficas}

[1] Andrew S. Tanenbaum, Computer Networks, $4^{a}$ edição, Prentice Hall, Vrije University, Amsterdam, 2003.

[2] Sudhir Dixit, "IP Over WDM: building the next-generation optical internet", WileyInterscience, New York, NY, 2003.

[3] D. Gutierrez, "Next-Generation Fiber-To-The-Home Networks", Tese de Doutorado, Departamento de Engenharia Elétrica, Universidade de Stanford, Califórnia, dezembro de 2007.

[4] Mohammad Ilyas, Hussein T. Mouftah: "The Handbook of Optical Communication Networks", CRC Press, 2003.

[5] D. Nowak and J. Murphy, "FTTH: The overview of existing technologies," in Proc. SPIE Optoelectronics, Photonic Devices, and Optical Networks, Opto-Ireland, vol. 5825, pp. 500-509, 2005.

[6] IEEE Standard 802.11.

[7] IEEE Standard 802.16.

[8] Larry L. Peterson, Bruce S. Davie, "Computer Networks: A Systems Approach", Morgan Kaufmann Publishers, São Francisco, California, Maio de 2003.

[9] http://tecnologia.terra.com.br/interna/0,OI676163-EI4802,00.html. Acesso em: 27 de abril de 2009 . 
[10] http://www.revistadewimax.com.br/Revista/Corpora\%C3\%A7\%C3\%B5eseGoverno /tabid/85/Default.aspx. Acesso em: 27 de abril de 2009.

[11] http://www.cpqd.com.br/1/3017+parintins-na-amazonia-ganha-rede-wimaxparintinswim ax.html. Acesso em: 27 de abril de 2009.

[12] C. Eklund, R.B. Marks, e K.L. Stanwood. "A technical overview of the wireless MAN air interface for broadband wireless access," IEEE Communications Magazine, 40 (6): 98-107, Junho de 2002.

[13] Nokia Siemens Networks Corporation, "LTE performance for initial deployments", White Paper. Disponível em http://www.nokiasiemensnetworks.com. Acesso em 10 de outubro de 2008.

[14] Rysavy Research, "EDGE, HSPA and LTE: The mobile broadband advantage", White Paper. Disponível em http://www.rysavy.com/papers.html. Acesso em 10 de outubro de 2008 .

[15] LTE: Solução OFDMA Otimizada para Espectro com Maior Largura de Banda, disponível em http://www.teleco.com.br/tutoriais/tutorialofdma, elaborado pela Qualcomm, publicado em Dezembro 2009. Acesso em: 22 de Dezembro de 2009.

[16] R. Padjen. "CCNP: Building Cisco Remote Access Networks Study Guide". Sybex, 2004.

[17] CableLabs, http://www.cablemodem.com. Acesso em: 27 de abril de 2009.

[18] J.R. Stern, et al., "TPON-a passive optical network for telephony", in Proc. ECOC 1988, Brighton, UK, pp. 203-206.

[19] F. Effenberger, D. Cleary, O.Haran, G. Kramer et al., "An Introduction to PON Technologies", IEEE Communications Magazine, pp. S17-S25, março de 2007.

[20] C. Orencia, "Alocação dinâmica de largura de banda em redes EPON", Dissertação de mestrado, Escola de Engenharia de São Carlos, Universidade de São Carlos, São Paulo, 2007. 
[21] Biswanath Mukherjee, Optical WDM Networks, Springer-Verlag New York, Inc., Secaucus, NJ, 2006.

[22] Mark Abrams, Philippe C. Becker, Y. Fujimoto, Vincent O’Byrne, and David Piehler, "FTTP Deployments in the United States and Japan-Equipment Choices and Service Provider Imperatives,"J. Lightwave Technol. 23, No 1, pp. 236-246, 2005.

[23] ITU G.983 Recommendations.

[24] IEEE Standard 802.3ah.

[25] ITU G.984 Recommendations.

[26] Cisco Systems, "Fiber to the Home Architectures", White Paper. Disponível em http://www.cisco.com/en/US/solutions/collateral/ns341/ns525/ns537/ns547/net_ implementation_white_paper0900aecd807259b7_ps4324_Products_White_Paper. html. Acesso em: 11 de maio de 2009.

[27] 10Gb/s Ethernet Passive Optical Network, IEEE P802.3avTask Force. Disponível em http://www.ieee802.org/3/av/. Acesso em: 13 de maio de 2009.

[28] W.P. Sanchez, "PON: Redes Ópticas de Acesso de Baixo Custo", http://www.teleco.com.br/tutoriais/tutorialpon/Default.asp. Acesso em: 20 jan 2008.

[29] Richard E. Wagner, John R. Igel, Robert Whitman, Mark D. Vaughn, A. Boh Ruffin, and Scott Bickham, "Fiber-Based Broadband-Access Deployment in the United States,"J. Lightwave Technol. 24, 4526-4540, 2006.

[30] D. Gutierrez, J. Cho, and L.G. Kazovsky, "TDM-PON security issues: upstream encryption is needed," in Proc. OFC, 2007.

[31] Y. Horiuchi, N. Edagawa, "ONU Authentication Technique Using Loopback Modulation within a PON Disturbance Environment", Proceedings of OFC, OFI3, 2005. 
[32] S. Wong, W.-T. Shaw, S. Das, L.G. Kazovsky, "Enabling Security Countermeasure and Service Restoration in Passive Optical Networks", Proceedings of IEEE Globecom 2006.

[33] Y. Meng, T. Jiang, D. Xiao, "Analysis and Solutions of Security Issue in Ethernet PON", Proceedings of SPIE, Vol. 5626, 2005.

[34] Vincent O’Byrne, "Verizon's Fiber to the Premises: Lessons Learned", Proceedings of OFC, OWP6 2005.

[35] OptiSystem 8, http://www.optiwave.com/site/products/system.html. Acesso em: 9 de março de 2009.

[36] Bill Woodward, Emile B. Husson: "Fiber Optics Installer and Technician Guide (Hardcover)", Sybex, 2005.

[37] EXFO Electro-Optical Engineering, http://www.exfo.com. Acesso em: 07.06.2009.

[38] NeoPhotonics, www.neophotonics.com. Acesso em: 10 de abril de 2009.

[39] F. T. An, K. S. Kim, D. Gutierrez, S. Yam, E. Hu, K. Shrikhande, and L. G. Kazovsky, "SUCCESS: A next-generation hybrid WDM/TDM optical access network architecture," J. Lightw. Technol., vol. 22, no. 11, pp. 2557-2569, Novembro de 2004.

[40] Y.-L. Hsueh, "A Highly Flexible and Efficient Passive Optical Network Employing Dynamic Wavelength Allocation,” J. Lightwave Tech., Janeiro de 2005.

[41] Michael P. MacGarry, Martin Reisslen e Martin Maier, "WDM Ethernet Passive Optical Networks", IEEE Optical Communications Magazine, vol. 44, № 2, pp. 1522, Fevereiro de 2006.

[42] M. Maier, "WDM Passive Optical Networks and Beyond: the Road Ahead [Invited],"J. Opt. Commun. Netw., vol.1, No 4, Setembro de 2009.

[43] Ponzini et al, "Evolution Scenario Toward WDM-PON [Invited],"J. Opt. Commun. Netw., vol.1, Nº 4, Setembro de 2009. 
[44] Chang et al, "Key Technologies of WDM-PON for Future Converged Optical Broadband Access Networks [Invited],"J. Opt. Commun. Netw., vol.1, Nº 4, Setembro de 2009 .

[45] A. Banerjee, Y. Park, F. Clarke, H. Song, S. Yang, G. Kramer, K. Kim, and B. Mukherjee, "Wavelength-division-multiplexed passive optical network (WDM-PON) technologies for broadband access: a review [Invited],"J. Opt. Netw. 4, 737-758, 2005.

[46] H. Matsuda, T. Kaminogou, T. Yasui, "A challenge to access/backbone integrated network," IEICE Transactions on Communications, Vol. 90, No. 8, pp. 1960-1967, Janeiro de 2007.

[47] Chang-Hee Lee, Wayne V. Sorin, and Byoung Yoon Kim, "Fiber to the Home Using a PON Infrastructure,"J. Lightwave Technol. 24, 4568-4583, 2006.

[48] Soo-Jin Park, Chang-Hee Lee, Ki-Tae Jeong, Hyung-Jin Park, Jeong-Gyun Ahn, and Kil-Ho Song, "Fiber-to-the-Home Services Based on Wavelength-DivisionMultiplexing Passive Optical Network,"J. Lightwave Technol. 22, 2582-, 2004.

[49] G. Kramer, G. Pesavento, Alloptic Inc., "Ethernet passive optical network (EPON): building a next-generation optical access network", IEEE Communications Magazine, vol. 40, No 2, pp. 66-73 Fevereiro de 2002.

[50] JP Morgan Securities, Inc., Broadband 2001, "A Comprehensive Analysis of Demand, Supply, Economics, and Industry Dynamics in the U.S. Broadband Market," Abril de 2001.

[51] J. Halpernand, G. Garceau, Fiber: Revolutionizing the Bell's Telecom Networks. New York: Bernstein/Telcordia Technologies Study, Maio de 2004.

[52] NET, http://netcombo.globo.com. Acesso em: 03 de maio de 2009.

[53] Joseph C. Crimi: "Next Generation Network (NGN) Services", Telcordia Technologies White Paper. 
[54] C. Ollivry, "Why Fiber? Why Now?", http://www.idate.org/jii04/bio04/actes/FTTH_ Christian_ OLLIVRY.ppt. Acesso em 5 de maio de 2009.

[55] The Furukawa Electric, http://www.furukawa.co.jp/english/index.htm. Acesso em: 9 de março de 2009.

[56] NTT Electronics, http://www.nel-world.com. Acesso em: 9 de março de 2009.

[57] D. Gutierrez, W.-T. Shaw, F.-T. An, K. S. Kim, Y.-L. Hsueh, M. Rogge, G. Wong and L. G. Kazovsky, "Next generation optical access networks", (Invited Paper), Proceedings of IEEE/Create-Net BroadNets 2006, Outubro de 2006.

[58] Leonid G. Kazovsky, Wei-Tao Shaw, David Gutierrez, Ning Cheng, and Shing-Wa Wong, "Next-Generation Optical Access Networks,"J. Lightwave Technol. 25, 3428$3442,2007$.

[59] K.M. Choi, S.M. Lee, M.H. Kim, and C.H. Lee, "An Efficient Evolution Method From TDM-PON to Next-Generation PON", IEEE Photonics Technology Letters, Vol. 19, $\mathrm{N}^{\circ} 9$, Setembro de 2007.

[60] P. Munoz, "Arrayed Waveguide Gratings: modeling, design and applications", Tese de doutorado, Optical Communications Group and IMCO2 Research Institute and Department of Communications, University of Valencia, Spain, 2003.

[61] Lidgate, S. "Advanced Finitite Difference - Beam Propagation Method Analysis of Complex Components". Tese, University of Nottingham. 2004.

[62] M. K. Smit and C. van Dam, "PHASAR-based WDM-devices: Principles, design and applications," IEEE J. Select. Topics Quantum Electron., vol. 2, pp. 236-250, Junho de 1996.

[63] K. A. McGreer, "Arrayed waveguide gratings for wavelength routing," IEEE Commun. Mag., vol. 36, pp. 62-68, Dezembro de 1998.

[64] H. Tsuda, K. Okamoto, T. Ishii, K. Naganuma, Y. Inoue, H. Takenouchi, and T. Kurokawa, "Second- and thir-order dispersion compensator using a high-resolution 
arrayed-waveguide grating, "IEEE Photonics Technology Letters, vol. 11, pp. 569571, Maio de 1999.

[65] M. Zirngibl, C. Dragone, and C. H. Joyner, "Demonstration of a $15 \times 15$ arrayed waveguide multiplexer on InP,"IEEE Photonics Technology Letters, vol. 4, pp. 12501253, Novembro de 1992.

[66] H. Takahashi, K. Oda, H. Toba, and Y. Inoue, "Transmission characteristics of arrayed waveguide N x N wavelength multiplexer, "IEEE Journal of Lightwave Technology, vol. 13, pp. 447455, Março de 1995.

[67] T. Makino, G. P. Li, A. Sarangan, and W. Huang, "Multiwavelength gain-coupled MQW DFB laser array with fine tunability," in Optical Fiber Communication Conference, Vol. 2 of OSA Technical Digest Series (Optical Society of America), paper FB1, 1996.

[68] M. Zirngibl, "Multifrequency lasers and applications in WDM networks," IEEE Commun. Mag. 36(12), 39-41, 1998.

[69] Mukaihara, T.; Nasu, H.; Kimoto, T.; Tamura, S.; Nomura, T.; Shinagawa, T.; Kasukawa, A.; Oike, M.; Matsuura, H.; Shiba, T.; Ninomiya, T., "Highly reliable 40 mW, $25 \mathrm{GHz}$ x 20 ch thermally tunable DFB laser module integrated with wavelength monitor", Optical Communication, 2002. ECOC 2002. 28th European Conference on , vol.3, no., pp. 1-2, 08-12 Setembro de 2002.

[70] C. J. Buczek, R. J. Freiberg e M. L. Skolnick, "Laser injection locking," Proc. IEEE, vol. 61, pp. 1411-1431, Outubro de 1973.

[71] Sil-Gu Mun, Jung-Hyung Moon, Hoon-Keun Lee, Jun-Young Kim, and Chang-Hee Lee, "A WDM-PON with a $40 \mathrm{~Gb} / \mathrm{s}(32 \times 1.25 \mathrm{~Gb} / \mathrm{s})$ capacity based on wavelengthlocked Fabry-Perot laser diodes,"Opt. Express 16, 11361-11368, 2008.

[72] Xiaofei Cheng, Yang Jing Wen, Zhaowen Xu and Yixin Wang, "Characterization of Fabry-Perot laser diodes injection locked by spectrum sliced ASE noise in WDMPON," Opt. Fiber Technol., Volume 15, Pag. 161-164 Março 2009. 
[73] D. J. Shin, D. K. Jung, J. K. Kee, Y. K. Oh, J. H. Lee, H. S. Kim, C. H. Lee,S. T. Hwang, J. H. Ko, Y. J. Oh, T. I. Kim,and C. S. Shim, "Transmission of HDTV and Ethernet data over a WDM-PON employing ASE-injected Fabry-Perot laser diodes," in Proceedings of the Optical Fiber Communication Conference (OFC2004), paper WO3, 2004.

[74] S. -M. Lee, K. -M. Choi, S. -G. Moon, J. -H. Moon, and C. -H. Lee, "Dense WDMPON based on wavelength-locked Fabry-Perot laser diodes," IEEE Photon. Technol. Lett., vol. 17, $\mathrm{N}^{o}$ 7, pp. 1579-1581, Julho de 2005.

[75] K. -Y. Park, S. -G. Mun, K. -M. Choi, and C. -H. Lee, "A theoretical model of a wavelength-locked Fabry-Perot laser diode to the externally injected narrowband ASE,” IEEE Photon. Technol. Lett., vol.17, № 9, pp. 1797-1799, Setembro de 2005.

[76] H. D. Kim, S. -G. Kang, and C. -H. Lee, "A low-cost WDM source with an ASE injected Fabry-Pérot semiconductor laser," IEEE Photon. Technol. Lett., vol. 12, No 8, pp.1067-1069, Agosto de 2000.

[77] S.J. Park, et al, "Fiber-to-the-home services based on wavelength division multiplexing passive optical network", JLT, vol. 22, no. 11, Novembro de 2004.

[78] R.D. Feldman, E.E. Harstead, S. Jiang, T.H. Wood, and M. Zirngibl, "An evaluation of architectures incorporating wavelength division multiplexing broad-band fiber access", J. Lightwave Technol. 16, 1546-1558 (1998).

[79] N. Kashima, "Upgrade of passive optical subscriber network," J. Lightwave Technol. 9, 113-119, 1991.

[80] Y. K. Lin, D. R. Spears, "Passive optical subscriber loops with multi-access," J. Lightwave Technol. 7, 1769-1777, 1989.

[81] Q. Yaojun, Q. Jiang, P. Hongtu, C. Shuqiang, G. Kejian, "A new scheme for WDMBased passive optical access network," International Conference on Communication Technology Proceedings, vol.2, pp. 1201-1204, Agosto de 2000. 
[82] M. Zirngibl, C.H. Joyner, L.W. Stulz, C. Dragone, H.M. Presby, and I.P. Kaminow, "LARNET, a local access router network", IEEE Photon. Technol. Lett. 7, 215-217, 1995.

[83] M. Oksanen, O.P. Hiironen, A. Tervonen, A. Pietilainen, et al., "Spectral slicing passive optical access network trial', Proceedings, OFC '02, Anaheim, CA, pp. 439440, Março de 2002.

[84] S. L. Wroodward, P. P. Iannone, K. C. Reichmann, and N. J. Frigo, "A spectrally sliced PON employing Fabry-Perot lasers," IEEE Photon. Technol. Lett., vol. 10, pp. 1337-1339, Setembro de 1998.

[85] S. S. Wagner and T. E. Chapuran, "Broadband high-density WDM transmission using superluminescent diodes,"Electron. Lett., vol. 26, N 11, pp. 696-697, Maio de 2001.

[86] Jung, D.K.; Kim, H.; Han, K.H.; Chung, Y.C., "Spectrum-sliced bidirectional passive optical network for simultaneous transmission of WDM and digital broadcast video signals,"Electronics Letters , vol.37, no.5, pp.308-309, Março de 2001.

[87] N. J. Frigo, P. P. Iannone, P. D. Magill, T. E. Darce, M. M. Downs, B. N. Desai, U. Koren, T. L. Koch, C. Dragone, H. M. Presby, and G. E. Bodeep, "A wavelengthdivision multiplexed passive optical network with cost-shared components," IEEE Photon. Technol. Lett. 6, 1365-1367, 1994.

[88] J. Kani, M. Teshima, K. Akimoto, N. Takachio, S. Suzuki, K. Iwatsuki, and M. Ishii, "A WDM based optical access network for wide-area gigabit access services" IEEE Opt. Commun. Mag. 41, S43-S48, 2003.

[89] Xu, Z.; Wen, Y.J.; Zhong, W.-D.; Cheng, T.H.; Cheng, X.; Wang, Y.; Yeo, Y.-K., "10Gb/s carrier-reuse WDM-PON based on injection locked FP-LDs,"Opto-Electronics and Communications Conference, 2008 and the 2008 Australian Conference on Optical Fibre Technology. OECC/ACOFT 2008. Joint conference of the , vol., no., pp.1-2, 710 Julho de 2008. 
[90] P. Chanclou, F. Payoux, T. Soret, N. Genay, R. Brenot, F. Blache, M. Goix, J. Landreau, O. Legouezigou, and F. Mallécot, "Demonstration of RSOA-Based Remote Modulation at 2.5 and 5 Gbit/s for WDM PON,"in Optical Fiber Communication Conference and Exposition and The National Fiber Optic Engineers Conference, OSA Technical Digest Series (CD), Optical Society of America, paper OWD1, 2007.

[91] Berrettini, G.; Meloni, G.; Giorgi, L.; Ponzini, F.; Cavaliere, F.; Ghiggino, P.; Poti, L.; Bogoni, A., "Colorless WDM-PON Architecture for Rayleigh Backscattering and Path-Loss Degradation Mitigation,"Photonics Technology Letters, IEEE, vol.21, no.7, pp.453-455, Abril de 2009.

[92] D. J. Shin, Y. C. Keh, J. W. Kwon, E. H. Lee, J. K. Lee, M. K. Park, J. W. Park, Y. K. Oh, S. W. Kim, I. K. Yun, H. C. Shin, D. Heo, J. S. Lee, H. S. Shin, H. S. Kim, S. B. Park, D. K. Jung, S. Hwang, Y. J. Oh, D. H. Jang, and C. S. Shim, "Low-cost WDM-PON with colorless bidirectional transceivers," J. Lightw. Technol., vol. 24, no. 1, pp. 158-165, Janeiro de 2006.

[93] C.-H. Lee, S.-M. Lee, K.-M. Choi, J.-H. Moon, S.-G. Mun, K.-T. Jeong, J. H. Kim, B. Kim; "WDM-PON experiences in Korea [Invited]"; J. Of Optical Networking 6, $\mathrm{N}^{\circ} 5,2007$.

[94] H. Park, H. Yoon, T. Park, S. Park, and J. H. Kim, "Recent Research Activities of WDM-PON in Korea, "in Optical Fiber Communication Conference and Exposition and The National Fiber Optic Engineers Conference, OSA Technical Digest Series (CD), Optical Society of America, paper OWL1, 2007.

[95] Cho, K.Y.; Takushima, Y.; Chung, Y.C., "10-Gb/s Operation of RSOA for WDM PON,"Photonics Technology Letters, IEEE , vol.20, no.18, pp.1533-1535, Setembro de 2008 .

[96] W. Lee, M. Y. Park, S. H. Cho, J. H. Lee, C. Y. Kim, G. Jeong, and B. Y. Kim, "Bidirectional WDM-PON based on gain-saturated reflective semiconductor optical amplifiers," IEEE Photon. Technol. Lett. 17, 2460-2462 (2005). 
[97] C.-H. Yeh, H.-C. Chien, S. Chi, "Cost-Effective Colorless RSOA-Based WDM-PON with 2.5Gbit/s Uplink Signal," Conference on Optical Fiber communication/National Fiber Optic Engineers Conference OFC/NFOEC 2008, pp. 1-3, Fevereiro de 2008.

[98] Ciphotonics Technologies, www.ciphotonics.com. Acesso em: 15 de Março de 2009.

[99] Borghesani, A., "Optoelectronic Components for WDM-PONs", International Conference on Transparent Optical Networks ICTON`07, Vol. 1, pp. 305-308, Julho de 2007.

[100] G. Mayer, M. Martinelli, A. Pattavina, and E. Salvadori, "Design and cost performance of the multistage WDM PON access networks", J. Lightwave Technol. 18, 121-142, 2000.

[101] G. Maier et al, "Multistage WDM Passive Access Networks: Design and Cost Issues,"IEEE International Conference on Communications, Vol.3, pp.1707-1713, 1999.

[102] K. Iwatsuki and J.-i. Kani, "Applications and Technical Issues of Wavelength-Division Multiplexing Passive Optical Networks With Colorless Optical Network Units [Invited],"J. Opt. Commun. Netw., vol.1, Nº 4, Setembro de 2009.

[103] John D. Angelopoulos, Nikos L. Lepidas, E.K. Fragoulopoulos, and Iakavos S. Venieris, "TDMA Multiplexing of ATM Cells in a Residential Access SuperPON," IEEE Journal on Selected Areas in Communications, vol. 16, No 7, pp. 1123-1133, Setembro de 1998.

[104] I. Van de Voorde, C. Martin, J. Vandewege, and X. Z. Qiu, "The SuperPON demonstrator: An exploration of possible evolution paths for optical access networks," IEEE Commun. Mag., vol. 38, pp. 74-82, Fevereiro de 2000.

[105] S.A. Jabar, "Alternative Architectures for Bidirectional Single Mode Fiber SuperPON 512 ONU, 100 km," TENCON 2005 IEEE Region 10, pp. 1-5, Novembro de 2005.

[106] D. P. Shea, and J. E. Mitchell, "Operating penalties in single-fiber operation 10-Gb/s, 1024-way split, 110-km long-reach optical access networks, "Photonics Technology Letters 18, 2463-2465, 2006. 
[107] G. Talli, P.D. Townsend, "Hybrid DWDM-TDM long-reach PON for next-generation optical access," Journal of Lightwave Technology, vol. 24, No 7, pp. 2827-2834, Julho de 2006.

[108] Sang-Mook Lee, Sil-Gu Mun, Min-Hwan Kim, and Chang-Hee Lee, "Demonstration of a Long-Reach DWDM-PON for Consolidation of Metro and Access Networks,"J. Lightwave Technol. 25, 271-276, 2007.

[109] Jung-Hyung Moon et al, "A WDM-PON with a 40 Gb/s (32 x 1.25 Gb/s) capacity based on wavelength-locked Fabry-Perot laser diodes,"Opt. Express 16, 11361-11368, 2008.

[110] Hoon-Keun Lee et al., "A Simple and Color-Free WDM Passive Optical Network Using Spectrum-Sliced Fabry-Pérot Laser Diodes," IEEE Photonics Technology Letters, Vol. 20, No 3, pp. 220-222, Fevereiro de 2008.

[111] Zhaowen Xu et al, "High-speed WDM-PON using CW injection-locked Fabry-Pérot laser diodes,"Opt. Express 15, 2953-2962, 2007.

[112] X. Cheng et al., "Characterization of Fabry-Pérot laser diodes injection locked by spectrum sliced ASE noise in WDM-PON," Opt. Fiber Technol.,vol.15, pp. 161-164, Março de 2009.

[113] T. R. Zaman and R. J. Ram, "Modulation of Injection Locked Lasers for WDM-PON Applications,"in National Fiber Optic Engineers Conference, OSA Technical Digest (CD), Optical Society of America, paper JThA100, 2008.

[114] K. -Y. Park, and C. -H. Lee, "Noise Characteristics of a Wavelength-Locked FabryPérot Laser Diode", IEEE Journal of Quantum Electronics, vol. 44, n. 11, Novembro de 2008 . 